Portland State University

PDXScholar

\title{
Transportation Cost Index: A Comprehensive Performance Measure for Transportation and Land Use Systems and its Application in OR, FL, and UT
}

\author{
Liming Wang \\ Portland State University \\ Jenny H. Liu \\ Portland State University, jenny.liu@pdx.edu
}

Follow this and additional works at: https://pdxscholar.library.pdx.edu/trec_reports

Part of the Transportation Commons, Urban Studies Commons, and the Urban Studies and Planning Commons

Let us know how access to this document benefits you.

\section{Recommended Citation \\ Wang, L. and Liu, J. Transportation Cost Index: A Comprehensive Performance Measure for Transportation and Land Use Systems and its Application in OR, FL, and UT. NITC-RR-758. Portland, OR: Transportation Research and Education Center (TREC), 2017. https://doi.org/10.15760/trec.169}

This Report is brought to you for free and open access. It has been accepted for inclusion in TREC Final Reports by an authorized administrator of PDXScholar. Please contact us if we can make this document more accessible: pdxscholar@pdx.edu. 

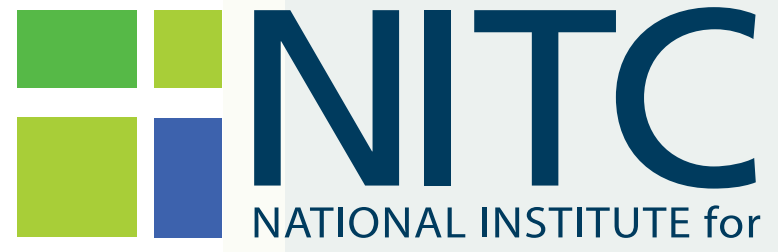

TRANSPORTATION and COMMUNITIES

FINAL REPORT

Transportation Cost Index: A Comprehensive Performance Measure for Transportation and Land and its Application in OR, FL, and UT

NITC-RR-758 a April 2017

NITC is a U.S. Department of Transportation national university transportation center.

HI! TREC 



\section{TRANSPORTATION COST INDEX: A COMPREHENSIVE PERFORMANCE MEASURE FOR TRANSPORTATION AND LAND USE SYSTEMS AND ITS APPLICATION IN OREGON, FLORIDA, AND UTAH}

Final Report

NITC-RR-758

by

Liming Wang and Jenny Liu

Portland State University

for

National Institute for Transportation and Communities (NITC)

P.O. Box 751

Portland, OR 97207
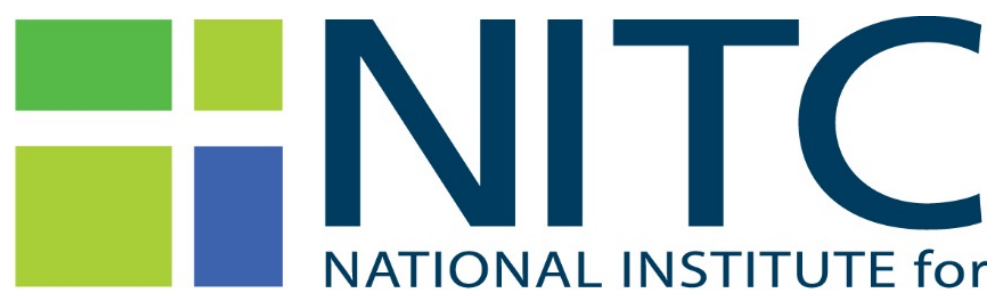

TRANSPORTATION and COMMUNITIES

April 2017 




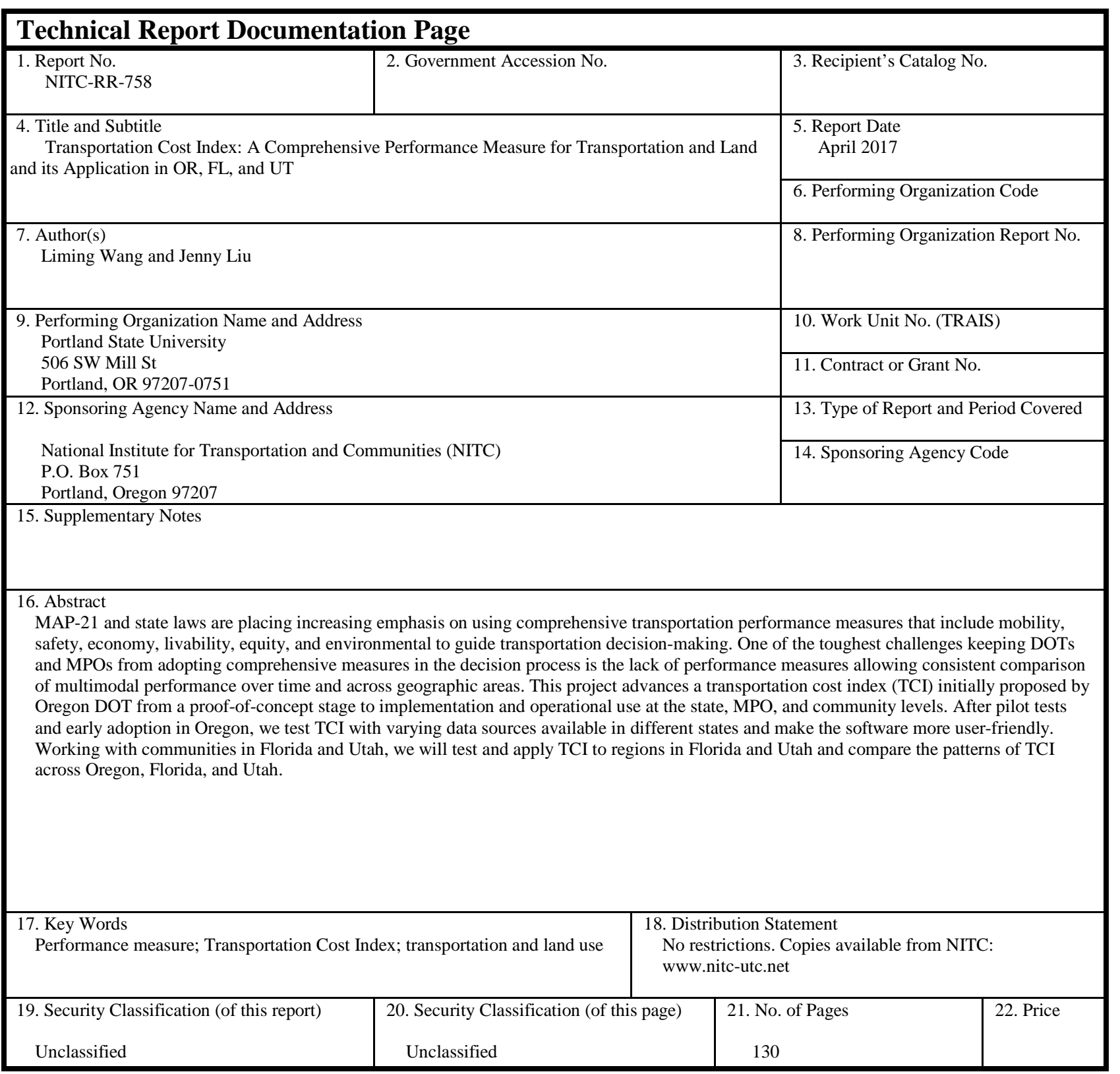





\section{ACKNOWLEDGMENTS}

This project was funded by the National Institute for Transportation and Communities (NITC) and Oregon Department of Transportation SPR 760. We would like to acknowledge the helpful feedback from members of the Technical Advisory Committee for the SPR project, including Alex Bettinardi (ODOT), Lisa Cortes (ODOT), Brian Gregor (Oregon System Analytics), Xiugang (Joe) Li (ODOT), Richard Munford (ODOT), Lucia Ramirez (ODOT), Bud Reiff (Metro), and Satvinder Sandhu (FHWA). We appreciate the data and technical support in the process of this study by the staff at Metro, the ODOT Transportation Planning Analysis Unit (TPAU), and the Wasatch Front Regional Council, in particular, Bud Reiff, Peter Bosa, Alex Bettinardi, and Andy Li. Graduate students at Portland State University, Huajie Yang, Wei Shi and Kirstin Munro, made valuable contributions to this project.

\section{DISCLAIMER}

The contents of this report reflect the views of the authors, who are solely responsible for the facts and the accuracy of the material and information presented herein. This document is disseminated under the sponsorship of the U.S. Department of Transportation University Transportation Centers Program in the interest of information exchange. The U.S. Government assumes no liability for the contents or use thereof. The contents do not necessarily reflect the official views of the U.S. Government. This report does not constitute a standard, specification, or regulation.

\section{RECOMMENDED CITATION}

Wang, Liming, and Jenny Liu. Transportation Cost Index: A Comprehensive Performance Measure for Transportation and Land Use Systems and its Application in OR, FL, and UT. NITC-RR-758. Portland, OR: Transportation Research and Education Center (TREC), 2017. 


\section{TABLE OF CONTENTS}

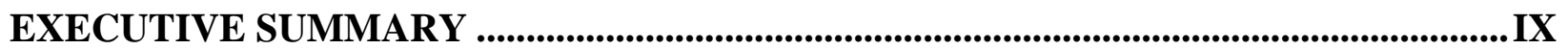

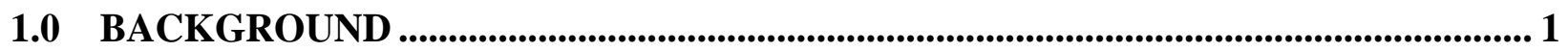

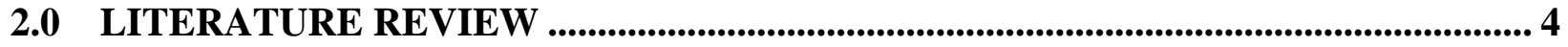

2.1 EXISTING SIMILAR PERFORMANCE MEASURES ......................................... 4

2.2 ACCESSIBILITY OBSERVATORY …............................................................... 5

2.2.1 Methodology ............................................................................................. 5

2.2.1.1 Cumulative Opportunities Accessibility........................................................... 5

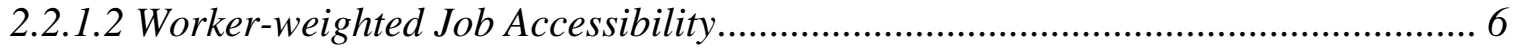

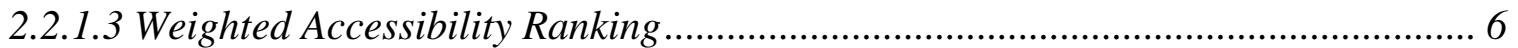

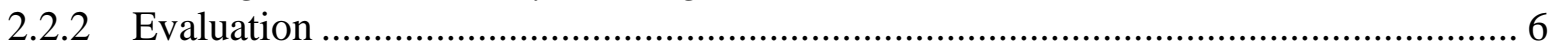

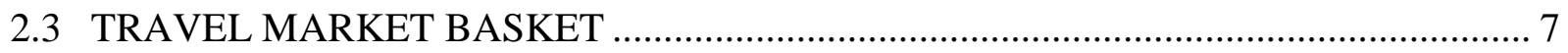

2.3.1 The CPI Calculation Process .................................................................... 7

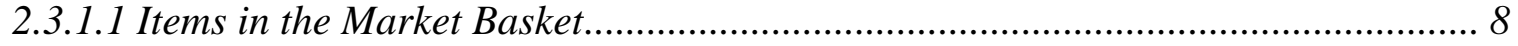

2.3.1.2 Relative Importance of Items ........................................................................... 9

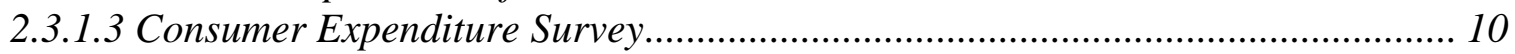

2.3.2 Travel Market Basket............................................................................... 10

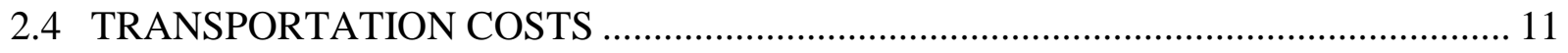

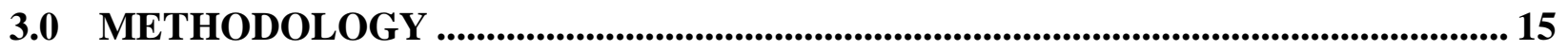

3.1 TRANSPORTATION MARKET BASKET IDENTIFICATION …............................ 15

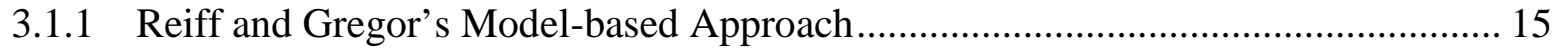

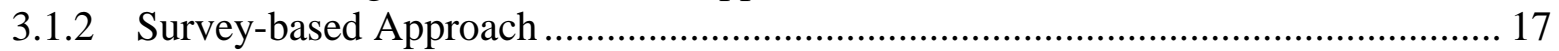

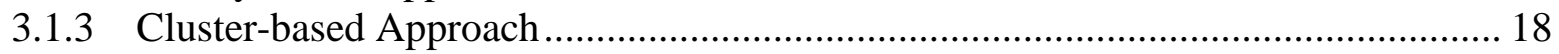

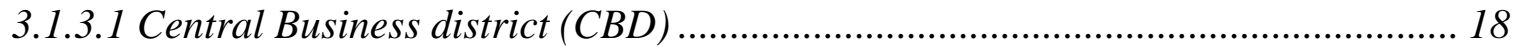

3.1.3.2 Spatial Identification of Employment Centers .................................................. 19

3.1.3.3 Cluster-based Approach for Activity Center Identification .................................... 19

3.1.4 Individual-level Model-based Approach ................................................................. 24

3.2 TRANSPORTATION COST CALCULATION METHODOLOGY ............................ 25

3.2.1 Utility-based Travel Cost Calculation ............................................................ 25

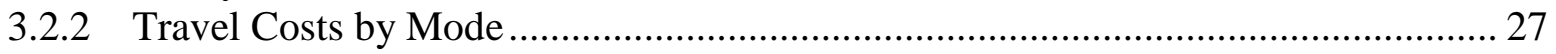

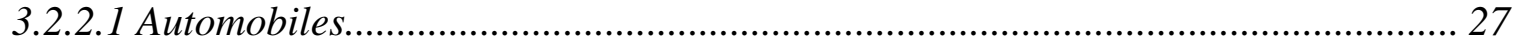

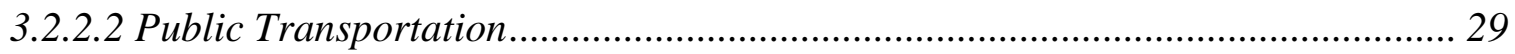

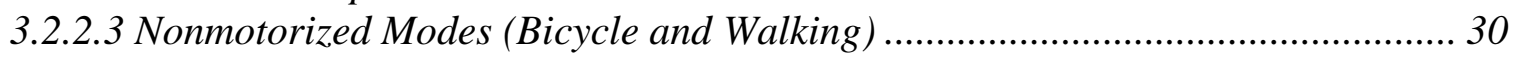

3.2.3 A Generic Travel Cost Calculation Algorithm .................................................. 30

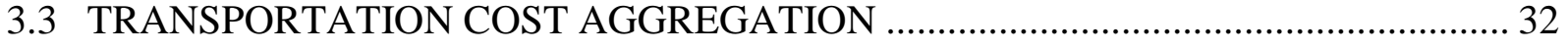

4.0 IMPLEMENTATIONS AND THE PORTLAND APPLICATION........................... 35

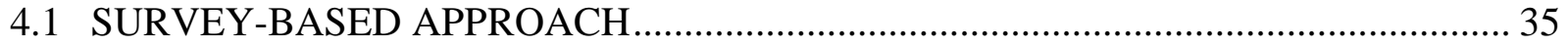

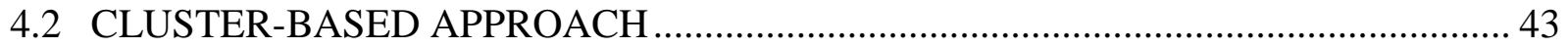

5.0 TESTING SCALABILITY WITH THE CORVALLIS APPLICATION.................... 50

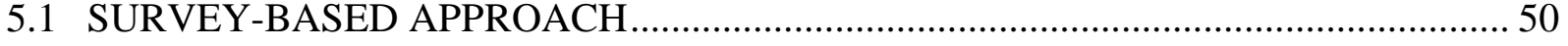

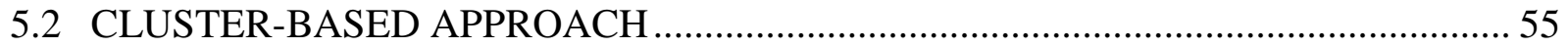

6.0 APPLICABILITY TESTING ................................................................................6. 64

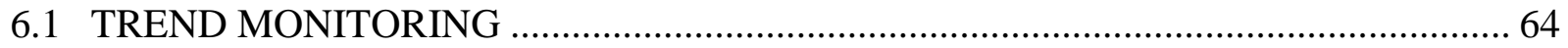




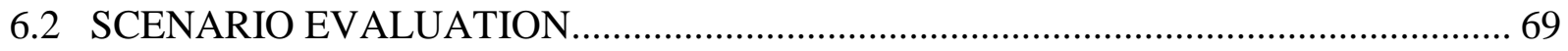

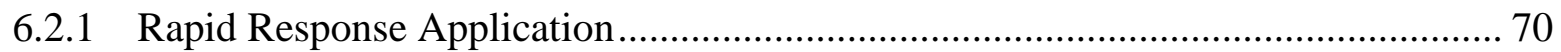

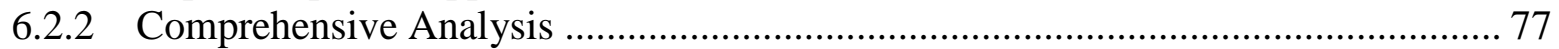

7.0 APPLICATIONS TO UTAH, FLORIDA AND NATIONWIDE................................. 84

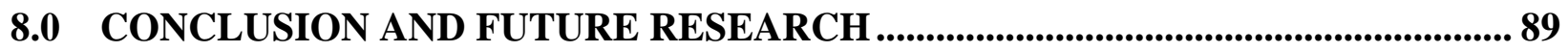

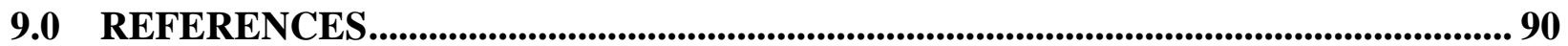

\section{APPENDICES}

APPENDIX A: INPUT DATA FOR THE SURVEY-BASED APPROACH

APPENDIX B: INPUT DATA FOR THE CLUSTER-BASED APPROACH

APPENDIX C: SENSITIVITY ANALYSIS OF CUTOFFS FOR THE CLUSTER-BASED APPROACH FOR PORTLAND

APPENDIX D: SOURCE CODE AND INSTRUCTIONS

\section{LIST OF TABLES}

Table 2.1: Details of Estimated Value of One Hour of Travel-Time by Vehicle Class, Oregon

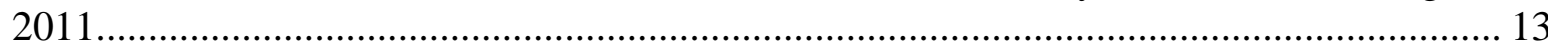

Table 2.2: Recommended Value of Travel Time................................................................................ 13

Table 2.3: Relative mean Value of Travel Time, after controlling for covariates (bus-none

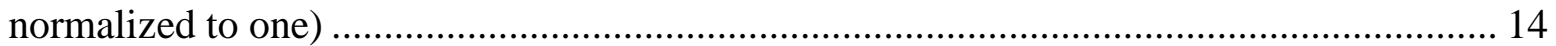

Table 2.4: Travel Time Values Relative to Prevailing Wages......................................................... 14

Table 3.1: Recommended Value of Time by Mode Relative to 2011 Oregon Hourly Wage........ 31

Table 3.2: Monetary Costs per Mile by Travel Mode ................................................................ 32

Table 5.1: Travel costs with various cutoff values ..................................................................... 58

Table C.1: Weighted TAZ-level aggregated travel costs for peak period with different cutoffs ... 4

Table C.2: Weighted TAZ-level aggregated travel costs for off-peak period with different cutoffs

Table C.3: Weighted TAZ-level aggregated travel costs with different cutoffs............................... 6

\section{LIST OF FIGURES}

Figure 2.1: 2-Stage Process of the CPI Calculation.............................................................. 8

Figure 3.1: Employment density distribution of HBW ..................................................... 22

Figure 3.2: Size terms density distribution of HBS ........................................................... 22

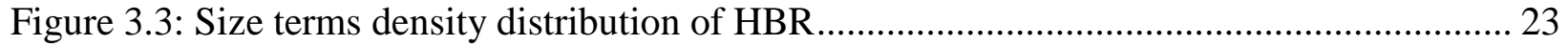

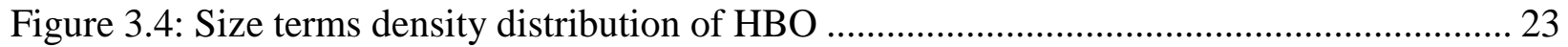

Figure 4.1: Density distributions of household-level travel costs by income level for Portland

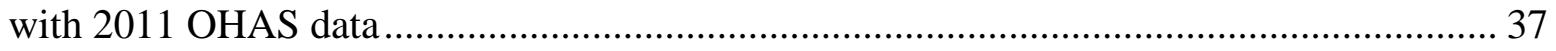


Figure 4.2: Density distributions of household-level travel costs by household size for Portland

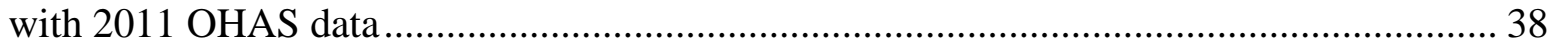

Figure 4.3: Density distributions of household-level travel costs by presence of children for Portland with 2011 OHAS data 39

Figure 4.4: Density distributions of average travel costs per person by income for Portland with 2011 OHAS data 40

Figure 4.5: Box plot of trip-level travel costs by trip purpose and traveler's household income level for Portland with 2011 OHAS data....

Figure 4.6: District level average household travel costs by income level and trip purpose for Portland with 2011 OHAS data ... 42

Figure 4.7: Heat map of per person travel costs for Portland with 2011 OHAS data (grid cell size $=0.02^{\prime}$ * $0.02^{\prime}$, overlaid with traffic district boundaries) .............................................. 43

Figure 4.8: Density distributions of travel costs by income level for Portland with the 2010 travel

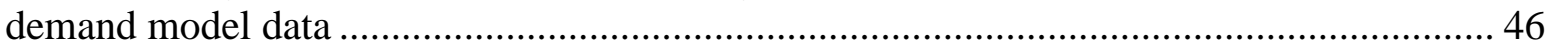

Figure 4.9: Density distributions of travel costs by trip purpose for Portland with the 2010 travel

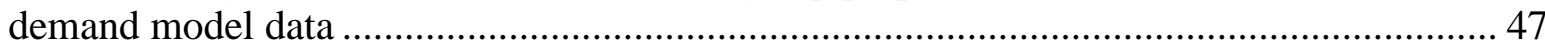

Figure 4.10: Box plot of travel costs by income level and trip purpose for Portland with the 2010

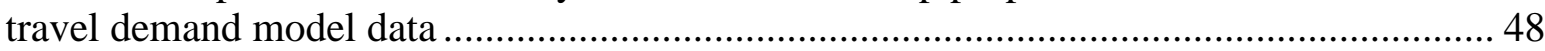

Figure 4.11: TAZ level spatial distribution of travel costs by income level and trip purpose for Portland with 2010 travel demand model data ............................................................ 49

Figure 5.1: Density distributions of household-level travel costs by income level for Corvallis

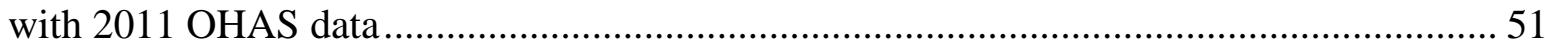

Figure 5.2: Density distributions of household-level travel costs by household size for Corvallis with 2011 OHAS data............................................................................................... 52

Figure 5.3: Density distributions of household-level travel costs by presence of children for

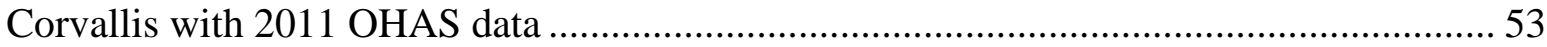

Figure 5.4: Density distributions of average travel costs per person by income for Corvallis with

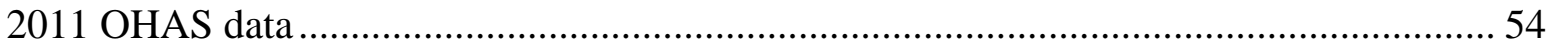

Figure 5.5: Box plots of trip-level travel costs by income level and trip purpose for Corvallis

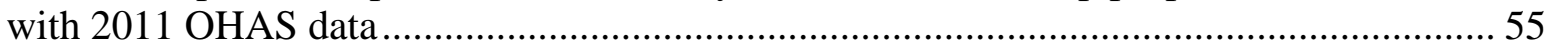

Figure 5.6: Sensitivity analyses of cutoff values for HBW trips ............................................. 57

Figure 5.7: Activity centers by trip purpose for Corvallis identified with the cluster-based

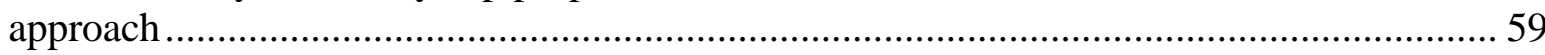

Figure 5.8: Density distributions of travel costs by income level for Corvallis with the 2010

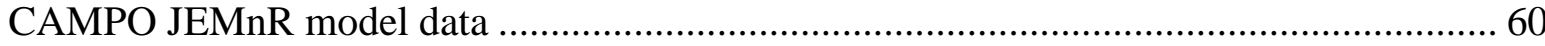

Figure 5.9: Density distributions of travel costs by trip purpose for Corvallis with the 2010 CAMPO JEMnR model data

Figure 5.10: Box plot of travel costs by income level and trip purpose for Corvallis with the 2010 CAMPO JEMnR model data 62

Figure 5.11: TAZ level travel costs by income level and trip purpose for Corvallis with the 2010 CAMPO JEMnR model data .

Figure 6.1: Density distributions of household-level travel costs by income level for Portland with 1994 travel survey data ................................................................................ 65

Figure 6.2: Density distributions of household-level travel costs by household size for Portland with 1994 travel survey data. 
Figure 6.3: Density distributions of household-level travel costs by presence of children for

Portland with 1994 travel survey data

Figure 6.4: Density distributions of average travel costs per person by income for Portland with 1994 travel survey data 68

Figure 6.5: Box plots of trip-level travel costs by income level and trip purpose for Portland with 1994 travel survey data 69

Figure 6.6: Density distributions of travel costs by income level for Corvallis Scenario A (halving auto travel time and all other data from the 2010 CAMPO JEMnR model).... 71

Figure 6.7: Density distributions of travel costs by income level for Corvallis Scenario B (halving bus travel time and all other data from the 2010 CAMPO JEMnR model) .......... 72

Figure 6.8: Box plot of travel costs by trip purpose and income level for Corvallis Scenario A (halving auto travel time and all other data from the 2010 CAMPO JEMnR model) ......... 73

Figure 6.9: Box plot of travel costs by trip purpose and income level for Corvallis Scenario B (halving bus travel time and all other data from the 2010 CAMPO JEMnR model) .......... 74

Figure 6.10: TAZ level travel costs by income level and trip purpose for Corvallis Scenario A (halving auto travel time; all other data from the 2010 CAMPO JEMnR model).............. 75

Figure 6.11: TAZ level travel costs by income level and trip purpose for Corvallis Scenario B (halving bus travel time; all other data from the 2010 CAMPO JEMnR model)............... 76

Figure 6.12: Density distributions of travel costs by income group for 2030Preferred Scenario 78 Figure 6.13: Density distributions of travel costs by income group for Corvallis 2030 Preferred

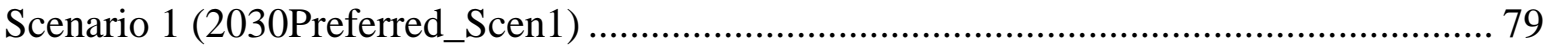

Figure 6.14: Box plot of travel costs by income level and trip purpose for Corvallis 2030Preferred Scenario. 80

Figure 6.15: Box plot of travel costs by income level and trip purpose for Corvallis 2030 Preferred Scenario 1 (2030Preferred_Scen1) 81

Figure 6.16: TAZ level travel costs by income level and trip purpose for Corvallis 2030 Preferred Scenario 82

Figure 6.17: TAZ level travel costs by income level and trip purpose for Corvallis 2030 Preferred

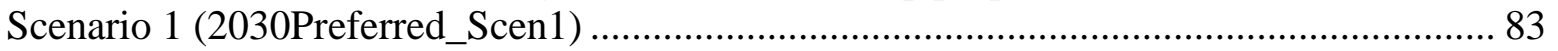

Figure C.1: Maps of identified centers for HB Work with different cutoffs .............................. 1

Figure C.2: Maps of identified centers for HB Shopping with different cutoffs ........................... 2 Figure C.3: Maps of identified centers for HB Recreation with different cutoffs ......................... 2 Figure C.4: Maps of identified centers for HB Other with different cutoffs ................................ 3 


\section{EXECUTIVE SUMMARY}

MAP-21 and state laws are placing increasing emphasis on using comprehensive transportation performance measures that include mobility, safety, economy, livability, equity, and environmental to guide transportation decision-making. Although there is a growing list of performance measures of land use and transportation systems largely centered on accessibility (see, for example Zietsman et al (2011)), one of the challenges in successfully implementing performance measures in the transportation planning process is the development of measures that present an overall picture of both transportation and land use systems and are relatively easy to interpret for policymakers and the public. Certain policy goals, such as the aspect of a balanced transportation system mandated by the state of Oregon's transportation planning rules, are also not well reflected by popular accessibility measures. Reiff and Gregor (2005) proposed a Transportation Cost Index (TCI) to fill this gap. Building on the concept of the widely used Consumer Price Index (CPI), the TCI aims to be a performance measure that fills the gap in policy areas including a balanced transportation system, environmental justice and land use compatibility.

To help make applications of the TCI more accessible to transportation professionals, several research projects have aimed to advance it from a proof-of-concept stage to implementation and operational use in different states. Previous and ongoing research on the performance measure piloted the concept, addressed the robustness of the method of calculating TCI, and tested it for scalability in communities in the state of Oregon.

This research will test the sensitivity and robustness of TCI computed from different data sources and make the TCI software easily accessible for application in other regions. We will test and apply TCI to regions in Florida and Utah and compare the patterns of TCI across regions in Oregon, Florida, and Utah. The Salt Lake City metropolitan area in Utah (Wasatch Front Regional Council, or WFRC) and Tampa, Florida, metropolitan area (Hillsborough County MPO) are selected preliminarily.

The outcomes of this project include:

- Thoroughly tested and well-documented TCI software released under an open-source license. It will help make TCI easily accessible to transportation researchers and professionals.

- Demonstration application of TCI to regions in Oregon, Florida, and Utah. The diversity of these regions would help showcase the wide applicability of TCI.

- Working paper documenting the robustness of TCI with different data sources and comparison of TCI patterns in different states.

The software, applications, and working papers are available at the project website: https://github.com/cities-lab/tci. 



\subsection{BACKGROUND}

MAP-21 and state laws are placing increasing emphasis on using comprehensive transportation performance measures that include mobility, safety, economy, livability, equity, and environmental to guide transportation decision-making. The federal MAP-21 law requires state departments of transportation (DOTs) and metropolitan planning organizations (MPOs) to set performance targets and report progress with respect to seven comprehensive national goals (MAP-21 2012). The Oregon Jobs and Transportation Act mandates that ODOT develop a leastcost planning process that uses performance measures in the comprehensive evaluation of all policies proposed to meet transportation goals.

One of the toughest challenges keeping DOTs and MPOs from adopting comprehensive measures in the decision process is the lack of performance measures allowing consistent comparison of multimodal performance over time and across geographic areas. Fortunately, previous ODOT research offers some direction in meeting this challenge. Proof-of-concept research in ODOT sponsored research project SPR 357 (Reiff and Gregor 2005) developed a Transportation Cost Index (TCI) to compare the performance of different transportation modes in common terms, building on the concept of the widely used Consumer Price Index (CPI). As a result of the logical appeal of the TCI and the proof-of-concept research, the Accessibility Indicator Development Team adopted this measure for the Oregon least-cost planning project (Carr, Hajiamiri, and Gros 2012).

This project and our other work (Wang, Yang and Liu 2016) build on and further develop a TCI of land use and transportation systems in order to fill three important gaps in popular accessibility measures.

First, we develop a composite indicator to present an overall picture of a community's accessibility that policymakers and the public can interpret relatively easily. Existing utility- and gravity-based metrics can present an overall picture of a community's accessibility, but they are difficult to communicate to a nontechnical crowd, which would be critical for transparent decision-making (Waddell 2011). On the other hand, more-intuitive indicators, such as opportunities accessible within a certain travel time by a certain mode can hardly present an overall picture of a community, as they reflect only an aspect of a complex picture (Cascetta, Cartenì, and Montanino 2013; Chen et al. 2011). We believe that it is critical to be able to make good on both ends.

Second, the TCI fills gaps left in policy areas by popular performance measures of land use and transportation systems. As state DOTs and MPOs in the U.S. move toward a performance-based approach to transportation planning, they need to measure the results of policies. In the state of Oregon, the Jobs and Transportation Act mandates that the Oregon DOT develop a least-cost planning process that uses performance measures in comprehensive evaluations of all possible solutions - both transportation and land use strategies — to meet transportation goals including economic vitality, a balanced transportation system, sustainability, adaptability, quality of life, environment justice, system preservation, land use compatibility, affordability, as well as accessibility, mobility, safety and security (Oregon Secretary of State 
2002). Reiff and Gregor (2005) found that some of these policy areas, such as balance and land use compatibility, are not well represented by commonly used performance measures. The balance policy area calls for a balanced transportation system, for demand management, land use planning and transportation system management, as well as for new infrastructure investment to match demand and supply, and for appropriate allocation of resources across multiple travel modes.

Finally, we want to develop a measure that can be used to monitor historical and projected trends, and to evaluate and compare outcomes from what-if scenarios, as well as to report the current status. Since current-year data and model inputs and outputs are more readily available, reporting the current status is usually the easiest to achieve. To enable trend monitoring and scenario evaluation, the performance measure needs to utilize and be sensitive to common transportation and land use model outputs.

TCI is a performance measure inspired by CPI. The CPI measures changes in relative prices for acquiring a reference market basket of goods and services. It may be used to compare living costs in different areas and their changes over time. The TCI measures the changes in the relative cost of reaching a market basket of travel destinations. It may be used to compare accessibility by trip purpose, income group, and geographic area. As in to the process of constructing the CPI, calculating the TCI involves identifying market baskets of travel opportunities and tracking and summarizing the costs of reaching these market baskets. A travel market basket identifies a set of destinations that provide a good set of choices for meeting daily needs, and the total costs of traveling to destinations in the travel market basket are calculated by travel mode for each Traffic Analysis Zone (TAZ). The costs can then be summarized by origin TAZ, trip purpose, and income group, or into weighted averages by collapsing some of these dimensions.

The TCI is designed to be a measure of accessibility and of the effects of transportation and land use systems on equity and quality of life. It can also serve as an indicator for such policy areas as transportation and land use system compatibility and balance, which are less represented by existing performance measures. The primary purpose of the transportation system, from the standpoint of an individual household, is to provide affordable access (timeand money-wise) to the goods, services, and daily activities that households desire. Like the CPI, which may be used to indicate relative change in the cost of the goods and services themselves, the TCI is designed to indicate changes in the costs to reach goods and services. The TCI may be used to measure how transportation affordability varies spatially across an urban area, how it changes over time, and how it is affected by various land use and transportation system alternatives. Increased TCI in future scenarios indicates problems with land use or transportation system compatibility and balance. Certain population subgroups suffering from higher TCI may suggest inequities in resource allocation. A high TCI may result from extreme traffic congestion or limited access to the travel market basket. Such situations might be addressed through a range of policies and investment decisions, including demand management, land use planning, transportation system management, additional roadway capacity, and investment in alternative modes, any of which may bring down transportation costs. TCI can be computed for each alternative solution to evaluate their relative effectiveness, and used in trade-off analysis to support resource allocation decisions among these alternatives.

The TCI algorithm can utilize data from different sources to define a travel market basket and to calculate transportation costs. The specifications can be readily adapted to traditional 4step travel demand models and potentially newer disaggregated discrete choice-based travel 
demand models. Since relying on travel model data makes it difficult to calculate historical TCI or infeasible for areas without a suitable travel demand model, we also test methods of computing TCI from more widely available data sources, such as population and household census, Longitudinal Employer-Household Dynamics (LEHD), household activity survey data, etc., without requiring data from a travel demand model.

Our earlier paper (Wang et al. 2015) and report (Wang and Liu 2015) adopt and test an algorithm for computing TCI that was initially proposed by Reiff and Gregor (2005). The algorithm relies solely on information from travel demand models to provide all the information needed to define travel market basket and to calculate transportation cost, which makes the specifications readily adapted to places with traditional 4-step travel demand models or potentially newer disaggregated discrete choice-based travel demand models. However, relying on travel model data makes it difficult to calculate historical TCI or infeasible for areas without a suitable travel demand model. In this project, we develop and test two methods of computing TCI with alternative data sources, including those that are widely available, such as population and household census, LEHD, household activity survey data, etc., potentially enabling applications without data from a travel demand model. Eventually we anticipate the TCI will cover all three desired use cases: current status reporting, trend monitoring, and scenario evaluation. 


\subsection{LITERATURE REVIEW}

We first review existing similar performance measures of transportation and land use systems, largely labeled as accessibility measures in the literature. We pay special attention to a set of accessibility measures developed by the Accessibility Observatory at University of Minnesota. We then review relevant literature on defining travel market baskets and calculating travel costs. This provides theoretical background and information for the two objectives of this project: robust definitions of the transportation market baskets to be used in the calculation of the Transportation Cost Index (TCI); and robust methods for calculating and aggregating multimodal travel costs to access market baskets by different modes including auto, public transit, walking and biking, and by different household segments.

\subsection{EXISTING SIMILAR PERFORMANCE MEASURES}

A growing body of literature documents accessibility metrics and their application as performance measures. Handy and Niemeier (1997) discuss commonly used accessibility measures and their limitations. NCHRP 446 (Cambridge Systematics 2000) categorizes a set of performance measures including accessibility by the policy areas they represent, and recommends practice for selecting performance measures.

The three common accessibility measures (Handy and Niemeier 1997) - cumulative opportunities measures, gravity-based measures and utility-based measures — face a dilemma in application. Comprehensive accessibility measures, such as utility- and gravity-based metrics, are good at presenting an overall picture of a community's accessibility level, but they are very technical and it is hard to communicate to the public what they actually measure. On the other hand, specific accessibility measures are intuitive but can hardly convey a comprehensive picture of accessibility. For example, cumulative opportunities measures such as number of employment accessible with 30 minutes during am peak by transit is appealing in that it is very straightforward to communicate what it measures, but they can hardly be used to present an overall picture of a community, as they reflect only a certain aspect of a much more complex picture.

Geurs and van Wee (2004) proposed another topology of accessibility measures after reviewing a number of them that are suitable for evaluation of land use and/or transportation strategies. They classify accessibility measures as infrastructure-based, location-based, person-based or and utility-based. While infrastructure-, location-, and person-based measures are relatively easier to interpret, it is more difficult for them to present a comprehensive picture of the systems to be measured; vice-versa for utility-based measures. For example, most accessibility indicators that are based on travel time or opportunity are location- or person-based measures. Within this topology, the TCI is a location-based measure and aims to be an intuitive measure of overall system performance.

The idea of the TCI is in line with the approach Koopmans et al. (2013) propose - measuring generalized travel cost as an indicator for accessibility change. They calculate the average costs 
per kilometer of trips by transportation mode, trip purpose, trip distance, region and time of day, and monitor the cost change over time. The measure has the advantage of easy interpretability, but since it accounts only for per-distance costs for motorized trips and thus ignores potential land use changes, it is infeasible as a measure for land use and transportation systems. By tracking the generalized travel cost to access a pre-defined travel market basket, the TCI will be sensitive to changes in both land use and transportation systems.

Geurs et al. (2010) propose to use a disaggregated logsum accessibility measure from a land use transportation interaction model to compute changes in consumer surplus between policy scenarios. While the goal of their research is similar to that of this project in terms of providing an elegant and convenient method to measure benefits of land use and/or transportation policies, their consumer surplus metric is meaningful only for measuring the difference between two scenarios, and thus not suitable to monitor accessibility trends over time. It also lacks the capacity to examine balance across geographic regions and population subgroups.

\subsection{ACCESSIBILITY OBSERVATORY}

The Accessibility Observatory at the University of Minnesota focuses on the research and application of accessibility-based transportation system evaluations. It builds on earlier work conducted at the University of Minnesota, including the Access to Destinations study and the first Access Across America series report.

The Access to Destinations study (Owen and Levinson 2012) laid the groundwork for their accessibility evaluation. The Observatory uses the methods and tools developed there as the starting point for an integrated, multi-modal accessibility evaluation system that they plan to apply nationwide.

The Access Across America series measures accessibility to jobs via various modes of transportation in major metropolitan areas across the United States. Latest release reports are Access Across America: Transit 2014 (Owen and Levinson 2014) and Access Across America: Auto 2013 (Owen and Levinson 2014).

\subsubsection{Methodology}

\subsubsection{Cumulative Opportunities Accessibility}

Owen and Levinson (2012) use a cumulative opportunities measure of accessibility. The approach begins by specifying a mode and travel time threshold, and then counts the number of opportunities that can be reached via that mode within the specified travel time threshold. The study examines six time-threshold ranges from 0 to 10 minutes, from 10 to 20 minutes, from 20 to 30 minutes, from 30 to 40 minutes, from 40 to 50 minutes and from 50 to 60 minutes. Accessibility is calculated as:

$$
A_{i, c o}=\sum_{j=1}^{n} o_{J} * f\left(C_{i j}\right)
$$

$A_{i, c o}=$ cumulative opportunities of the considered type (e.g., employment) accessible from zone i 
$O_{j}=$ number of opportunities of the considered type in zone $\mathrm{j}$

$C_{i j}=$ generalized (or real) time or cost of travel from $\mathrm{i}$ to $\mathrm{j}$

$f\left(C_{i j}\right)=$ impedance function

For the cumulative opportunities measure, $f\left(C_{i j}\right)$ is defined as 1 if $C_{i j} \in \mathrm{T}$ and 0 otherwise. $\mathrm{T}$ is the pre-specified travel time-threshold range.

\subsubsection{Worker-weighted Job Accessibility}

To compare the accessibility of different levels of geography (e.g zones and subzones), Owen and Levinson (2012) propose a worker-weighted accessibility measure. The cumulative accessibility measure is averaged across all subzones with each subzone's contribution weighted by the number of workers in that subzone.

$$
\begin{aligned}
\boldsymbol{A}_{\boldsymbol{p} w}= & \frac{\sum_{i=\mathbf{1}}^{n} \boldsymbol{A}_{i} * \boldsymbol{P}_{i}}{\sum_{i=1}^{n} \boldsymbol{P}_{i}} \\
& A_{p w}=\text { worker-weighted average accessibility of all subzones } \\
& A_{i}=\text { accessibility of subzone } \mathrm{i} \\
& P_{i}=\text { worker population in subzone } \mathrm{i}
\end{aligned}
$$

\subsubsection{Weighted Accessibility Ranking}

Metropolitan area rankings are based on an average of worker-weighted job accessibility for each metropolitan area over the six travel time-threshold ranges. With the weighted average job accessibility, destinations reachable in shorter travel times are given more weight. Here two time thresholds are used to get a series of "donuts" (e.g., jobs reachable from 0 to 10 minutes, from 10 to 20 minutes, from 20 to 30 minutes, from 30 to 40 minutes, from 40 to 50 minutes, from 50 to 60 minutes).

$$
a_{w}=\sum_{t}\left(a_{t}-a_{t-10}\right) * e^{\beta t}
$$

$a_{w}=$ Weighted accessibility ranking metric for a single metropolitan area

$a_{t}=$ Worker-weighted accessibility for threshold $\mathrm{t}$

$\beta=-0.08$ (calculated through survey data)

\subsubsection{Evaluation}

This performance measure developed by the Accessibility Observatory is a type of opportunitybased accessibility measure. The chief advantages of the cumulative opportunities measure are its simplicity to interpret and its focus on commuting by a particular mode, but it also has a few limitations. First, cumulative opportunities and weighted opportunities measures of accessibility do not account for differences in preferences among individuals - they imply that all people living in the same location (e.g. TAZ) will experience the same level of accessibility. For example, it does not differentiate accessibility by income groups. Travelers of different incomes 
usually have different time constraints, preferences and access to travel modes. Second, it only measures the access to jobs, but not necessary the destinations that travelers travel to. For example, low-income households may live in downtown areas with the best cumulative opportunity accessibilities, but they still have long commutes to the jobs for which they are qualified. Access to nonemployment activities, including shopping and recreation, is not considered. Finally, the thresholds in the impedance function may create cliff effects, counting, for instance, a job 29 minutes away while excluding one 31 minutes away.

\subsection{TRAVEL MARKET BASKET}

The term "market basket” refers to a fixed list of items used specifically to track inflation in an economy or of a specific market. The most common type of market basket is the basket of goods and services used to define the Consumer Price Index (CPI), which is intended to track the prices of goods and services in the basket. In this section, we examine the methodology for the CPI. The CPI was first developed to characterize the rapid increases in necessary cost-of-living adjustments (COLA) during World War I (Bureau of Labor Statistics, 2007). Three of the main CPI series are CPI for All Urban Consumers (CPI-U), Chained CPI for All Urban Consumers (CCPI-U) and CPI for Urban Wage Earners and Clerical Workers (CPI-W).

\subsubsection{The CPI Calculation Process}

The CPI is built in two stages (figure 2.1): Lower-level aggregation and upper-level aggregation. The technical calculation process is provided in Chapter 17, The Consumer Price Index, of the Bureau of Labor Statistics (BLS) Handbook of Methods ${ }^{1}$. This section provides a brief summary of the process, especially focusing on the construction of the market basket with Consumer Expenditure (CE) Survey.

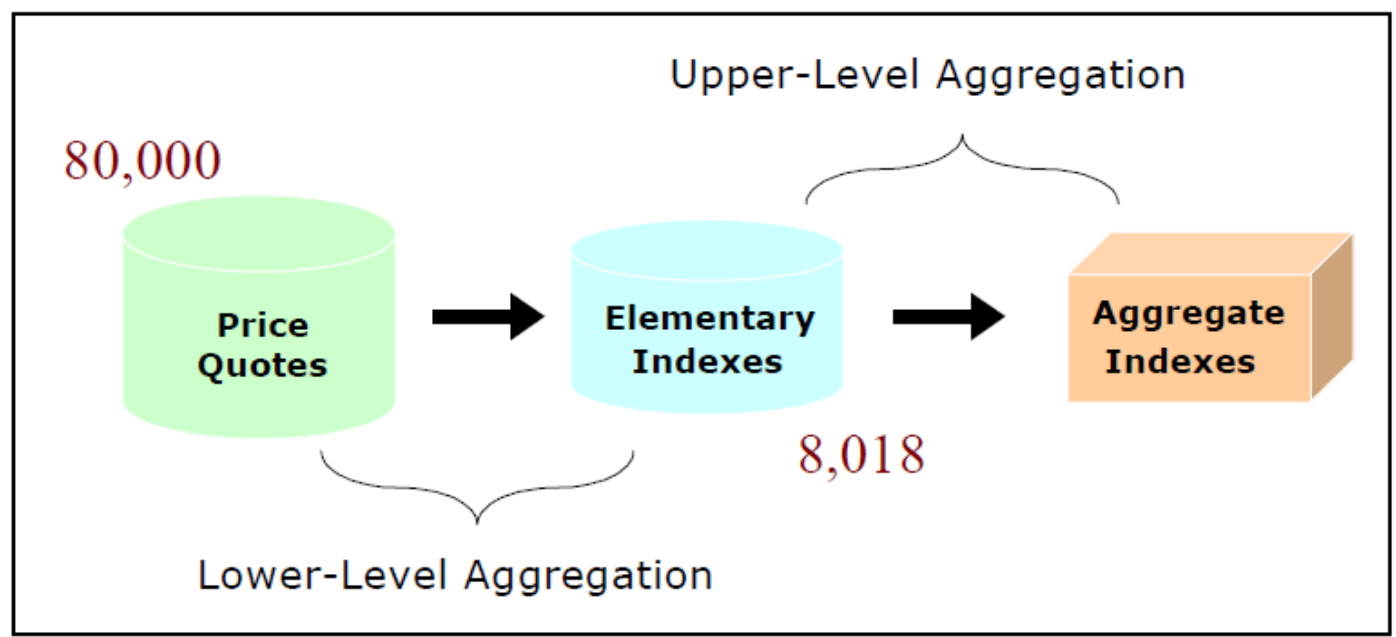

\footnotetext{
${ }^{1}$ U.S. Bureau of Labor Statistics, Handbook of Methods, Chapter 17 The Consumer Price Index, available at http://www.bls.gov/opub/hom/pdf/homch17.pdf
} 
Figure 2.1: 2-Stage Process of the CPI Calculation

The first stage, “lower-level aggregation” or “elementary-level aggregation,” involves averaging the most fundamental component of the index - observed price changes for specifically defined consumer goods, services, and products. In this stage, monthly price changes for roughly 80,000 specific items are averaged to yield 8,018 estimates of aggregate price change.

In the CPI calculation process, the urban portion of the United States is divided into 38 geographic areas called "index areas," and the set of all goods and services purchased by consumers is divided into 211 categories called "item strata." This results in 8,018 (38 x 211) item-area combinations. An elementary-level index is computed for each combination of an item stratum and index area.

The CPI item structure has four levels of classification: Eight major groups, 70 expenditure classes (ECs), 211 item strata and 305 entry-level items (ELIs). Major groups and ECs do not figure directly in CPI sample selection, although ECs are used in smoothing item stratum expenditure estimates during composite estimation. The ELIs are the ultimate sampling units for items as selected by the BLS national office. They represent the level of item definition from which data collectors begin item sampling within each sample outlet. Each ELI has a corresponding sampling frame of outlets that sell the ELI. In each there are several unique items. A single selection of a unique item is referred to as a quote. An example of a unique item for the ELI "Cookies" is a one-pound bag of chewy-style chocolate-chip cookies with walnuts, of a particular brand name.

For example, the prices of approximately 10 different brands and styles of watches at various locations in Chicago are observed each month, compared to the prices observed in the previous month, and averaged together to produce an index of price change for watches in Chicago. A watch (ITEM=AG01) is one of 211 elementary items, and Chicago (AREA=A207) is one of 38 elementary areas in the current CPI market basket structure. The Chicago-watch index is one of the 8,018 (211 items $x 38$ areas) elementary indexes produced in the first stage of CPI construction.

In the second stage, the elementary indexes are averaged together to yield various aggregate indexes and ultimately the All-Items, U.S. City Average index of price change.

Aggregation of elementary CPI data into published indexes requires three ingredients: input elementary price indexes, input elementary expenditure to use as aggregation weights, and a price index number formula that uses the expenditures to aggregate the sample of elementary indexes into a published index. More technical details are available on pages 33-36 of Chapter 17, Consumer Price Index, in the BLS Handbook of Methods.

\subsubsection{Items in the Market Basket}

The CPI market basket is developed from detailed expenditure information provided by families and individuals on what they actually bought. For the current CPI, this 
information was collected from the CE Surveys for 2011 and 2012. In each quarter of each of those years, about 7,000 families from around the country provided information on their spending habits in the interview survey. To collect information on frequently purchased items, such as food and personal care products, another 7,000 families in each of these years kept diaries listing everything they bought during a two-week period.

Over the two years, then, expenditure information came from approximately 28,000 weekly diaries and 60,000 quarterly interviews used to determine the importance, or weight, of the more than 200 item categories in the CPI index structure.

For each of the more than 200 item categories, using scientific statistical procedures, the Bureau has chosen samples of several hundred specific items within selected business establishments frequented by consumers to represent the thousands of varieties available in the marketplace. For example, in a given supermarket, BLS may choose a plastic bag of golden delicious apples, U.S. extra fancy grade, weighing 4.4 pounds, to represent the apples category.

To enable the CPI to reflect changes in the marketplace, new item and outlet samples are selected each year, on a rotating basis, for approximately 25 percent of the item strata. Each year, four regional item universes are tabulated from the 2 most recent years of CE data. Independent samples of ELIs are selected from the corresponding regional item universe for each item stratum scheduled for rotation that year. Within each sample, each item sample is based on a systematic probability-proportional-to-size (PPS) sampling procedure, in which each ELI has a probability of selection proportional to the CPI-U population expenditures for the region for the ELI within its stratum.

\subsubsection{Relative Importance of Items}

According to Schmidt (1995), the relative importance based on consumer expenditure data refers to the ratio of expenditure on an item or a group of items to the total expenditures for all items. The patterns of expenditures at major group levels are quite similar over these time periods.

According to Mason and Butler (1987), the expenditure weight for each item stratum is an estimate of total expenditure by the index population for that item. It is calculated as the product of estimates of mean expenditures of consumer units and the number of consumer units.

Mason and Butler (1987) define relative importance as the share that the base-period expenditure multiplied by the price relative for a particular item stratum of the sum of all base-period expenditures multiplied by their price relatives.

$$
R I_{t, i}=\frac{E_{0 i}\left(\frac{p_{t i}}{p_{0 i}}\right)}{\sum_{i} E_{0 i}\left(\frac{p_{t i i}}{p_{0 i}}\right)} * 100
$$


Where

$P_{t i}$ is the price of item I in the comparison period $t$;

$P_{0 i}$ is the price of item I in the base period;

$E_{0 i}$ is the expenditure for item $\mathrm{i}$ in the base period

\subsubsection{Consumer Expenditure Survey}

The objectives of the CE Survey are to provide the basis for revising weights and associated pricing samples for the CPI and to meet the need for timely and detailed information on the spending patterns of different types of families. CE results are used to select new market baskets of goods and services for the index, to determine the relative importance of components, and to derive cost weights for the baskets.

The BLS follows these steps when using CE data in the $\mathrm{CPI}^{2}$.

1. The BLS combines the spending information from respondents across the country to see how much is spent on each type of item.

2. All reported expenses are used to estimate how much urban households spend on each item.

3. These estimates are used to construct the market basket, which contains a representative sample of expenses.

4. The BLS conducts another survey to find out where consumers purchased items in the market basket.

5. BLS data collectors visit housing units and a sample of the identified stores to obtain current price information on about 80,000 items each month across the country.

6. The BLS combines the information about the items purchased, the expenditures on these items, and their current prices to calculate the CPI.

\subsubsection{Travel Market Basket}

Inspired by the CPI, Reiff and Gregor (2005) proposed a TCI as a multimodal performance measure of transportation and land use systems. To do so, they first define market areas with data and models within the traditional 4-step travel demand modeling framework. The advantage of this approach is that the data for market definitions are readily available from most travel demand models and defining travel market areas by trip purpose and income group is very straightforward at the Traffic Analysis Zone (TAZ) level. Ideally, to be consistent with how CPI works, a representative travel market basket would be identified for each travel purpose and perhaps even each income group for the study area. However, various methods of defining reference travel market baskets (varying by income group and trip purpose) via the identification

\footnotetext{
2 The CE and the Consumer Price Index, available at http://www.bls.gov/respondents/cex/ceandcpi.htm
} 
of a reference TAZ were tested, as an analog to a reference market basket of goods and services used by the CPI measure, and there is variation in the sizes of the identified market baskets because of idiosyncrasy. Thus in their study a reference travel market basket is not used; instead, travel market areas are identified for each TAZ and for each income group and trip purpose. Even though such an approach would resemble the actual travel cost for each combination more closely, it deviates from the market basket definition used by CPI, which inspired the original idea of creating the TCI. This project will explore alternative methods of defining travel market basket. Details of Reiff and Gregor (2005)'s original approach are available in their final report; below, we summarize their approach for contrasting and comparison with our approaches later.

Since then, Diana and Mokhtarian (2009) have defined "modal baskets” as an individual's transportation modal mix, but we are unable to identify additional research relating to the development of transportation market baskets either on an individual level or based on a geographical region.

The main objective of developing TCIs is for policymakers and stakeholders to understand the distribution of transportation costs for different trip purposes in a specific geographic location. In keeping with this main objective, it is reasonable for the transportation market basket to follow the CPI methodology of including only conditional transportation costs that users of transportation explicitly pay or experience.

\subsection{TRANSPORTATION COSTS}

Transportation costs are characterized in the economic literature as trade-offs of scarce resources, such as money, time or land. These costs can be categorized into internal costs (also known as private or user costs) and external costs, which can be aggregated to equal the total social cost (Litman and Doherty 2009). Both internal and external costs can then be subdivided into variable costs (incremental costs, usually associated with level of consumption or miles traveled) and fixed costs (costs not affected by level of consumption). Internal costs of transportation typically involve costs that are directly incurred by the user or consumer of transportation, whereas external costs of transportation include costs that are imposed on other travelers (e.g., congestion costs or crash damages) or others who may not be involved in the provision or consumption of transportation (e.g., air pollution or noise pollution). Litman and Doherty (2009) further point out issues associated with choosing a discount rate for future costs, incorporating variability and uncertainty, and the complications associated with "conservative" cost estimates that only include easily quantifiable costs (such as fuel costs or travel time) and ignore intangible ones (such as social disparities or environmental impacts of various emissions).

Once a travel market basket is defined for a certain trip purpose, transportation costs associated with the transportation market baskets may include costs that are associated directly with travelers who undertake the trip, both internal and external. Researchers such as Bhat (1995; 1998a; 1998b; 2000); Hensher (1994); Anas (1981; 2007); Kahn, Deneubourg and De Palma (1981); Train and McFadden (1978); Train (1980); Gillen (1977); Louviere (1988); Louviere and Hensher (1982); Zhao, Yan and Gao (2013); and Pinjari et al. (2011) have extensively studied transportation choice. User costs of transportation, costs of alternative (substitute) modes and travel time (and other related time spent) have been found to be primary determinants of transportation choice. 
Reiff and Gregor (2005) derive travel costs from “access utilities” calculated for the destination choice model. The access utilities measure the perceived "costs" of traveling between TAZs by trip purpose, income group and travel mode. The model-derived costs are converted into monetary units and are aggregated across travel modes and averaged across the market place for the TAZ. The cost by travel mode is then combined into one representative cost to be averaged across each TAZ market place.

In addition to model-derived cost calculation, Litman and Doherty (2009) summarized the transportation cost literature between 1975 and 2012.

For travelers who drive private motor vehicles, their transportation cost includes marginal internal costs and marginal external costs. Marginal internal costs can be defined as the costs to the traveler for each mile traveled, such as vehicle operating costs (i.e. fuel costs), vehicle depreciation costs, time costs and parking fees; marginal external costs include social costs (i.e. congestion, land use alterations, safety/accidents, public infrastructure and energy) and environmental costs (i.e. air pollution, water pollution, noise and vibration pollution, and greenhouse gas/climate change) (for a review see Quinet 2004 and Litman and Doherty (2009)).

Public transportation includes options such as bus, light rail, heavy rail and streetcars. Public transportation marginal internal costs include the same costs as those for motor vehicles, except that vehicle operating costs and depreciation costs are replaced by public transit fares; and marginal external costs also include social costs (i.e. public infrastructure and accidents) and environmental costs depending on the situation (for a review see Ellwanger(2000) and Litman and Doherty (2009)).

Active transportation modes such as walking and bicycling incur marginal internal costs such as time costs, bicycle operating cost and health impacts due to environmental exposure or accidents, but do not include the marginal external costs associated with motorized travel such as air pollution or greenhouse gas emissions (COWI 2009). Oja et al. (2011) found strong fitness benefits and moderate benefits in reducing cardiovascular risk factors (inconclusive benefits for others) in a review of studies on the health benefits of cycling, while Wanner et al. (2012) found limited evidence that active transport leads to higher levels of physical activity and lower body weight after screening more than 14,000 references and reviewing 36 unique studies.

It is important to note that the geographic scope, time period evaluated, traffic conditions (i.e. urban/rural, peak/nonpeak or overall) and chosen discount rate may significantly influence the magnitude of these costs. Smith et al. (2009) examined several modes of transportation including private car, bus, rail and active modes such as walking and cycling to characterize costs and benefits for the New Zealand Transport Agency, and conducted case studies of urban areas in New Zealand, Australia and the United Kingdom. The authors' conclusion reiterates the contextspecific nature of transportation costs and provision.

To determine the exact cost of time, it is essential that the concept of Value of Travel Time (VOT) be clarified for each mode and travel purpose. VOT refers to the cost of time spent on transport, including waiting as well as actual travel. It includes costs to consumers of personal (unpaid) time spent on travel, and costs to businesses of paid employee time spent in travel. 
Jiang and Morikawa (2004) use the theoretical framework to derive the variation in VOT with respect with travel time, wage, and work time.

The Oregon Department of Transportation (ODOT) estimates the hourly value of travel time for two types of travel with three types of vehicles (ODOT 2012, shown in Table 2.1 below). Onthe-clock business trips represent travel for work and do not include commute trips. The value of on-the-clock business trips is a reflection of the total cost of the employee's time to the employer and so is a function of total compensation. Personal trips include recreation, shopping, commuting, and other personal travel. Value of personal time reflects the opportunity cost of time spent traveling vs. time that could be spent doing something else and is typically expressed as a fraction of household income. The fraction of the hourly median household income used to value personal time is currently $50 \%$ for local trips and $70 \%$ for intercity trips, applied equally to drivers and passengers.

Table 2.1: Details of Estimated Value of One Hour of Travel Time by Vehicle Class, Oregon 2011

\begin{tabular}{l|c|c|c}
\hline \multirow{2}{*}{ Category } & \multicolumn{3}{|c}{ Vehicle Category } \\
\cline { 2 - 4 } & $\begin{array}{c}\text { Automobile \& } \\
\text { Psngr. Truck }\end{array}$ & $\begin{array}{c}\text { Delivery \& Med. } \\
\text { Trucks }\end{array}$ & $\begin{array}{c}\text { Heavy } \\
\text { Trucks }\end{array}$ \\
\hline 2011 Oregon Median Hourly Wage & $\$ 16.90$ & $\$ 14.54$ & $\$ 18.41$ \\
\hline 2011 Value of Fringe Benefits & $\$ 7.35$ & $\$ 7.29$ & $\$ 9.23$ \\
\hline Total Hourly On-the-clock Compensation & $\$ 24.25$ & $\$ 21.83$ & $\$ 37.64$ \\
\hline $\begin{array}{l}\text { 2011 Oregon Hourly Median Household } \\
\text { Income }\end{array}$ & $\$ 24.77$ & N/A & N/A \\
\hline Hourly Value Personal Local Travel & $\$ 12.39$ & N/A & N/A \\
\hline Hourly Value Personal Intercity Travel & $\$ 17.34$ & N/A & N/A \\
\hline
\end{tabular}

The method used by ODOT is based on work done by the USDOT in the Revised Departmental Guidance on Valuation of Travel Time (U.S. Department of Transportation 2011). Table 2.2 illustrates USDOT's recommended travel time values. Personal travel is calculated relative to wages, and business travel relative to total compensation, averaging $120 \%$ of wages.

Table 2.2: Recommended Value of Travel Time

\begin{tabular}{l|l|l}
\hline Time component & Reference & Value \\
\hline In-Vehicle Personal (local) & Of wages & $50 \%$ \\
\hline In-Vehicle Personal (Intercity) & Of wages & $70 \%$ \\
\hline In-Vehicle Business & Of total compensation & $100 \%$ \\
\hline $\begin{array}{l}\text { Excess (waiting, walking, or transfer time) } \\
\text { Personal }\end{array}$ & Of wages & $100 \%$ \\
\hline $\begin{array}{l}\text { Excess (waiting, walking, or transfer time) } \\
\text { Business }\end{array}$ & Of total compensation & $100 \%$ \\
\hline
\end{tabular}

Fosgerau, Hjorth and Lyk-Jensen (2010) used stated preference survey data to measure the value of travel time for several transport modes (Table 2.3). The stated choice survey includes both an experiment measuring the VOT in the current mode of the respondents and a similar experiment 
for an alternative mode. Consequently, the authors observe the same individual's VOT in different modes, and can thereby disentangle mode effects from user type effects.

Table 2.3: Relative mean Value of Travel Time, after controlling for covariates (bus-none normalized to one)

\begin{tabular}{|c|c|c|c|c|}
\hline \multirow[t]{2}{*}{ Current mode } & \multirow{2}{*}{$\begin{array}{l}\text { Alternative } \\
\text { mode }\end{array}$} & \multicolumn{3}{|c|}{ Experiment Mode } \\
\hline & & Car & Bus & Train \\
\hline Car & None & 1.21 & & \\
\hline Car & Bus & 1.36 & 1.25 & \\
\hline Car & Train & 1.37 & & \\
\hline Bus & None & & 1.00 & \\
\hline Bus & Car & 1.06 & 0.90 & \\
\hline Bus & Train & & 0.79 & 0.71 \\
\hline Train & None & & & 1.36 \\
\hline Train & Car & 0.94 & & 1.45 \\
\hline Train & Bus & & 0.97 & 0.73 \\
\hline
\end{tabular}

Litman (2007) estimated travel time unit costs with respect to qualitative factors such as comfort, convenience, productivity and security for different types of travelers. Table 2.4 indicates how travel time values vary depending on the quality of conditions, using level-of-service ratings to reflect comfort and convenience factors.

Table 2.4: Travel Time Values Relative to Prevailing Wages

\begin{tabular}{l|l|l|l|l}
\hline Category & LOS A-C & LOS D & LOS E & LOS F \\
\hline Commercial vehicle driver & $120 \%$ & $137 \%$ & $154 \%$ & $170 \%$ \\
\hline Commercial vehicle passenger & $120 \%$ & $132 \%$ & $144 \%$ & $155 \%$ \\
\hline City bus driver & $156 \%$ & $156 \%$ & $156 \%$ & $156 \%$ \\
\hline Personal vehicle driver & $50 \%$ & $67 \%$ & $84 \%$ & $100 \%$ \\
\hline Adult car passenger & $35 \%$ & $47 \%$ & $58 \%$ & $70 \%$ \\
\hline Adult transit passenger - seated & $35 \%$ & $47 \%$ & $58 \%$ & $70 \%$ \\
\hline Adult transit passenger - standing & $50 \%$ & $67 \%$ & $83 \%$ & $100 \%$ \\
\hline Child (<16 years) - seated & $25 \%$ & $33 \%$ & $42 \%$ & $50 \%$ \\
\hline Child (<16 years) - standing & $35 \%$ & $46 \%$ & $60 \%$ & $66 \%$ \\
\hline Pedestrians and cyclists & $50 \%$ & $67 \%$ & $84 \%$ & $100 \%$ \\
\hline
\end{tabular}




\subsection{METHODOLOGY}

\subsection{TRANSPORTATION MARKET BASKET IDENTIFICATION}

Besides Reiff and Gregor's (2005) original model-based approach, in this chapter we discuss three alternative methods of defining travel market baskets: cluster-based approach, surveybased approach, and an individual model-based approach. We implemented and tested the cluster-based approach and survey-based approach, but suspended the effort for the individual model-based approach due to its extensive data requirement and poor computational performance. These two approaches implemented have different data requirements and are suitable for different types of applications, as we demonstrate later in this report.

\subsubsection{Reiff and Gregor's Model-based Approach}

Reiff and Gregor's (2005) original approach to market basket definition relies on data and models in a traditional 4-step travel demand model. The advantage of their approach is that the data for market definition are readily available and the computation for TAZ-level travel market baskets differentiated by trip purpose and income group is very straightforward. Although Reiff and Gregor tested methods of defining reference travel market baskets (varying by income group and trip purpose) via identifying a reference TAZ, as an analog to a reference market basket of goods and services used by the CPI measure, they abandoned the idea due to idiosyncrasy and variation in the sizes of the identified market baskets (2005). Instead, they identified a "travel market area” for each TAZ and for each income group and trip purpose. Even though such an approach would resemble the actual travel cost for each combination more closely, it deviates from the market basket definition used by CPI in that it defines a market area for each location (TAZ) while CPI keeps the same basket of goods and services for all households/locations.

According to Reiff and Gregor's (2005) original approach, defining the market basket for TAZ k for income group i and trip purpose $\mathrm{p}$ follows these steps:

Step 1 Determine size terms. The size terms of the destination choice model utilities measure the perceived attractiveness of TAZs to trips of different types. They are functions primarily of the numbers of jobs and households in a TAZ, but may include other factors. For example, the size term for home-based recreation trips is calculated with this equation:

$$
\text { size }_{k}=\operatorname{emp}_{k}+1.175 \mathrm{hhs}_{k}+7.614 \text { park }_{k}
$$

where

emp = number of employees working in TAZ $k$;

hhs = number of households;

parks $=$ park land in acres. 
Step 2 Identify the potential market area of TAZ $\boldsymbol{k}$ for income group $i$ and trip purpose $p$. Reiff and Gregor used a threshold to identify the set of TAZs that is to be included in the market area of the focus TAZ. They tested two different methods: the first method bases the threshold on percentage of the total trips attracted to each TAZ from TAZ $k$, as shown in Equation (3.2); the second method establishes a log sum threshold as in Equation (3.3):

$$
\begin{aligned}
& J_{\text {pik }}=\left\{j: \frac{\text { Trips }_{\text {pikj }}}{\sum_{t \in T} \text { Trips }_{\text {pikt }}} \geq \text { cutoff } 1\right\} \\
& J_{p i k}=\left\{j: \operatorname{logsum}_{\text {pikj }} \geq \text { cutoff } 2\right\}
\end{aligned}
$$

where

$T=$ the set of all TAZs in the model area;

cutoff $=$ chosen threshold for defining the market area;

trips $_{p i k j}=$ the number of trips for purpose $p$ by income group $i$ between TAZ $k$ and

TAZ $j$;

$\operatorname{logsum}_{p i k j}=$ the log sum of the access utilities for travel for purpose $p$ by income group $i$ between TAZ $k$ and TAZ $j$.

Several percentage cutoffs were tested, in particular $75 \%$ and $50 \%$. The log sum threshold in Equation (3.3) was chosen by examining ordered plots of log sum values for all TAZs and each trip purpose. Reiff and Gregor (2005) conducted a study in Medford, Oregon, in which the value of 1 was chosen as the threshold for determining the market area, because the average log sum trends for all zones have inflection points of 1 , as log sums increase rapidly to the left of the inflection points and decline gradually to the right (Reiff and Gregor 2005).

Because of the difficulty in describing a market basket defined by using a threshold log sum value in common sense terms, a 50\% trip percentage cutoff in Equation (3.2) was used in the Medford case study (Reiff and Gregor 2005).

$\underline{\text { Step } 3}$ Create market baskets for each TAZ by income group and by trip purpose. Once a market area has been identified for TAZ $k$, income group $i$ and trip purpose $p$, the market basket can be calculated by adding up the size terms for all the TAZs in the market area.

$$
\mathrm{MB}_{\text {pik }}=\sum_{j \in J_{p i k}} \operatorname{size}_{j}
$$

where

$\mathrm{MB}_{p i k}=$ market basket for TAZ $k$ for income group $i$ and trip purpose $p$;

$\mathrm{J}_{p i k}=$ market area for TAZ $k$ for income group $i$ and trip purpose $p$, as defined in Equation (3.2) or (3.3);

size $_{j}=$ the size term for TAZ $j$.

Step 4 Identify a reference TAZ and reference market baskets. The purpose of identifying a reference TAZ is two-fold: First, through a reference TAZ, reference market baskets (one for each combination of income and trip purpose) can be identified as the 
market area of the reference TAZ. Second, once travel market baskets are identified and travel costs aggregated, aggregated travel costs by TAZ can be compared with the travel cost of the reference TAZ for the same income group and trip purpose (Reiff and Gregor 2005, page 50, Equation 4-16).

Identifying the reference TAZ begins with calculating a score for each TAZ:

$$
\text { score }_{k}=\sum_{p i} \frac{\mathrm{MB}_{p i k}}{\max _{j}\left(\mathrm{MB}_{p i j}\right)}
$$

where

$\mathrm{MB}_{p i k}=$ market basket for TAZ $k$ for income group $i$ and trip purpose $p$, as defined in Equation (4).

The reference TAZ is the TAZ with highest score in scorek.

Reiff and Gregor tested different methods for identifying market areas (Equation 3.2 and 3.3) and subsequently identified the reference TAZs. They found the two methods resulted in two very different reference TAZs and reference travel market baskets with varying sizes, and concluded that there is a practical limitation with this approach of identifying reference travel market baskets, as the market basket for the reference TAZ can be very idiosyncratic. They therefore abandoned the idea of identifying reference travel market baskets via the reference TAZ and used the reference TAZ only in indexing the aggregated travel cost.

\subsubsection{Survey-based Approach}

The cluster-based approach still heavily relies on travel demand models. Although some of the information used in the approach may be available from alternative sources, it would be difficult to adapt it to places without travel demand models and use it to compute historical transportation costs for monitoring purposes. Therefore, we develop an approach that does not rely on travel demand models.

The travel survey-based approach, or sampling-based approach, computes transportation costs based on travel diaries of a sample of travelers who are assumed to be representative of travel patterns in the region. From the travel diaries, the travel time and associated costs are aggregated by trip purpose, household, income group and geography.

The sampling-based approach requires these steps:

\section{Identify linked trips in the travel survey diaries.}

2. Identify home-based trips as travel costs will be attributed to households' residence geography, much like the cluster-based approach;

3. Identify home-based trips by trip purpose and income group. Home-based trips are classified into four trip purposes: Home-Based Work (HBW), Home-Based Shopping (HBS), Home-Based Recreation (HBR) and Home-Based Other (HBO). 
4. Summarize the costs of making the trips for various purposes at the household level and use the information as an approximation of household-level travel costs for the study area.

The survey-based approach calculates observed travel costs. It is informative to describe the current "burden" of traveling for households in the sample and the distribution of travel costs for households in various groups (income groups, racial/ethnic groups, geographical locations, etc). However, it may not be a fair benchmark when comparing travel costs across groups for policymaking purpose, as the observed travel behavior may be the result of households' coping strategies. For example, a household may forgo recreational trips on weekdays because the residence is in such a bad location that those trips are too costly, even though recreational trips are desirable. A household may also chain its trips of different purposes, because making an individual trip for each purpose is too expensive, even though trip chaining may mean it cannot use the ideal mode for each trip purpose. It is equivalent to defining a travel market basket for each household, which includes all the trips the household made during the day of the survey. A household's costs of making ("purchasing") the trips in the basket approximate its true transportation costs. Thus it would useful to use the survey-based Transportation Cost Index (TCI) to monitor the pattern of transportation cost distribution. For the purpose of evaluating policy scenarios, it would be better to have a fixed travel market basket that is shared by all households.

\subsubsection{Cluster-based Approach}

The cluster-based approach identifies activity centers in a study area with spatial clustering of activities and uses them as travel market baskets. The rationale is that, when properly identified, these activity centers represent common destinations for various types of trips, and keeping track of the transportation costs of accessing these destinations could measure the performance of transportation and land use systems. This approach needs to balance the tradeoffs among computational complexities, data requirements and accurately capturing activity centers (i.e. for employment, recreation and shopping). The following spatial clustering approaches present alternatives to the identification of trip destinations that form transportation market baskets.

\subsubsection{Central Business district (CBD)}

For this methodology, a mono-centric city is assumed in which a CBD (or a TAZ that contains the CBD) is where all employment opportunities, entertainment and shopping options are concentrated (Anas, Arnott and Small (1998) describes this standard urban spatial structure based on the bid-rent theory). The data requirements for this method are low, and a mono-centric city may sufficiently describe very small cities where most businesses are concentrated on a small geographical scale.

Helsley and Sullivan (1991) and Chen (1996) theorize that the diseconomies of transportation and congestion as CBDs experience growth, combined with technological advances in transportation (which lower transportation costs), may lead to more polycentric urban spatial trends. In addition, Giuliano and Small (1991), Giuliano et al. (2007), McDonald and McMillen (2000) and Greene (2008) have empirically documented the existence of multiple employment centers within U.S. metropolitan 
areas. For most modern metropolitan areas, assuming a mono-centric city with a central CBD may be unrealistic and over-simplistic for the purposes of calculating a TCI. However, the mono-centric CBD approach provides a straightforward baseline for a minimalist TCI calculation. Therefore, we propose additional methodologies that take this complexity into account.

\subsubsection{Spatial Identification of Employment Centers}

To better describe the reality, a poly-centric city model is extended from the monocentric model and various forms of spatial analysis are applied to identify the centers. Although most of the research in the literature examines employment centers specifically, the methodology is applicable to identify other types of travel destinations such as recreation or shopping. Methods to identify spatial centers include:

- Spatial cluster analysis - This methodology has been used mainly in identifying crime hotspots within metropolitan areas, and is built into many geographical information system (GIS) packages.

- Employment density thresholds - McDonald (1989) and Giuliano and Small (1993) agree that "employment, not population, is the key to understanding the formation of urban centers; and that a center is best identified by finding a zone for which gross employment density exceeds that of its neighbors”. Empirically, Giuliano and Small (1993) and Giuliano et al. (2007) identify urban centers by employing "a density cutoff of 10 employees per acre, and a minimum total employment of 10,000" in their analysis. Redfearn (2007) expands upon this idea by mapping employment densities, identifying peaks in the densities, and testing these peaks for significance.

- Nonparametric identification - McMillen (2001) utilizes a two-stage nonparametric procedure to identify employment centers. In the first step, a nonparametric locally weighted regression (LWR, also known as geographically weighted regression) is conducted to smooth employment densities over space to create a benchmark. Next, actual employment densities are compared to the estimated (smoothed) densities to identify candidates for subcenters. McMillen also clusters nearby significant residuals together (within a 3-mile radius) to avoid counting nearby sites as multiple candidates for employment centers. A semiparametric regression is conducted during the second stage to identify which candidate subcenters display "significant local effects on the overall employment density.”

\subsubsection{Cluster-based Approach for Activity Center Identification}

For our purpose, the method proposed in Giuliano and Small (1991) and Giuliano and Small (1993) maintains a good balance among reasonableness, data requirements and computing complexity, and is what we implement for our cluster-based approach of travel market definition. Specifically, for each trip purpose (HBW, HBS, HBR and 
HBO), we identify activity centers for a cluster of activities. A center is defined as a contiguous set of zones in which:

1. Each zone in the center has a density of activities above cutoff D,

2. All the immediately adjacent zones outside the center have a density below $\mathrm{D}$, and

3. The center has at least $\mathrm{E}$ total activities.

The detailed steps are:

1. Calculate TAZ-level employment density for HBW and size terms ${ }^{3}$ density for HBR, $\mathrm{HBS}$, and $\mathrm{HBO}$;

2. Identify TAZs with densities greater than cutoff D;

3. Group the TAZs identified in step 2 into spatially contiguous centers;

4. Calculate total employment or size terms for each center identified in step 3;

5. Eliminate centers with total employment or size terms below cutoff $\mathrm{E}$. The remainder are activity centers.

All data needed for the center identification process, such as TAZ, employment by sector group, households, acreage of park areas, etc. (types of data vary depending on the formula for the size terms), are available from the travel demand model, or sources such as the Longitudinal Employer-Household Dynamics (LEHD) and population census data. If data from external sources are needed, they are aggregated to TAZ. LEHD releases LEHD Origin-Destination Employment Statistics (LODES) annually. Workplace Area Characteristics in the LEHD provide information on jobs totaled by Census Block.

The cutoffs D and E should match the theoretical concept of centers, to be able to analyze commuting to centers, and to end with a manageable number suitable for statistical analysis. Giuliano et al. (2007) identify employment centers as having a minimum density of 10 employees per acre and a minimum total employment of 10,000 in their analysis for the Los Angeles area, basing their selection on expert opinion. Figures 3.1 to 3.4 show the histogram of log of TAZ activity density for the Portland area. For trip purposes like HBS, there is a threshold with clear discontinuity in their distribution that can be used as cutoff D, while the density distribution for HBW resembles a normal distribution and lacks a threshold with clear discontinuity.

We aim for these cutoffs to be objective and easily applicable to areas of different sizes. However, merely looking at the statistical distribution of activity density does not seem to

\footnotetext{
${ }^{3}$ Size terms measure the perceived attractiveness of TAZs to trips of different types. Formulas to calculate size terms are taken from travel demand models, for example, Metro's 2013 Trip-Based Travel Demand Model or Corvallis, Oregon's JEMnR model.
} 
give a clear choice for cutoffs for all the cases. We thus conduct sensitivity analysis to select these cutoffs. The details of the analysis are provided in Chapter 4. 


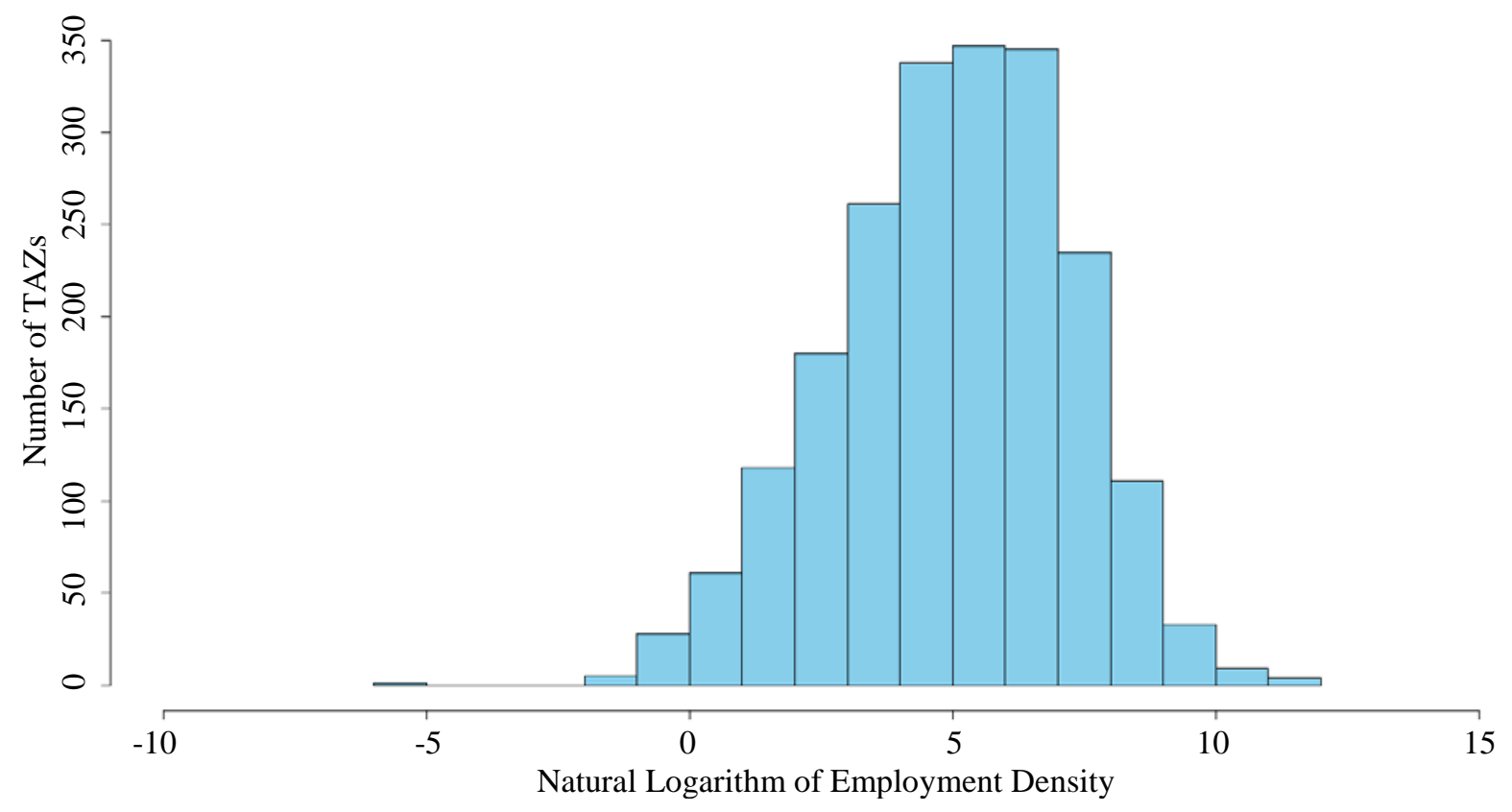

Figure 3.1: Employment density distribution of HBW

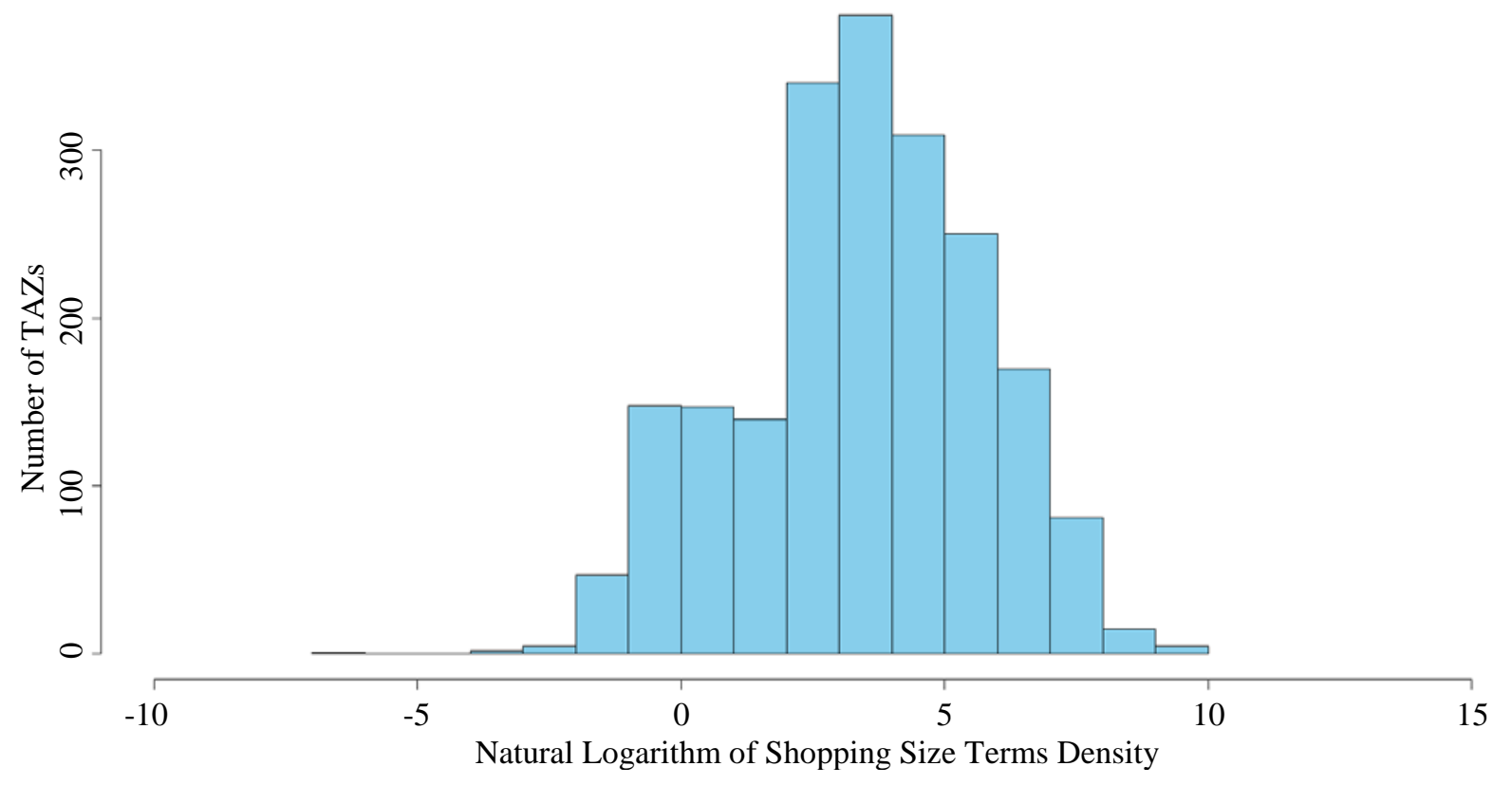

Figure 3.2: Size terms density distribution of HBS 


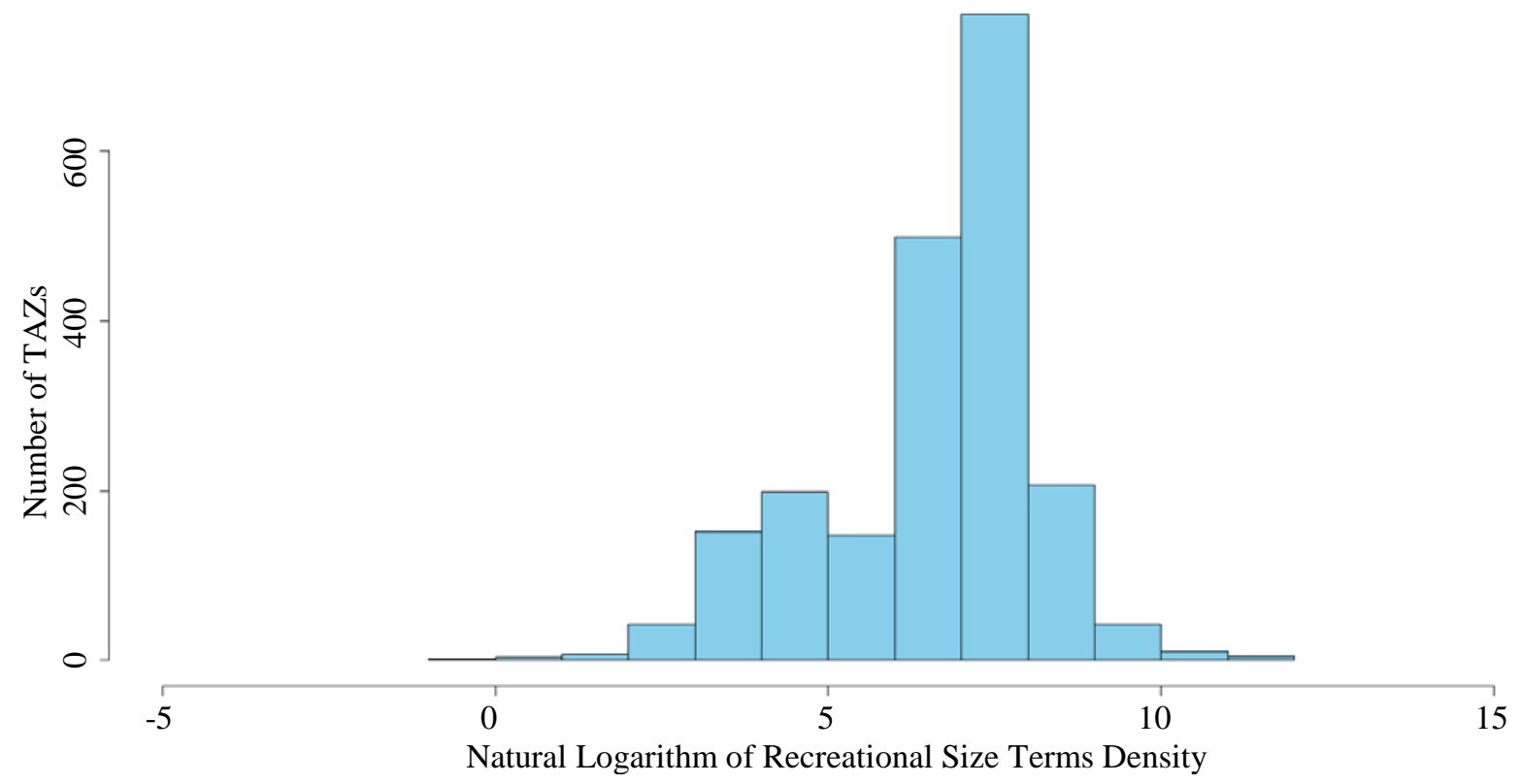

Figure 3.3: Size terms density distribution of HBR

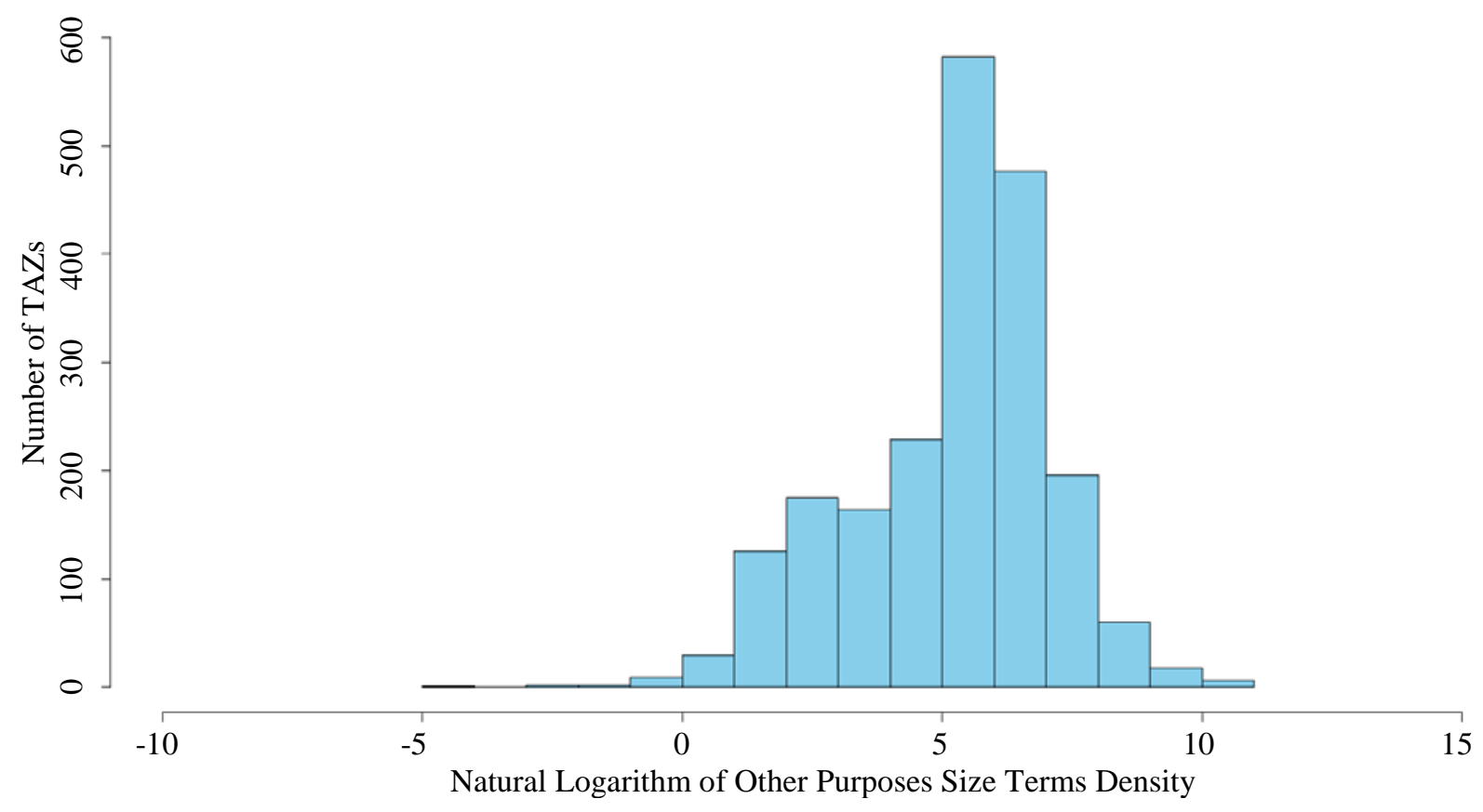

Figure 3.4: Size terms density distribution of HBO 


\subsubsection{Individual-level Model-based Approach}

This approach, like Reiff and Gregor's (2005) travel market area approach, relies on models, but works at the individual level and can incorporate detailed socio-economic and demographic characteristics of individual households as well as spatial and travel information at fine resolution. With the trip generation model and destination choice model, the approach can theoretically approximate the travel needs, thus travel market basket, of any individual household. The disadvantages of this approach are that it has a much higher data requirement and is more computation-intensive.

Another theoretical limitation is that this individual-level approach relies on first estimating travel behavior models for individual households, as these models may not be readily available in a traditional travel demand model system, and then applying the estimated model specifications to simulate travel needs for individual households. Besides the land use and accessibility information used in Reiff and Gregor's (2005) approach, model estimation requires individual household level observations, such as household activity survey data, while model application needs synthesized population (households) data, usually from a population synthesizer.

Step 1 Determine trip rates for households by trip purpose with trip generation models. Various models have been used to determine the trip rates for households. Crossclassification analysis and linear regression are commonly used in a four-step travel demand model (Martin and McGuckin 1998). In a linear regression model, trip rates for household $n$ are modeled with:

Where

$$
\operatorname{trips}_{n}=\alpha+X_{n} \beta
$$

trips $_{\mathrm{n}}=$ trip rates for a select trip purpose for household $n$;

$\mathrm{X}_{\mathrm{n}}=$ socio-economic and demographic characteristics of household $\mathrm{n}$, including

household size, income, number of vehicles, etc;

$\alpha, \beta=$ parameters in the model to be estimated.

Once the model parameters are estimated from observed data, the model can be applied to predict trip rates for any household for which we have information. The advantage of an individual-level approach is that households don't need to be segmented by income, as in Reiff and Gregor's (2005) approach, or by other variables.

Step 2 Simulate trip destinations for household by trip purpose. Destination choice model is a commonly used method in determining trip destination. Taking HBW trips as an example, the destination of HBW trips can be modeled with a workplace location choice model (Wang, Waddell and Outwater 2011). Let the probability that worker $n$ chooses workplace location $i$ from the set $C_{n}$ of potential workplace locations, conditional on variables including personal characteristics and locational attributes $X_{n i}$, be given by the following multinomial logit form: 


$$
\mathrm{P}_{n}\left(i \mid X_{n}, C_{n}\right)=\operatorname{Pr}\left(U_{n i} \geq U_{n j}, i, j \in C_{n}\right)=\frac{\exp \left(\beta X_{n i}\right)}{\sum_{j \in C_{n}} \exp \left(\beta X_{n j}\right)}
$$

where

$U_{n i}$ is a vector of utilities for choosing workplace $i$ for individual $n ; X_{n i}$ is a vector of variables associated with workplace location $i$ for individual $n$, including socio-economic and demographic characteristics of household n (interacting with origin and/or destination attributes), attributes of origin and destination (choice), as well as accessibility between origin and destination. $\beta$ is a parameter vector to be estimated.

Once the model parameters are estimated from observed data, Equation (3.7) can be applied to simulate trip destinations for any household. It is possible to predict the probabilities of a household's choosing any destination in alternative set $\mathrm{C}_{n}$ or predict a single destination for a trip via a Monte Carlo process. Either method should produce similar results when examined at aggregated level (by TAZ or by income group etc.). For simplicity, a single destination will be predicted.

Steps 1 and 2 together identify a travel market basket of a given trip purpose for any household by predicting its trip frequency and destinations. Coupling with a mode choice model and using skims data from a travel demand model, it is possible to calculate trip-level transportation cost for the household, which can be aggregated to total transportation costs by household or further to any summary information useful, such as average transportation costs by TAZ or by household income group.

\subsection{TRANSPORTATION COST CALCULATION METHODOLOGY}

Reiff and Gregor (2005) calculate transportation costs with a utility-based approach, which we summarized in the first subsection. However, such an approach is limited by the formula and quality of the mode choice model in the travel demand modeling system. Through literature review, we determined that conditional transportation costs are the appropriate costs to include within a TCI calculation. These costs include costs that are explicitly charged to the users of transportation, such as operating, maintenance and ownership costs of various transportation modes and the cost of travel/wait/delay time. Research by Bhat (2000; 1998a; 1998b; 1995); Hensher (1994); Anas (2007, 1981); Kahn, Deneubourg and De Palma (1981); Train and McFadden (1978); Train (1980); Gillen (1977); Louviere (1988); Louviere and Hensher (1982); Zhao, Yan and Gao (2013); and Pinjari et al. (2011) has shown that these costs are the primary determinants of transportation choice. The transportation cost calculation methodologies and potential data sources for automobile, public transportation and nonmotorized modes (walking and cycling) are detailed below.

\subsubsection{Utility-based Travel Cost Calculation}

In Reiff and Gregor's (2005) approach, once travel market areas for each TAZ are defined, average costs to access the market areas are calculated for each TAZ. The costs are calculated from the travel model access utilities, which measure the perceived ease of travel between every pair of TAZs for each trip purpose, income group and mode of travel. The utilities are calculated 
from linear utility equations that were statistically estimated from household activity surveys. The terms of the equations are factors that affect people's perceptions of the ease of travel. The coefficients for the terms indicate the strength of each factor. Some examples of factors included in the utility equations are:

- The time spent traveling in a vehicle,

- The time to walk to get to the vehicle (e.g. walk time to a bus stop),

- $\quad$ The time spent waiting, and

- $\quad$ The money cost of the trip (i.e. operating cost).

Since the utilities are unitless quantities in preference space, they are not intuitive to understand. They can be easily converted into more understandable monetary units in willingness-to-pay space by dividing them by the coefficient of a monetary cost factor, such as operating cost:

where

$$
M C_{p i m k j}=\frac{U_{p i m k j}}{O C_{p i}}
$$

$M C_{\text {pimkj }}$ is the monetary cost for traveling by mode $m$ between TAZs $k$ and $j$ for purpose $p$ by income group $i$;

$U_{\text {pimkj }}$ is the utility for traveling by mode $m$ between TAZs $k$ and $j$ for purpose $p$ by income group $I$;

$O C_{p i}$ is the cost coefficient for purpose $p$ and income group $i$.

A composite approach of calculating travel costs across all modes is to compute a cost from a composite of the access utilities for the travel modes. This is done in the standard traveling modeling approach by calculating the log sum of the mode choice model. It can be thought of as a measure of travel opportunities rather than travel cost. The composite cost for traveling between two TAZs $k$ and $j$ by a household of income group $i$ for purpose $p$ is calculated as follows:

$$
T C_{p i k j}=\ln \left(\sum_{m \prime} \exp \left(U_{\text {pimıkj }}\right)\right)
$$

The average cost to access the market basket for a TAZ $k$ can be computed as a weighted average of the travel costs from TAZ $k$ to each TAZ $j$ in the market areas for that TAZ $k$. The weighting factor in calculating the average is the proportion of the size term of each TAZ. Thus the weighted average cost to access the market areas for income group $i$ and purpose $p$ from zone $k$ is calculated as follows: 
where

$$
A C_{p i k}=\frac{\sum_{j \in J_{p i k}} T C_{p i k j} * s i z e_{p i j}}{\sum_{j \in J_{p i k}} s_{i z e_{p i j}}}
$$

$J_{p i k}$ is the set of market areas for TAZ $k$;

$T C_{p i k j}$ is the equivalent cost for traveling between TAZ $k$ and TAZ $j$ for income group $i$ and purpose $p$;

size $_{p i j}$ is the size term for income group $i$ for purpose $p$ in TAZ $j$.

\subsubsection{Travel Costs by Mode}

\subsubsection{Automobiles}

For travel by private automobiles, the transportation cost is characterized by operating costs (fuel cost and tire usage), ownership costs (maintenance, repair, etc.), parking costs and the value of travel time. The cost of automobile travel for a trip between a TAZ or a household location and a travel destination is defined as follows:

$$
C_{\text {auto }}=D * f_{\text {auto }}+D * O_{\text {auto }}+\text { Parking }+w * T T_{\text {auto }}
$$

where

$$
\begin{aligned}
& \mathrm{D}=\text { distance between origin and destination (miles); } \\
& \mathrm{f}_{\text {auto }}=\text { per-mile fuel and tire costs; } \\
& \mathrm{O}_{\text {auto }}=\text { per-mile ownership costs including maintenance and repair; } \\
& \text { Parking = parking cost for trip (and/or toll costs); } \\
& \mathrm{w}=\text { value of travel time per hour; } \\
& \mathrm{TT}_{\text {auto }}=\text { estimated travel time for trip. }
\end{aligned}
$$

Potential data sources for each of the cost components are:

Fuel and tire costs (f $\mathbf{f}_{\text {auto). }}$. Per-mile fuel costs are calculated as the price per gallon of gasoline divided by fuel economy of vehicles (miles per gallon). Although the American Automobile Association (AAA) reports average per-mile driving cost for the entire country, it is preferable to obtain regional fuel prices and regional vehicle fleet fuel economy data because both of these components may vary significantly by the region or state. 
Estimated city and highway fuel economies can be obtained from the Environmental Protection Agency's (EPA) fuel economy data. Alternatively, if a regional or state Department of Transportation maintains more detailed data on fleet composition, more accurate average fuel economy may be estimated. Per-mile fuel cost data may be obtained from AAA's Fuel Gauge Report on average fuel prices or the Energy Information Administration's (EIA) regional gasoline price series.

For tires, AAA estimates the cost to be $\$ 0.01$ per mile based on tires of similar quality to those that came with the car. IntelliChoice (2002) also estimates tire costs based on an estimated lifetime of 45,000 miles for each set of tires, without the assumption that car owners continue to purchase the same tires as the original set.

Ownership costs (Oauto). Assuming vehicles are driven for 15,000 miles per year and maintained at the manufacturer's recommended maintenance schedule, AAA estimates a maintenance average cost per mile of $\$ 0.497$, which is consistent with the average maintenance cost of $\$ 0.54$ found by Polzin, Chu and Raman (2008). AAA estimates average maintenance cost for small, medium, and larger sedans while Polzin, Chu and Raman (2008) estimated averages for both older and newer cars. Since vehicle age is the main determinant of maintenance and required repairs, the costs estimated by Polzin, Chu and Raman (2008) may be more applicable for our purposes.

Following Barnes and Langworthy (2004), we will utilize estimated repair costs from IntelliChoice (IntelliChoice 2002). Similarly, we will also assume that 50\% of five-year repair costs occur in the first four years, $50 \%$ occur in the fifth year, and the same amount of repair (as the fifth year) occurs for every year thereafter. Marginal per-mile depreciation costs can be estimated using data from the National Automobile Dealers Association, Edmunds or Kelley Blue Book.

Parking. Direct parking costs for commuting and noncommuting purposes in different destinations would be estimated using parking meter rates and annual commuting and noncommuting mileages. Other fixed costs such as tolls will also be considered within this category.

Value of travel time ( $\left.\boldsymbol{w} \cdot \boldsymbol{T} \boldsymbol{T}_{\text {auto }}\right)$. The Oregon Department of Transportation (ODOT 2012) estimates the value of travel time associated with both business and personal travel by vehicle type following guidelines from the U.S. Department of Transportation. The most recent estimated weighted average value of travel time on automobile and passenger trucks is equal to $\$ 23.68$ per hour.

Ozbay, Bartin and Berechman (2001) use a regression-based approach to estimating marginal costs associated with vehicles. The authors separate user costs into two categories: self-vehicle operating costs ("car ownership, fuel and oil consumption, regular or unexpected maintenance, and so forth") and user interaction costs ("accident- and congestion-related costs”). For the purposes of estimating the TCI, we are particularly interested in the estimated self-vehicle operating costs $\left(C_{o p r}\right)$, formulated as a function of depreciation, gas cost, oil cost, tire cost, maintenance cost, insurance cost and parking 
fees and tolls. Ozbay, Bartin and Berechman (2001) estimate the marginal vehicle operating cost per mile as

$$
M C_{o p r}=0.1227+\frac{0.104}{a}
$$

where $a$ is equal to the vehicle age (years). When necessary regional data associated with vehicle operation and ownership are unavailable, this methodology represents a reasonable alternative. In this case, the cost of automobile travel for a trip between a TAZ or a household location and a travel destination is defined as:

$$
C_{\text {auto }}=D * M C_{\text {opr }}+w * T T_{\text {auto }}
$$

where

$$
\begin{aligned}
& D=\text { distance between origin and destination (miles); } \\
& M C_{o p r}=\text { per-mile cost of vehicle operation (including gas, oil, maintenance, etc.); } \\
& w=\text { value of travel time per hour; } \\
& T T_{\text {auto }}=\text { estimated travel time for trip. }
\end{aligned}
$$

\subsubsection{Public Transportation}

Costs for travel via public transit include transit user fares and value of travel/wait time. Specific data for the study area would be obtained from the appropriate source. Transit fares would be obtained from the regional public transit agency while transit travel time would be based on a few different sources. The cost of traveling on public transportation for a trip between a TAZ or a household location and a travel destination is defined as follows:

$$
C_{\text {public }}=\text { fare }+w * T T_{\text {public }}
$$

where

$$
\begin{aligned}
& \text { fare = transit fares; } \\
& w=\text { value of travel time per hour; } \\
& T T_{\text {public }}=\text { estimated travel time (including wait time) for trip. }
\end{aligned}
$$

Potential data sources:

Transit fares. For the Portland Metro area, we use the formula in Metro's travel demand model for estimates of transit fares, which are based on the average fares charged by the region's transit providers (Metro Research Center and Transportation Research and 
Modeling Services 2013). The average fares for all transit providers providing a transit pass option were estimated at $73 \%$ of the cash fare price, which is the 2010 ratio for TriMet.

Transit travel time. Transit travel time including accessing and transferring can be retrieved from travel skims when they are available. When travel skims are not available, it may be possible to approximate travel time from a transit network (Krizek et al. 2007), network with General Transit Feed Specification (Gandavarapu 2012), or query transit travel time from online application program interfaces (APIs) like Google Maps.

\subsubsection{Nonmotorized Modes (Bicycle and Walking)}

Bicycle. Litman (2009) estimates the cost per mile of bicycling to range between $\$ 0.47$ to \$0.56, including ownership, maintenance, value of travel time and parking cost estimations, depending on urban/rural travel and peak/off-peak hours.

$$
C_{\text {bicycle }}=\boldsymbol{D} * \boldsymbol{f}_{\text {bicycle }}
$$

where

$$
\begin{aligned}
& D=\text { distance between origin and destination (miles); } \\
& f_{\text {bicycle }}=\text { per-mile cost of bicycling. }
\end{aligned}
$$

Walking. Walking is estimated to cost $\$ 1.37$ per mile (Litman 2009). This cost is primarily the value of travel time, because walking usually incurs very little out-ofpocket cost.

$$
C_{w a l k}=D * f_{w a l k}
$$

where

$$
\begin{aligned}
& D=\text { distance between origin and destination (miles); } \\
& f_{\text {walk }}=\text { per-mile cost of walking. }
\end{aligned}
$$

Potential data ources for calculating travel costs for nonmotorized modes:

Biking and Walking Distance. Metropolitan planning organizations including Metro have started to incorporate biking and walking into their travel demand models, and thus the distance matrices may be available from travel model skims. When such skims are not available, it may be possible to approximate travel time from a bicycle and pedestrian network (Krizek et al. 2007), or via online APIs like Google Maps.

\subsubsection{A Generic Travel Cost Calculation Algorithm}

Although it may be desirable to know the travel costs by mode as discussed above, their data requirements are very high. To reduce the data requirement and simplify calculation while 
retaining as much realism as possible, we propose a generic travel cost calculation algorithm that works for all modes, and capture the travel costs with two major components:

- The time costs, including the time spent traveling in a vehicle, the time to get to the vehicle (e.g. walk time to a bus stop), the time spent waiting, and

- $\quad$ The monetary cost of the trip (i.e. operating cost, ownership cost, fares).

Generalized costs that include both components may be available from travel demand models. If they are not, they can be approximated:

$T C_{p i m k j}=C_{m}+$ TTime $_{p i m k j} * V O T_{p i m}+$ TDist $_{p i m k j} * M C_{m}$

Where

$C_{m}$ is a constant for mode $m$, which could be the fare for a fixed-fare transit system;

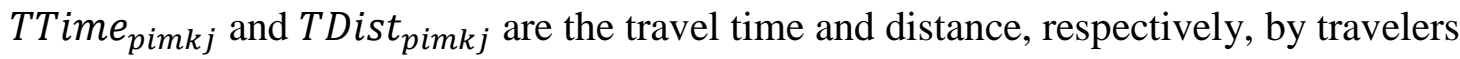
from income group $i$ using mode $m$ from TAZ $k$ to TAZ $j$ for purpose $p$;

$V O T_{\text {pim }}$ is the value of time for travelers from income group $i$ using mode $m$ for purpose p. We use the 2012 VOT values recommended by ODOT (table 3.1), which is closer in time to the data we are using in this project (2011 for the survey-based approach; 2010 for the cluster-based approach), even though more recent values are available.

$M C_{m}$ is the distance-based monetary cost for mode $m$. Monetary cost per mile is estimated from various sources described in table 3.2.

Table 3.1: Recommended Value of Time by Mode Relative to 2011 Oregon Hourly Wage

\begin{tabular}{l|l}
\hline \multicolumn{1}{c|}{ Mode } & \multicolumn{2}{c}{ Percent of Wage Rate } \\
\hline Walk & $50 \%$ \\
\hline Bike & $50 \%$ \\
\hline Auto/Van/Truck Driver & $50 \%$ \\
\hline Auto/Van/Truck Passenger & $35 \%$ \\
\hline Bus & $35 \%$ \\
\hline Rail & $35 \%$ \\
\hline Dial-A-Ride/Paratransit & $35 \%$ \\
\hline Taxi & $35 \%$ \\
\hline Carpool/Vanpool & $35 \%$ \\
\hline Other (Specify) & $50 \%$ \\
\hline
\end{tabular}

Data sources: Litman 2007; ODOT 2012 
Table 3.2: Monetary Costs per Mile by Travel Mode

\begin{tabular}{|c|c|c|}
\hline Mode & $\begin{array}{l}\begin{array}{c}\text { Monetary } \\
\text { Costs }\end{array} \\
\text { per Mile (\$) }\end{array}$ & Sources \\
\hline Driving & .592 & (American Auto Association (AAA)) \\
\hline Bus & 1.01 & (Portland Facts) \\
\hline Rail & 1.38 & (Portland Facts) \\
\hline Taxi & 2.60 & (Portland Taxi Cab Company) \\
\hline Bike / Walk & 0.0 & \\
\hline
\end{tabular}

Note that the accounting of travel costs can use dollars or minutes. These two units are both valid and, from our perspective, should make little difference in results as long as one unit is used consistently. We adopt the practice that is commonly applied in calculating generalized costs in the modeling community. For convenience, we use minutes as our unit of choice.

When measuring travel costs in dollars, convert the time cost component to dollars through multiplying by VOT, then combine it with the monetary cost component. On the other hand, to switch travel cost accounting to minutes, set VOT to 1, and $M C_{m}$ to the time-equivalent monetary costs.

The unit.name parameter in the code can be set to "dollars" or "minutes" to switch between these two units. It is also possible to set either VOT or MC to 0 to include only the time costs or monetary costs of traveling for diagnostic purposes.

\subsection{TRANSPORTATION COST AGGREGATION}

Once transportation market baskets are defined for an urban area and transportation costs have been identified for both motorized and nonmotorized modes for each TAZ or household location to destinations within a market basket, the total cost can be calculated across mode, trip purpose, and income group to get aggregated travel costs. Below are a few approaches described by Reiff and Gregor (2005) and adopted in this current project as well.

There are a few different approaches to incorporating varying costs by mode. The simplest is to pick the least costly mode:

$$
T C_{p i k j}=\min _{m}\left(T C_{p i m k j}\right)
$$

An alternative approach would be average costs weighted by mode probabilities:

$$
\begin{array}{r}
T C_{\text {pikj }}=\sum_{m}\left(T C_{\text {pimkj }} * P_{\text {pimkj }}\right) \quad \text { where } \\
P_{\text {pimkj }}=\frac{\exp \left(U_{\text {pimkj }}\right)}{\sum_{m \prime} \exp \left(U_{\text {pim } k j}\right)}
\end{array}
$$


and $U_{\text {pimkj }}$ is the utility for traveling by mode $m$ between TAZ $k$ and $j$ for purpose p by income group $i$.

The travel costs are weighted by trips and mode probabilities from each TAZ to destinations in travel market baskets:

$$
\begin{aligned}
& T C_{\text {pimk }}=\frac{\sum_{j \in C_{p} T C_{p i m k j} * T r i p s_{p i m k j}}}{\sum_{j \in C_{p}}{ }^{T r i p s_{p i m k j}}} \\
& \text { and } \\
& T C_{p i k}=\frac{\sum_{j \in C_{p} T C_{p i m k j} * \text { Trips }_{\text {pimkj }} * P_{\text {pimkj }}}}{\sum_{j \in C_{p}} \text { Trips }_{\text {pimkj }} * P_{\text {pimkj }}} \\
& \text { with } \\
& P_{\text {pimkj }}=\frac{\exp \left(U_{\text {pimkj }}\right)}{\sum_{m^{\prime}} \exp \left(U_{\text {pim }{ }^{\prime} j}\right)}
\end{aligned}
$$

Where

$j \in C_{p}$, the set of TAZs belonging to the travel market basket for purpose $p$;

Trips $_{\text {pimkj }}$ is the number of trips for purpose $p$ by income group $i$ using mode $m$ from TAZ $k$ to TAZ $j$;

$P_{\text {pimkj }}$ is the probability that mode $\mathrm{m}$ is used by income group $i$ for trip purpose $p$ from TAZ $k$ to TAZ $j$;

$U_{\text {pimkj }}$ is the utility for traveling by mode $m$ between TAZ $k$ and $j$ for purpose p by income group $i$.

Following the logic we used in calculating weighted average travel costs, it is possible to suppress the income group or trip purpose dimension and summarize the average costs by TAZ and other dimensions:

$$
\begin{aligned}
& T C_{p k}=\frac{\sum_{i} T C_{p i k} * \mathrm{hhs}_{i k}}{\sum_{i} h h s_{i k}} \\
& \boldsymbol{T} \boldsymbol{C}_{\boldsymbol{i k}}=\frac{\sum_{\boldsymbol{p}} \boldsymbol{T} \boldsymbol{C}_{\boldsymbol{p} \boldsymbol{k} \boldsymbol{k}^{* \text { trips }} \boldsymbol{p i k}}}{\sum_{\boldsymbol{p}} \boldsymbol{t r i p s}_{\boldsymbol{p i k}}}
\end{aligned}
$$

where

hhs $_{\text {pik }}$ is the number of households of income group $i$ in TAZ $k$;

trips $_{\text {pik }}$ is the number of trips made by income group $i$ for purpose $p$ in TAZ $k$. 
A similar process can be used to aggregate average travel costs to geographic units larger than TAZs, such as districts, cities and the whole region. In this process, the proportions of trips occurring among the zones within each larger geographic area are used as weights. The average cost $A C$ to access the market basket for all TAZs in district $d$ for purpose $p$ and income group $i$ is calculated as follows:

$$
T C_{p i d}=\frac{\sum_{k \in d} T C_{p i k} * \text { trips }_{p i k}}{\sum_{k \in d} \text { trips }_{p i k}}
$$




\subsection{IMPLEMENTATIONS AND THE PORTLAND APPLICATION}

Two approaches to defining travel market baskets for a Transportation Cost Index (TCI) are implemented in $\mathrm{R}$ for this project. The scripts are available on github at https://github.com/citieslab/tci. This chapter describes the implementations and the applications of the approaches to the Portland area.

\subsection{SURVEY-BASED APPROACH}

The survey-based approach calculates travel costs primarily with a travel survey dataset, in Portland's case, the Oregon Household and Activity Survey (OHAS) data (OMSC, 2011). The survey was conducted in 2011 covering the whole state of Oregon. The home-based trips are classified into four different types: Home-Based Work (HBW), Home-Based Shopping (HBS), Home-Based Recreation (HBR) and Home-Based Other (HBO), while non-home-based trips are excluded. Households are classified into 3 income groups: low-income, middle-income, and high-income. To be consistent with the classification used in Metro's travel demand model, data from which is used in the cluster-based approach, we use the same classification thresholds of \$25K, \$25-50K, and \$50K+ in 1994 dollars. All steps of the survey-based approach are implemented in the tci/code/survey directory (https://github.com/citieslab/tci/tree/master/code/survey). The inputs for the survey-based approach are listed in Appendix A.

\section{Step 1. Prepare the survey data for TCI computation: Classify each household by income group, and identify household characteristics and trip purpose}

Total 2010 household income (the INCOME field in the OHAS data) is used to classify households into three income groups: low-income $(<\$ 35 \mathrm{~K})$, middle-income $(\$ 35-75 \mathrm{~K})$, and high-income $(\$ 75 \mathrm{~K}+)^{4}$. Two additional household characteristics are used for the Portland application: traffic district of household residence and household size, both of which are available in the 2011 OHAS data. We directly use the trip purpose information processed and prepared by ODOT Transportation Planning Analysis Unit staff and consultants. We also retain the household weights (HHWGT) provided in the OHAS data for later use.

\section{Step 2. Calculate generalized costs for each trip}

Generalized costs that include both travel time cost and monetary cost components are aggregated for each trip (and thus for each trip purpose, mode and income level) using equation 3.17 described in section 3.2.3.

In the 2011 OHAS data, trip duration (TRPDRE) and trip distance (TRPDST) provide information for travel time and travel distance. Value of travel time and monetary cost per mile

\footnotetext{
${ }^{4}$ Those cutoffs in 2010 dollars are the brackets closest to $\$ 25 \mathrm{~K}$, \$25-50K, and $\$ 50 \mathrm{~K}+$ in 1994 dollars.
} 
parameters are specified in tables 3.1 and 3.2 in chapter 3. $C_{m}$ is set to 0 for the Portland application. Those parameters are specified in settings.R.

\section{Step 3. Compute travel costs by trip, person, household and districts}

From the trip-level travel costs computed in step 2, we can apply HHWGT and compute travel costs for different units. Trip-level travel costs can be compared across different income groups and different trip purposes. They can also be aggregated over people and households. Personand household-level travel costs can be summarized and examined by income group, trip purpose, residence district, or a combination of these characteristics using the aggregation methods described in section 3.3. Although it is possible to aggregate household-level travel costs by residence Traffic Analysis Zone (TAZ), there are usually few surveyed households per TAZ (some TAZs may not have any household observations at all), so the aggregated travel costs at the TAZ level are not robust and thus not used.

\section{Step 4. Generate plots and maps}

Plots and maps can be generated from the results of step 3.

Figures 4.1 to 4.4 demonstrate the results from the survey-based approach for the Portland area using 2011 OHAS data. 


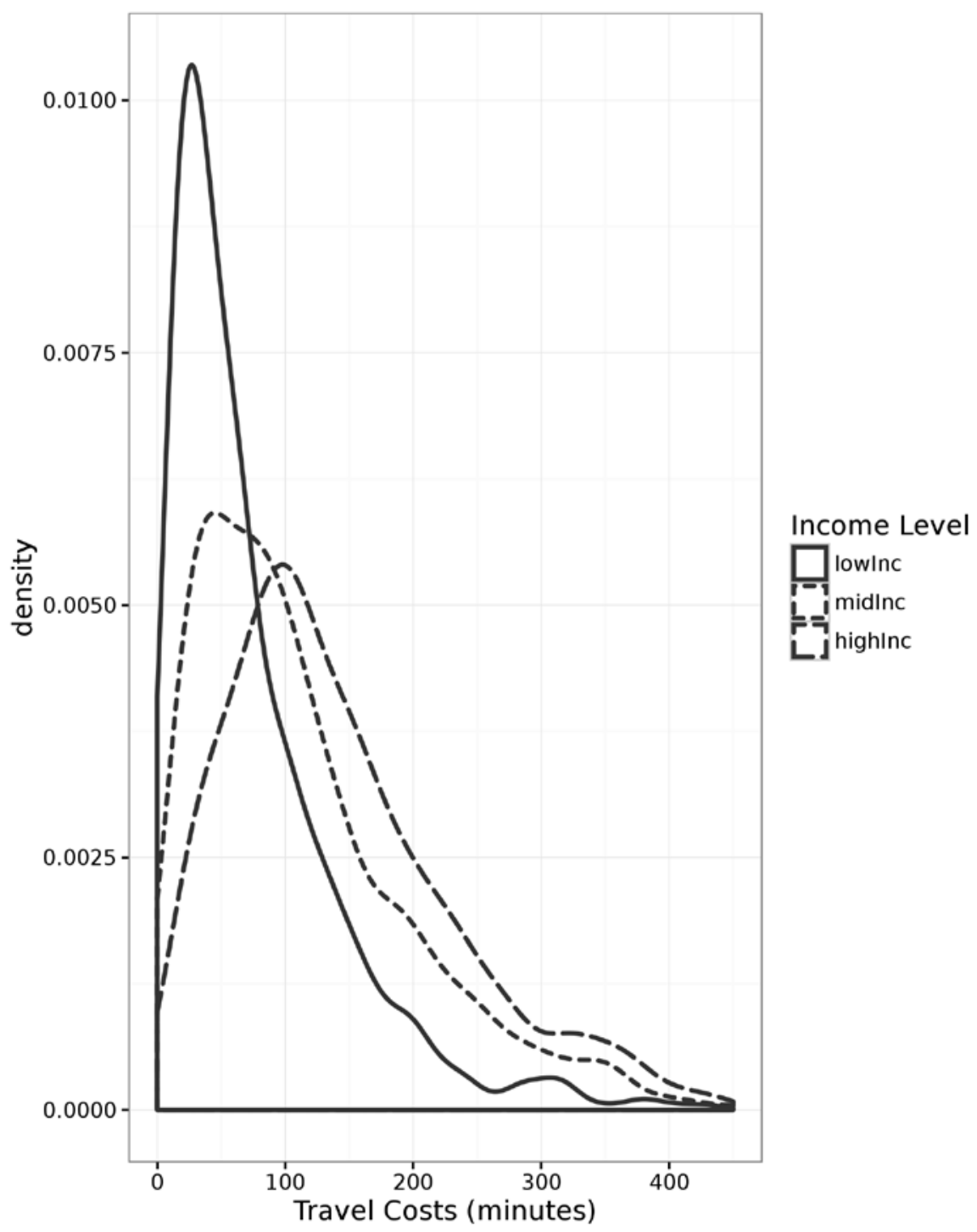

Figure 4.1: Density distributions of household-level travel costs by income level for Portland with 2011 OHAS data

Figure 4.1 shows the distributions of household-level daily travel costs by income level. Without considering other factors, low-income households in general spend less than middle-income and high-income households on traveling. Other factors may confound the pattern; for example, household size is highly likely to be correlated with income, which may explain the pattern observed in figure 4.1 . 


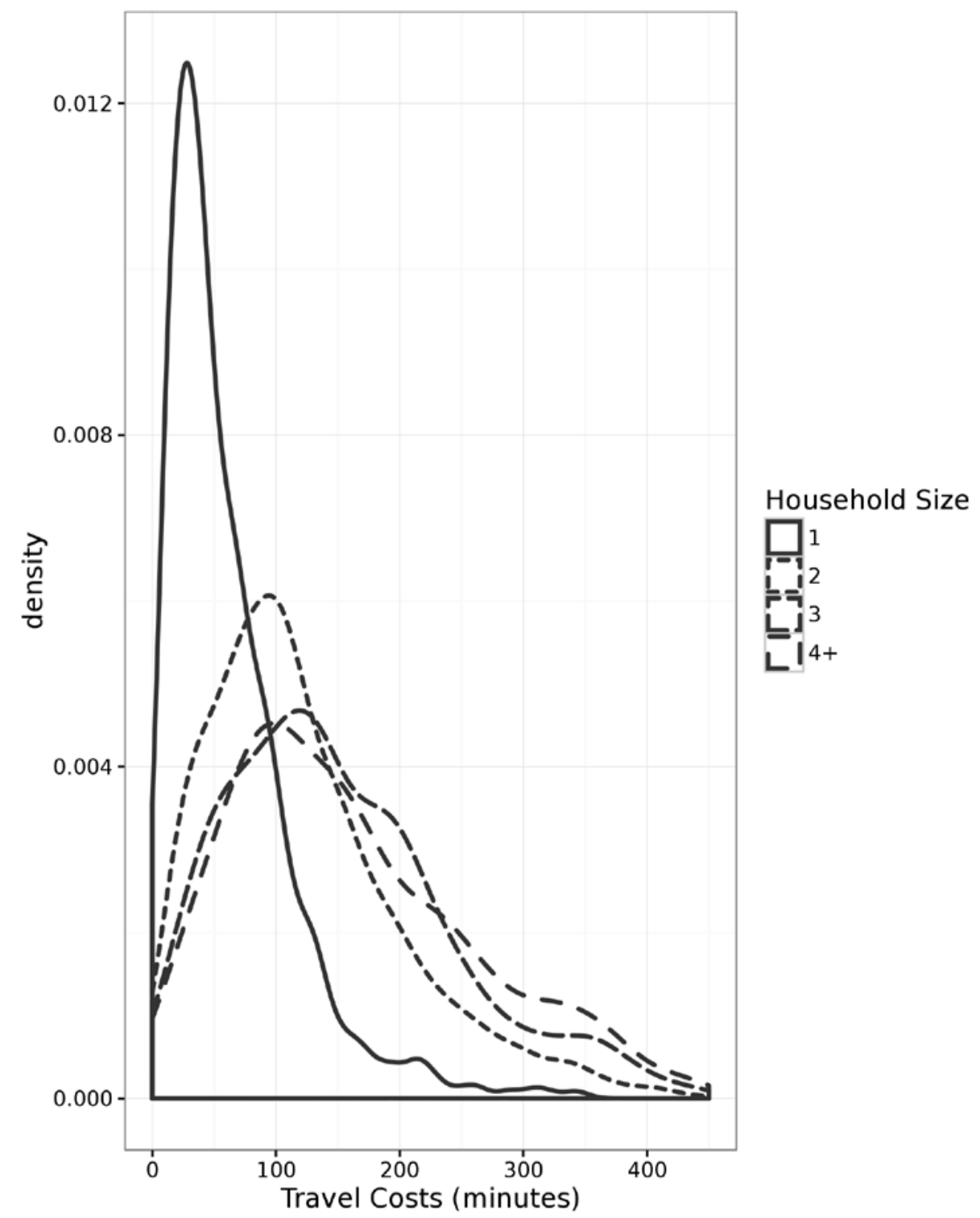

Figure 4.2: Density distributions of household-level travel costs by household size for Portland with 2011 OHAS data

Figure 4.2 displays the distributions of household-level travel costs by household size. It makes sense that smaller households have lower travel costs than larger households, as the householdlevel travel costs sum travel costs over all household members. The travel cost distributions for households with 3 and 4+ members are very similar.

In addition to income and household size, travel costs can be compared across other household characteristics. For example, Figure 4.3 shows household-level travel costs for households with and without children (at least one household member younger than 16). It seems to make sense 
that households with children have higher travel costs, as they may be larger and have to make trips with and for the children. Because detailed household information is available, the possibilities are limitless in how the travel costs can be plotted against household's socialdemographic characteristics and related to other information, such as land use, transportation infrastructure, etc.

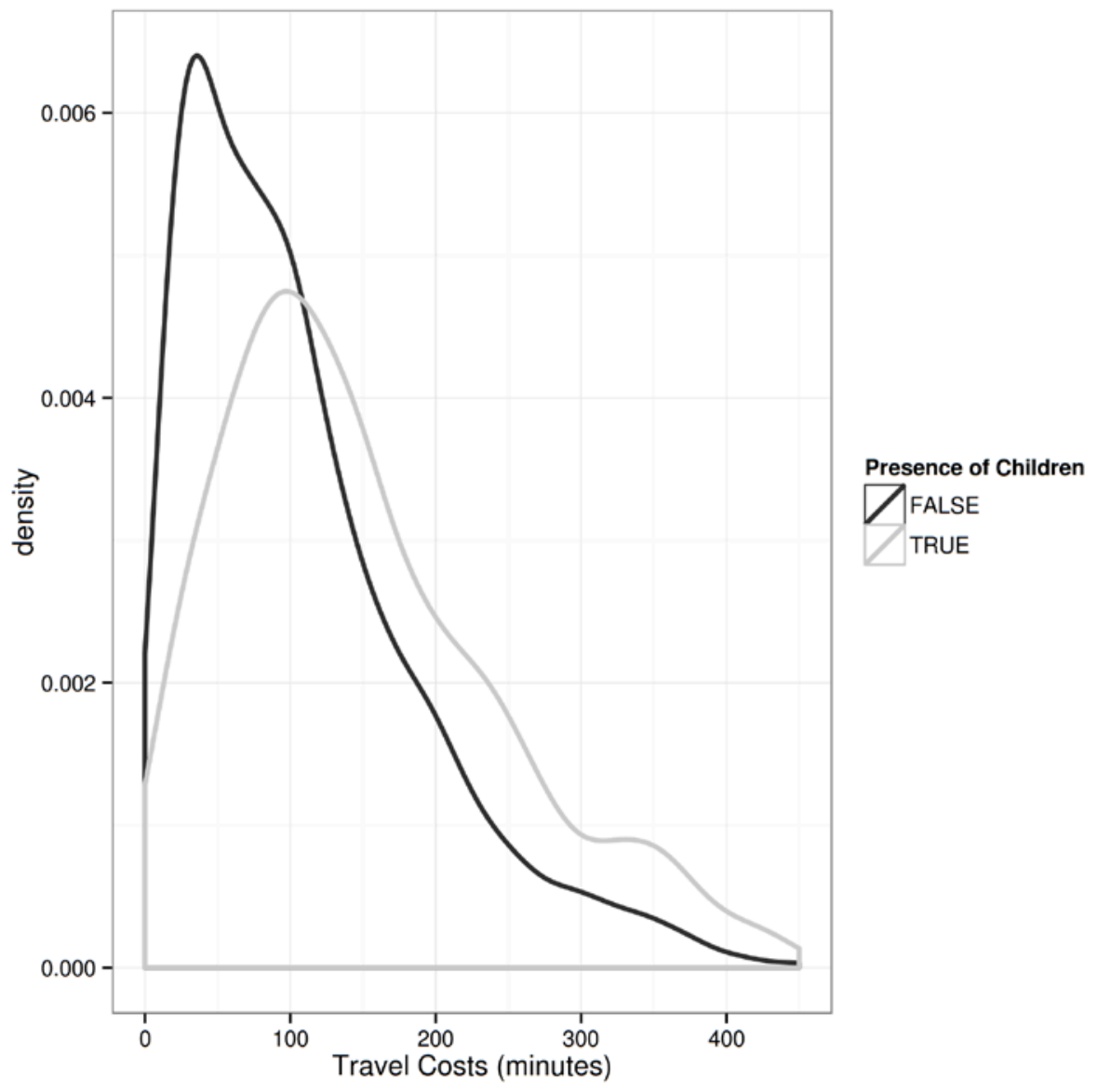

Figure 4.3: Density distributions of household-level travel costs by presence of children for Portland with 2011 OHAS data 
Given the relationship between household-level travel costs and household size shown in Figure 4.2, it may be useful to examine the average travel costs per person. Figure 4.4 shows the average household-level travel costs per person for Portland (household-level travel costs divided by household size). The difference in travel costs across income categories becomes much smaller once household size is factored in.

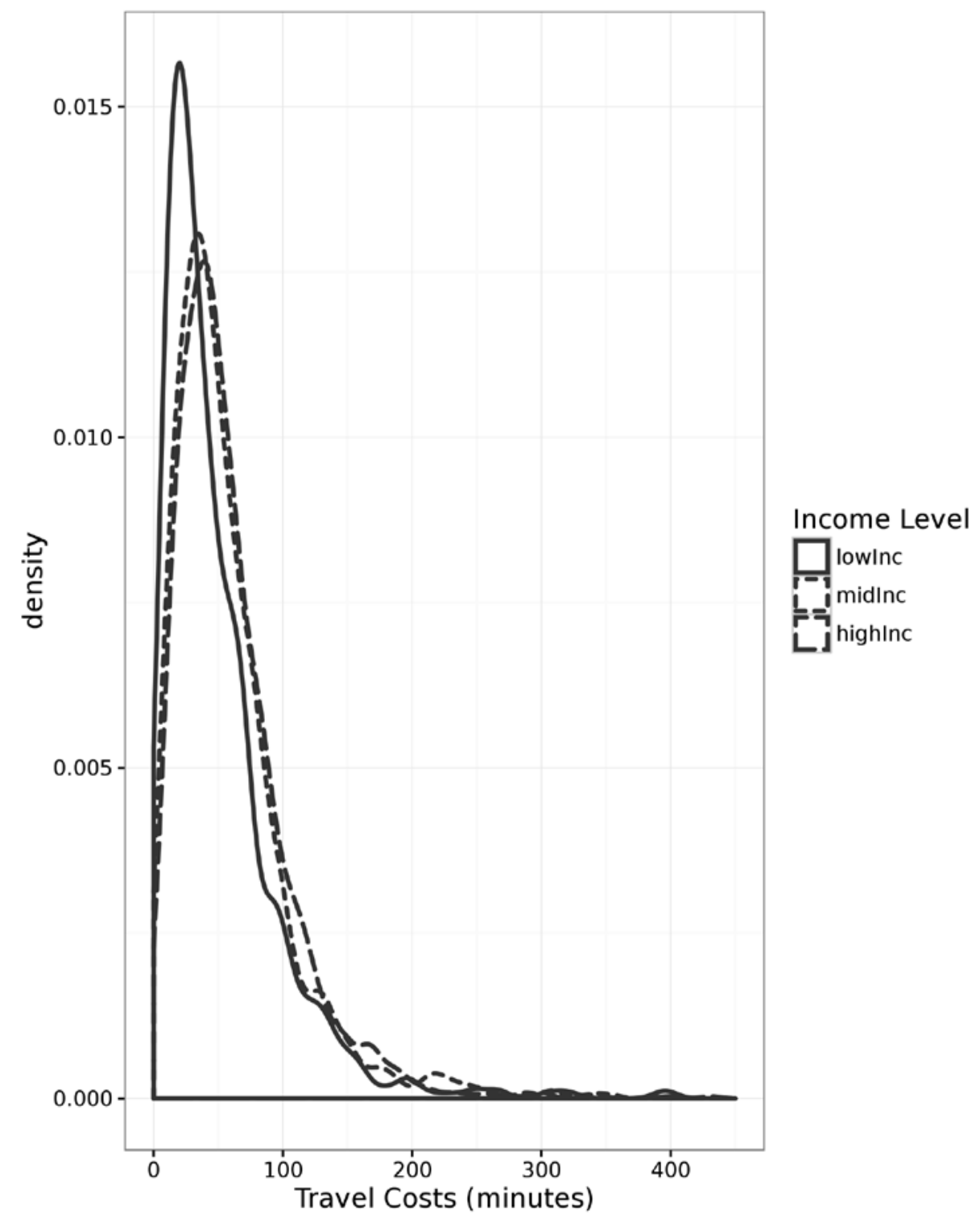

Figure 4.4: Density distributions of average travel costs per person by income for Portland with 2011 OHAS data 
Besides household-level travel costs, it is possible to examine travel costs at other levels with the survey-based approach. Figure 4.5 shows trip-level travel costs by trip purpose and the traveler's household income.

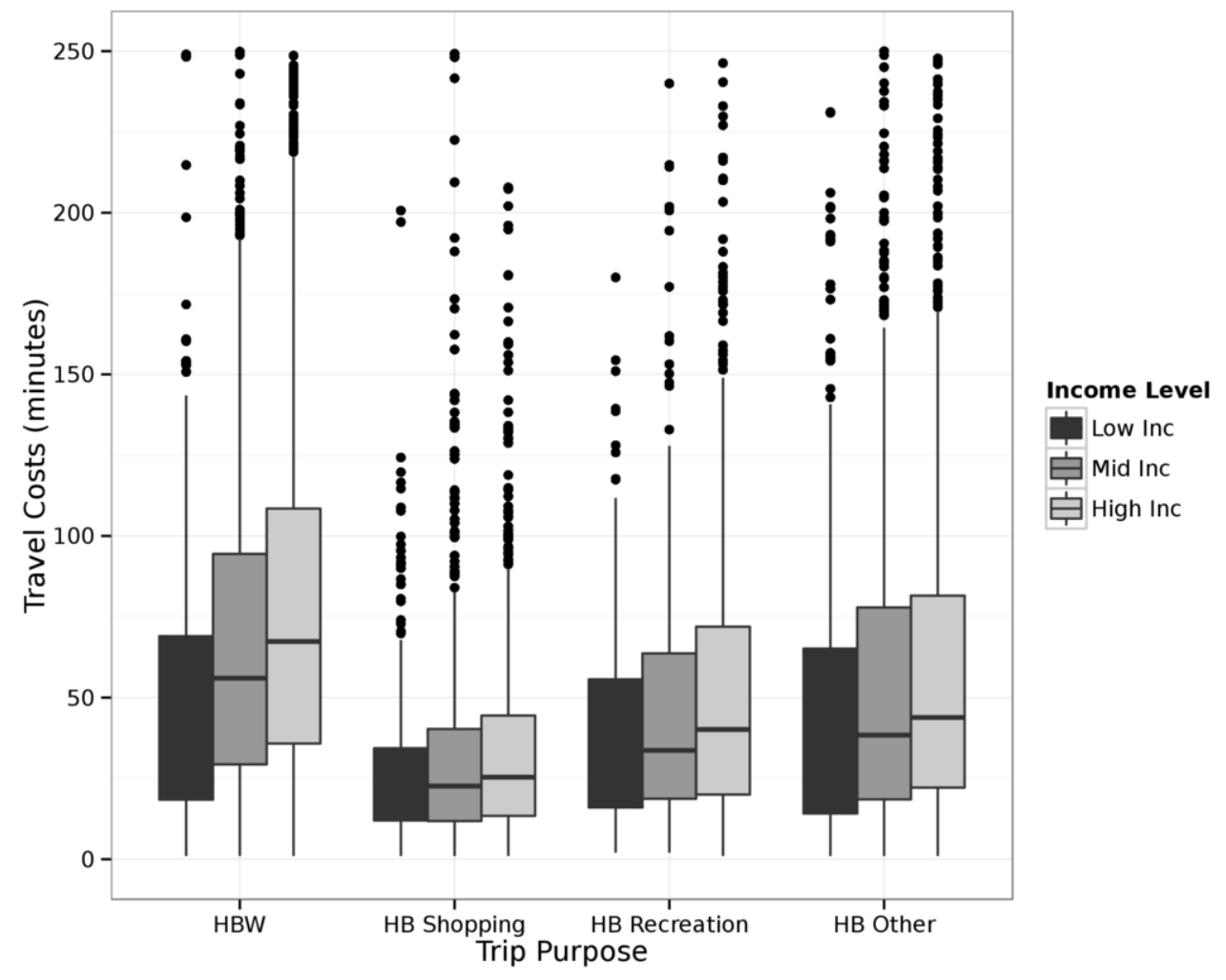

Figure 4.5: Box plot of trip-level travel costs by trip purpose and traveler's household income level for Portland with 2011 OHAS data

Finally, travel costs can be summarized geographically and plotted as maps. Figure 4.6 maps average household-level travel costs at the traffic district level by income and trip purpose. Maps on the first row plot average household-level travel costs making HBW, HBS, HBR, and HBO trips at district level for low, middle and high income, and for all households. Areas without data are shown in white (blank). Since the value for each district is calculated by averaging household-level travel costs over all corresponding households living in the district, there are anomalies where trips of certain purposes produce higher values than all trips. For example, for low-income households living in east Portland, the costs for HBR trips (the high-value area in the first map on the fourth row) are much higher than those for all trips. This surprising result is caused by the fact that very few low-income households in the district make home-based recreation trips. 

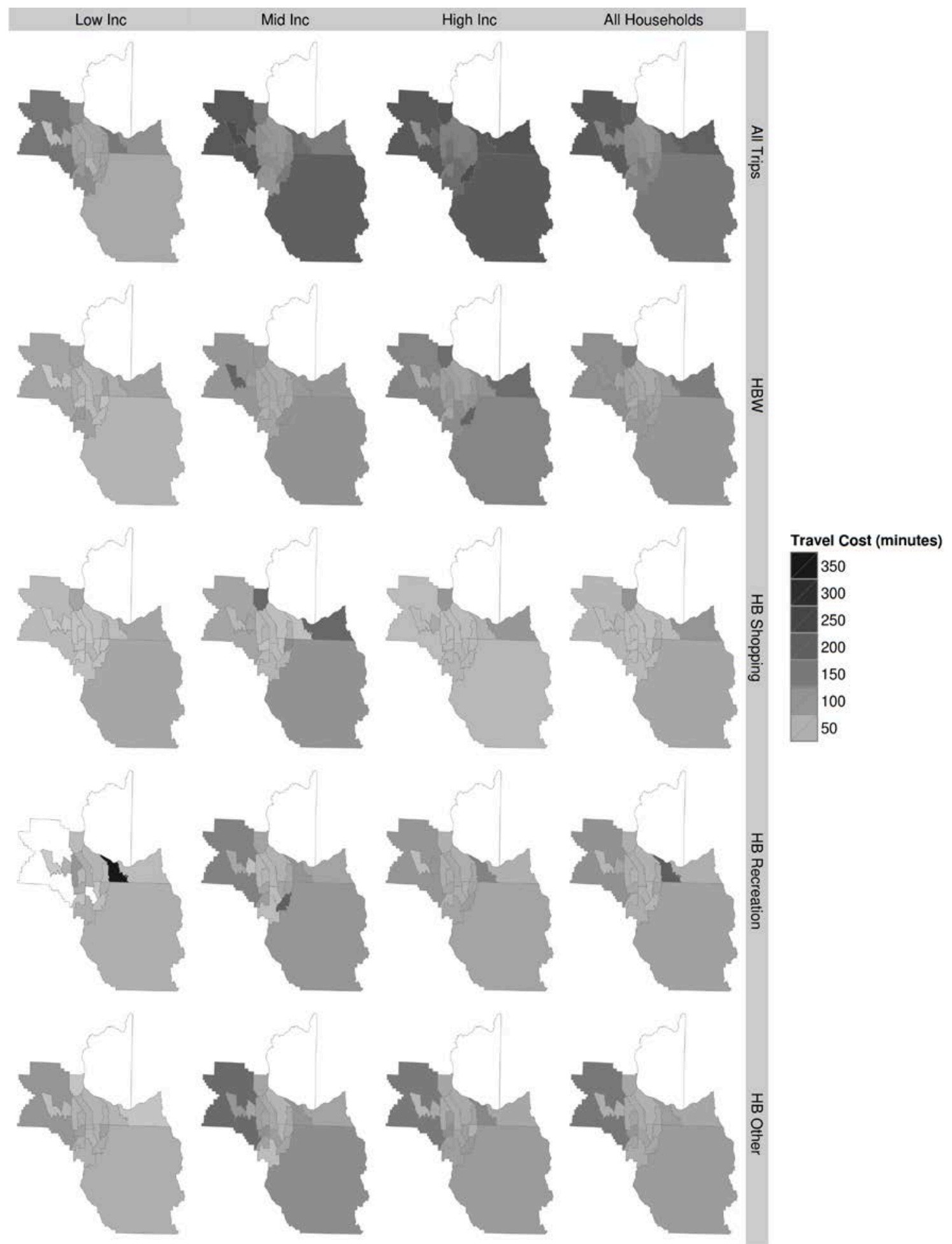

Figure 4.6: District level average household travel costs by income level and trip purpose for Portland with 2011 OHAS data

Due to the problem of the inconsistent result described above and of the potential modifiable areal unit problem (MAUP) in aggregating by geography, we test extrapolating per-person travel 
costs (log scale) to grid cells and plotting the extrapolated values in each grid cell as a heat map (figure 4.7; see script code/misc/plot_heatMap.R for details of how it is created).

However, the heat map is not conducive to show much of a pattern in the distribution of perperson travel costs.

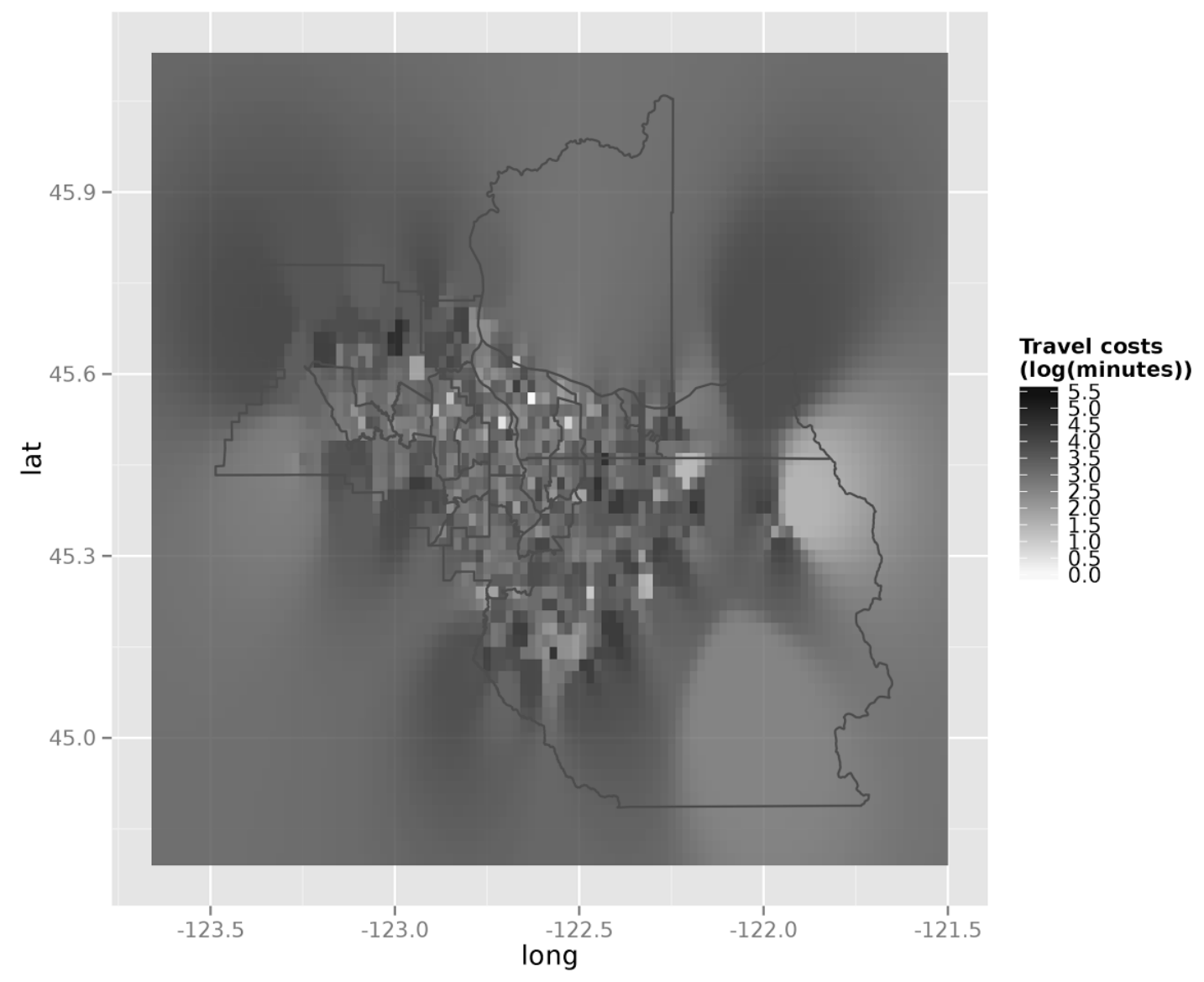

Figure 4.7: Heat map of per-person travel costs for Portland with 2011 OHAS data (grid cell size $=0.02^{\prime *} 0.02^{\prime}$, overlaid with traffic district boundaries)

\subsection{CLUSTER-BASED APPROACH}

Section 3.1.3 describes the cluster-based approach. The approach is implemented in $\mathrm{R}$ and the code is in the tci/code/cluster directory. Steps for implementing the cluster-based approach are described below. Inputs for the cluster-based approach are listed in Appendix B.

One of the unresolved issues from chapter 3 is to determine the cutoffs for center identification. Sensitivity testing on the response of the identified spatial distribution of centers and the resultant travel costs is analyzed in response to different cutoffs. The results for Portland are included in Appendix C. What we found is that the identified centers and TCI results are very stable when the cutoffs are set at the 50th to 70th percentiles. For applications of the cluster- 
based approach covered in the report, we use the 50th percentile as a cutoff. Users can change the parameters for cutoffs in R scripts.

\section{Calculate TAZ-level employment density and size term density}

This step calculates a TAZ's employment density for HBW and size term density for HBR, HBS, and HBO. For HBW, employment used here is the total employment of all sectors. For the Portland application, size terms for HBR, HBS and HBO are calculated as follows:

$$
\begin{aligned}
\text { HBSsizeterms }= & \text { RetEmp }+0.008396 * \text { NonRet }+0.022126 * \text { Hhold } \\
\text { HBRsizeterms }= & \text { TotEmp }+1.278 * \text { Hhold }+4.6833 * \text { ParkAcres } \\
\text { HBOsizeterms }= & 0.2393 * \text { Hhold }+ \text { RetEmp }+0.6419 * \text { SvcEmp }+0.6109 * \text { GvtEmp } \\
& +06802 * \text { NonRetSvcGvt }
\end{aligned}
$$

where

RetEmp $=$ retail trade (North American Industry Classification System (NAICS) 44, 45, 72)

NonRet $=$ all employment other than retail

Hhold = number of households in TAZ

TotEmp $=$ total employment of TAZ

ParkAcres $=$ acres of park in TAZ

SvcEmp $=$ service $($ NAICS 51, 54, 56, 61, 62, 71, 81)

GvtEmp = government administration (NAICS 92)

NonRetSvcGvt = all employment other than retail, service, and government

Densities are calculated as employment or size term divided by the area of the TAZ.

\section{Identify centers}

This step adds size term density data to the TAZ shape file and identifies centers in a spatial clustering process. This step identifies centers for each of the four trip purposes: HBW, HBS, HBR and HBO. Based on the results of the sensitivity analysis, a density cutoff of $50 \%$ and a total cutoff of $50 \%$ are used.

\section{Calculate trips by purpose, income, mode and time of day}

Since trips by purpose, income, mode and time of day were not provided to us (only trip distribution by purpose and income are available), we calculate them from mode choice utilities. This step calculates mode choice probabilities and trips by mode:

$$
\begin{aligned}
& M T_{\text {pikjm }}=M T_{\text {pikj }} * M P_{\text {pikjm }} \\
& M P_{\text {pikjm }}=\exp \left(U_{\text {pikjm }}\right) / \sum_{m}\left(U_{\text {pikjm }}\right)
\end{aligned}
$$

where 
$M T_{\text {pikjm }}$ is the number of trips of income group $i$ from TAZ $k$ to TAZ $j$ for trip purpose $\mathrm{p}$ by mode $m$

$M T_{p i k j}$ is the number of trips of income group $i$ for trip purpose from TAZ $k$ to TAZ $j$

$M P_{\text {pikjm }}$ is the probability that mode $\mathrm{m}$ is used by income group $i$ for trip purpose $p$ from TAZ $k$ to TAZ $j$

$U_{\text {pikjm }}$ is the utility for traveling by mode $m$ between TAZ $k$ and $j$ for purpose p by income group $i$

\section{Calculate travel time and distance}

This step calculates travel time and distance from each TAZ to activity centers. The travel time is weighted by number of trips from an origin TAZ to TAZs in the centers.

\section{Calculate trip-level generalized costs}

Generalized costs that include both travel time cost and monetary cost components are aggregated for each mode in the same way as in step 2 of the survey-based approach.

\section{Aggregate travel costs}

As in step 3 of the survey-based approach, the distribution of the travel costs computed in step 5 can be aggregated across various dimensions, such as mode, income group, trip purpose, home location or a combination of these characteristics following methods discussed in section 3.3.

\section{Generate plots and maps}

Plots and maps can be generated from the results of step 3.

Figures 4.8 to 4.11 show cluster-based results for Portland with data from Metro's 2010 travel demand model. 
Figure 4.8 shows the density distributions of household-level travel costs by income level with the cluster-based approach. Low-income households have much higher travel costs with a very different distribution than other households. This plot is theoretically comparable to figure 4.1, but the results from the survey-based approach and the cluster-based approach may not be directly comparable for a few reasons. First, the two approaches measure different things (see discussion in section 3.1.2). The survey-based approach depicts the travel costs given households' current travel patterns, while the cluster-based approach describes what the travel costs would be if households had similar travel patterns. Second, the unit of analysis for the survey-based approach is individual households on the survey day, while that for the clusterbased approach is aggregated households at TAZ level (theoretically an average low-, mid- or high-income household living in a TAZ when the income is used for segmentation).

Nevertheless, figure 4.8 shows that if all households share the same travel market baskets defined as activity centers in the cluster-based approach, low-income households tend to have higher transportation costs than mid- and high-income households. This makes sense as lowincome households are more likely to reside in locations (TAZs) with worse regional accessibility and it would cost them more to travel to regional activity centers. Figure 4.8 also shows that high-income households have higher costs than mid-income households, although the difference is less drastic than when compared with low-income households.

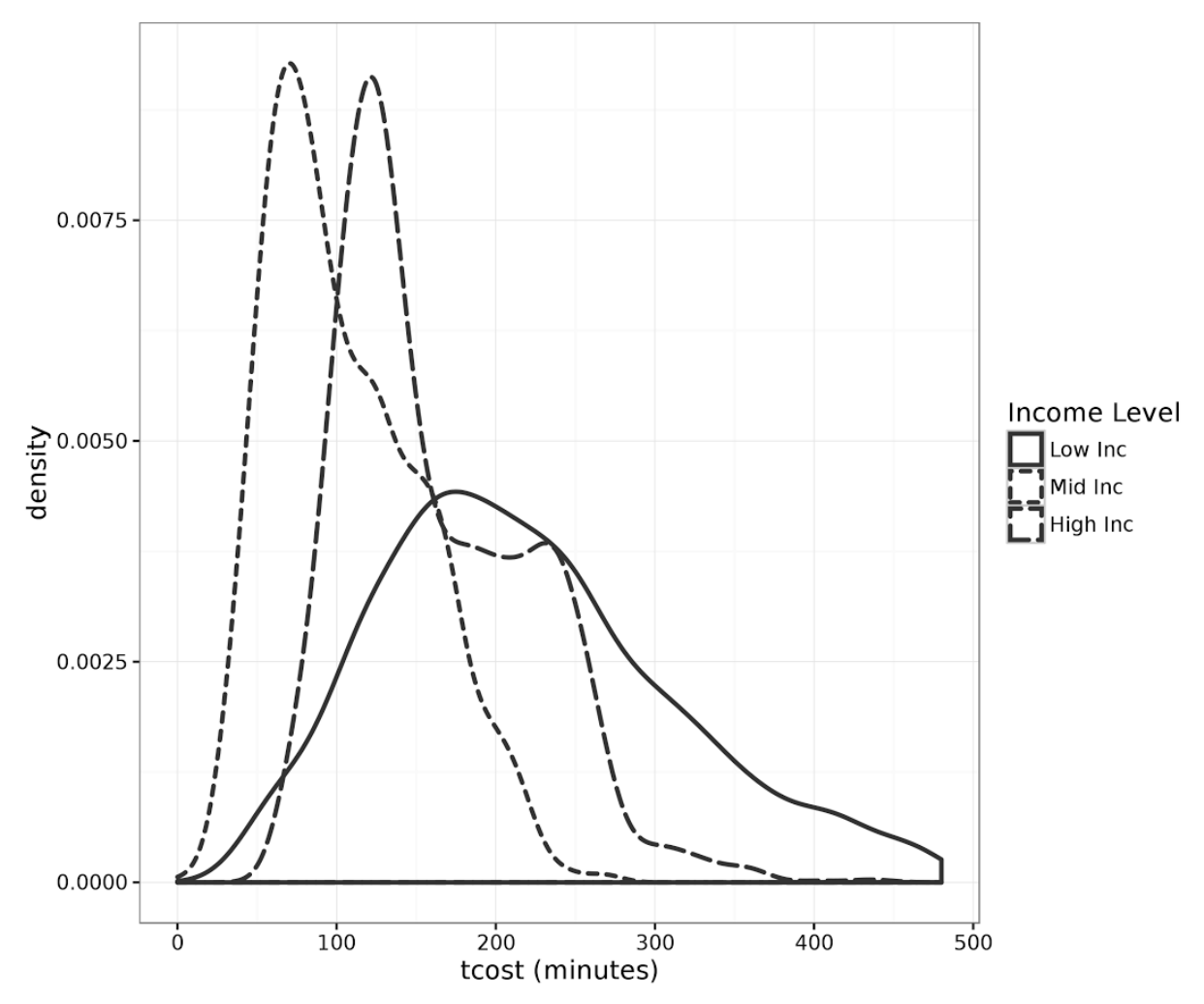

Figure 4.8: Density distributions of daily household travel costs by income level for Portland with the 2010 travel demand model data 
Just as in the survey-based approach, there are many ways to present the results from the clusterbased approach, although there is some difference in the output. There is more flexibility in describing the transportation costs distribution against household attributes in the survey-based approach because of the use of microdata as inputs. In the cluster-based approach, the household attributes available for analysis are limited by the travel demand model that provides most of the inputs. In a common 4-step model, the household data are usually aggregated by income and sometimes income alone, which limits ways to examine the transportation costs distribution. When TCI takes inputs from an activity-based travel model (ABM) (beyond the scope of this project and thus untested, but it is feasible), such limitations will be eliminated, as the inputs will again be microdata.

Because of this, we cannot plot some of the graphs as for the survey-based approach, for example, travel costs by household size or presence of children, or per-person travel costs. But there are plenty of attributes that can be used for analysis. For example, figure 4.9 shows the distribution of travel costs by trip purpose, and figure 4.10 the distribution of travel costs by trip purpose and income.

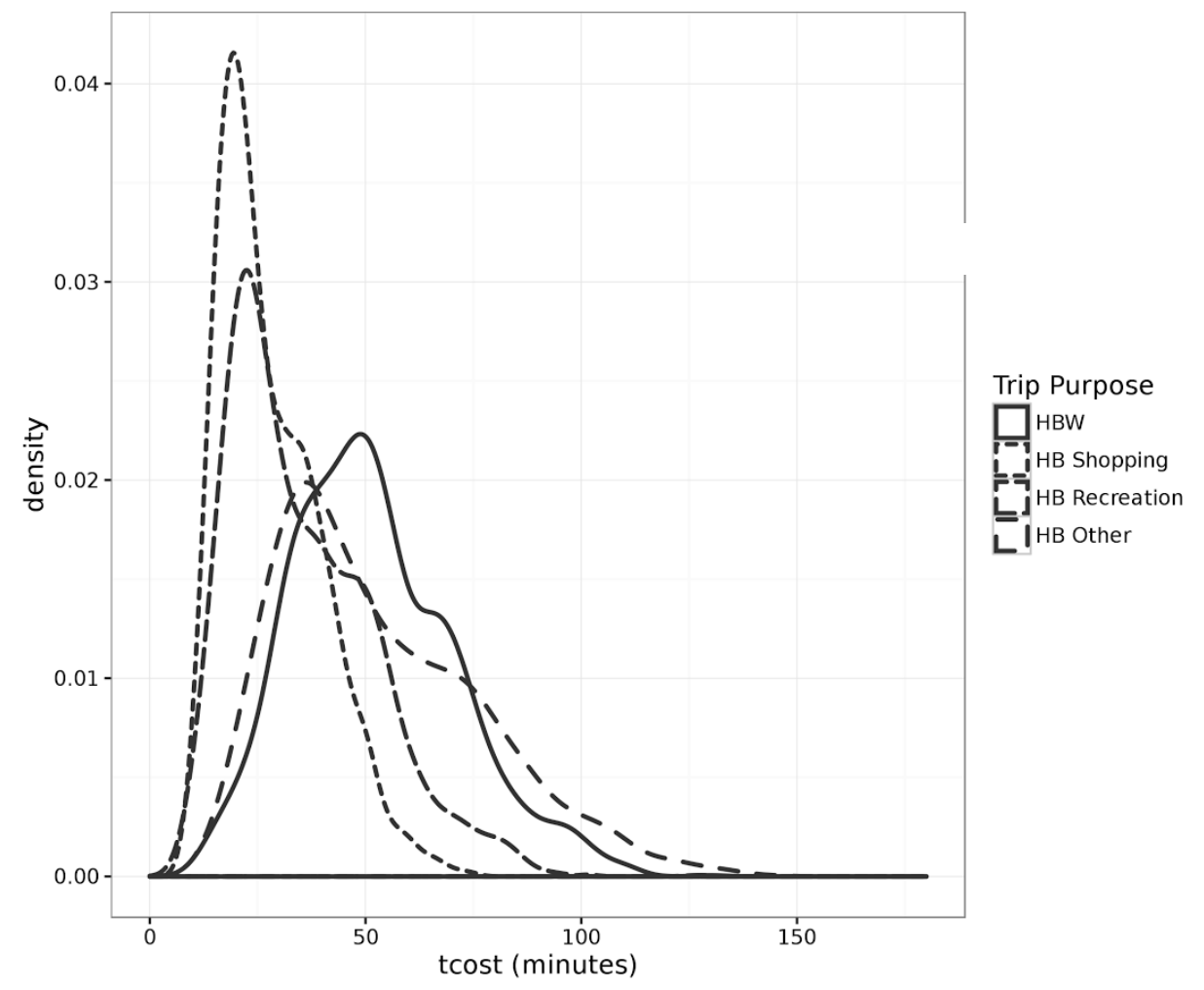

Figure 4.9: Density distributions of daily household travel costs by trip purpose for Portland with the 2010 travel demand model data 
Comparing figure 4.10 with figure 4.5 , it is easy to note that, with the exception of HB Shopping trips by low-income households, the range of travel costs by trip purpose and income from the cluster-based approach is smaller than that from the survey-based approach (as indicated by the height of the boxes in the two box plots). This is likely due to the fact that figure 4.10 (the cluster-based approach) reflects variation across TAZs, while Figure 4.5 (the survey-based approach) reflects the variation among households.

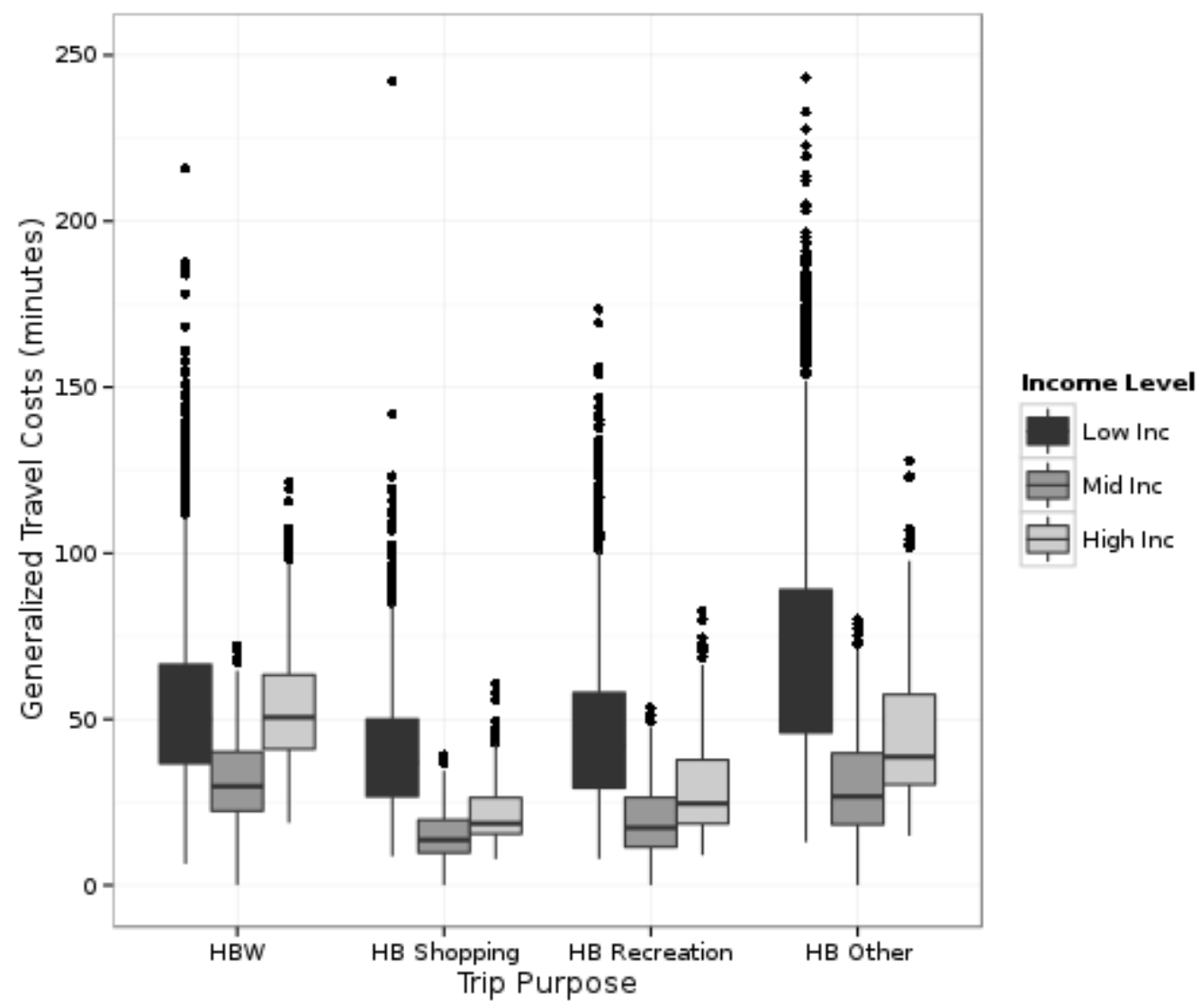

Figure 4.10: Box plot of daily household travel costs by income level and trip purpose for Portland with the 2010 travel demand model data

Just as for the survey-based approach, it is possible to plot the spatial distribution of transportation costs with maps. figure 4.11 shows the TAZ level spatial distribution of travel costs by trip purpose and income level. Maps in the first row are daily total travel costs for all trips per household, while those in other rows are costs for all trips of the specified purpose. 


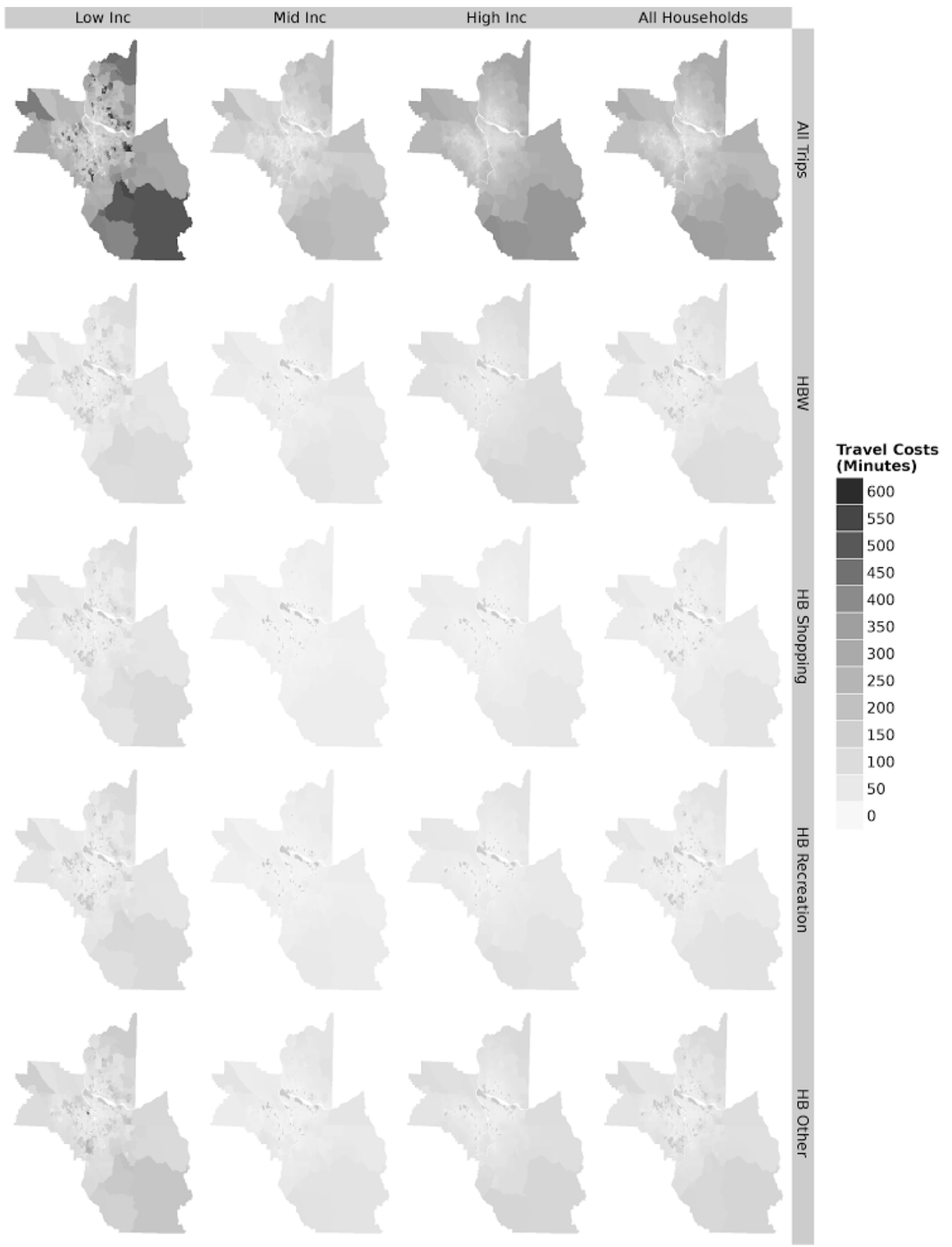

Figure 4.11: TAZ level spatial distribution of travel costs by income level and trip purpose for Portland with 2010 travel demand model data 


\subsection{TESTING SCALABILITY WITH THE CORVALLIS APPLICATION}

This chapter documents Task 5 - application of the travel market definitions to a mid-sized metropolitan area, Corvallis, in addition to Portland, to test their scalability and determine whether the travel market definitions are meaningful at all geographic levels, as the market basket definitions likely pose the most substantial scale issues in creating a robust Transportation Cost Index (TCI). The task may also show how the two approaches work in areas where data may not be as available, or as good, as for Portland. This chapter summarizes the testing of these two methods for Corvallis.

\subsection{SURVEY-BASED APPROACH}

The survey-based approach uses survey data like the Oregon Household and Activity Survey (OHAS) data to calculate travel costs for each trip and each household, and then aggregates triplevel and household-level costs by geography (e.g. Traffic Analysis Zone (TAZ), district), trip purpose and/or income group. Figures 5.1 to 5.3 show the results of the survey-based approach for Corvallis. Even though there are many fewer observations for Corvallis in the OHAS data ( $n=348$ versus $n=4,106$ for the Portland area) ${ }^{5}$, the results are still reasonable, which attests to the robustness and scalability of the survey-based approach.

Very similar patterns in the distributions of travel costs are observed in Corvallis and in Portland.

\footnotetext{
${ }^{5} \mathrm{n}$ - Number of households who reported at least one HBW/HBS/HBR/HBO trip during the day of the survey.
} 


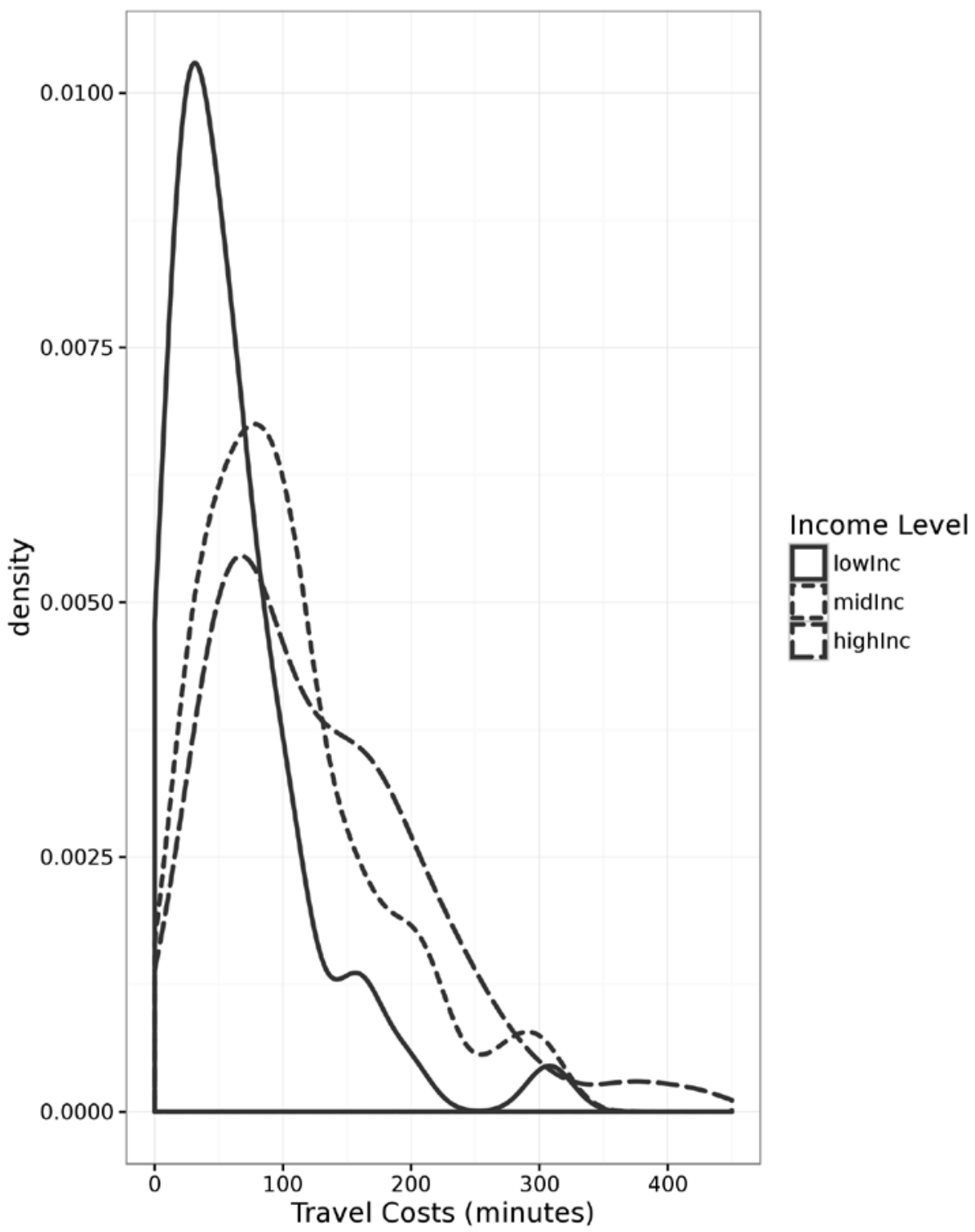

Figure 5.1: Density distributions of household-level travel costs by income level for Corvallis with 2011 OHAS data

Compared to Portland (figure 4.1), households in the Corvallis area on average have lower travel costs with a mean household-level daily travel cost of 105 minutes versus 119 minutes for Portland. However, the difference in means masks the subtle difference in the distribution of household-level travel costs between these two areas: In Corvallis, a larger share of low-income households enjoy low travel costs ( $<100$ minutes), but their travel costs are higher than those for low-income households in Portland, as demonstrated by the wider peak in figure 5.1. This is probably due to the fact that since Portland is a much bigger region, some households there would have to make very long trips. On the other hand, because there are more transportation options available in Portland, a substantial share of low-income households enjoy lower travel costs. 


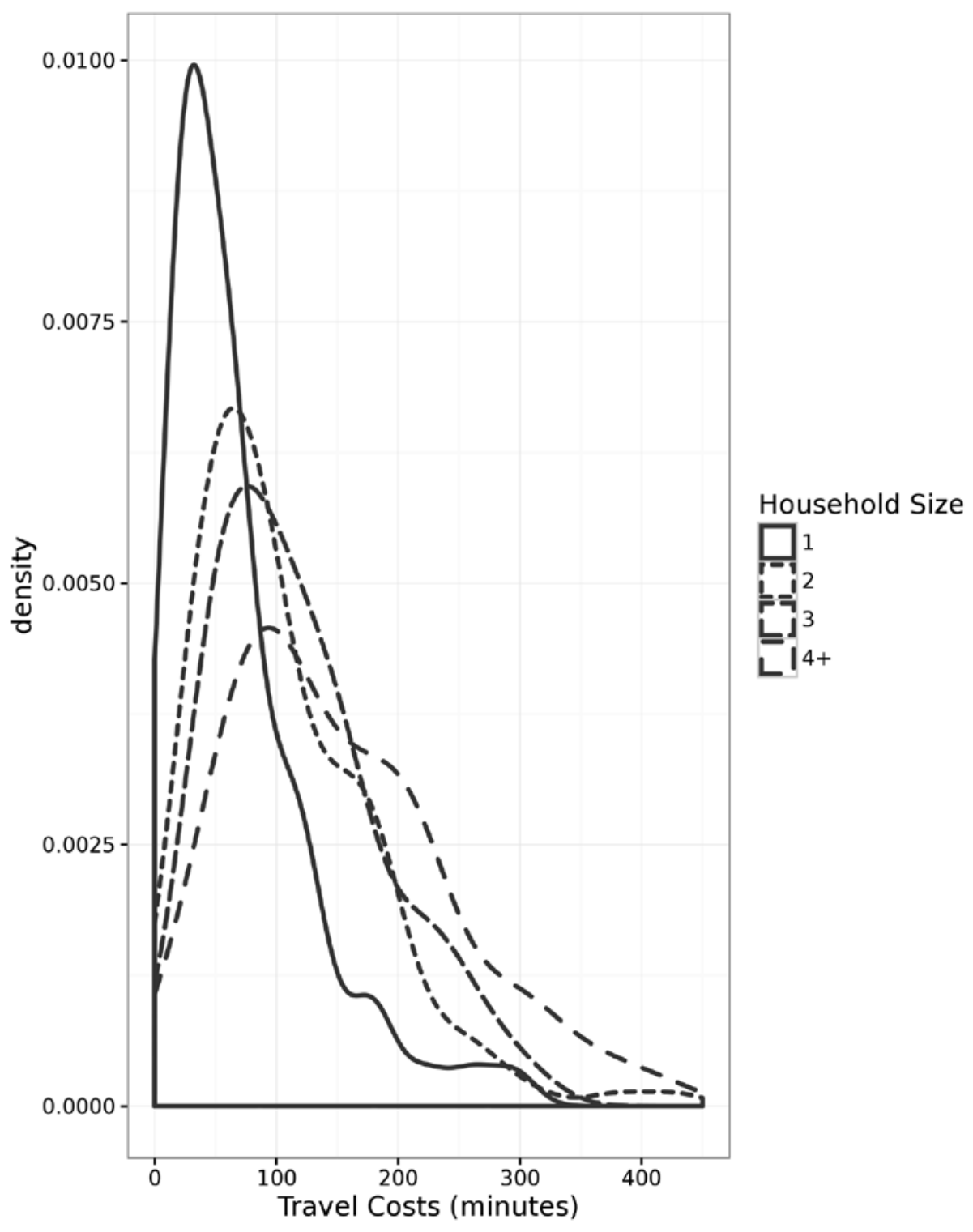

Figure 5.2: Density distributions of household-level travel costs by household size for Corvallis with 2011 OHAS data

In Corvallis, as in Portland, as households get larger, their travel costs increase (figure 5.2). But the difference between households with 3 members and those with 4+ members in Corvallis is larger than the difference in Portland (figure 4.2). 
As shown in figure 5.3, households with children have higher travel costs than those without in Corvallis, although the difference is smaller than shown in figure 4.3 for Portland, indicated by the fact that the two density lines are closer to each other in figure 5.3.

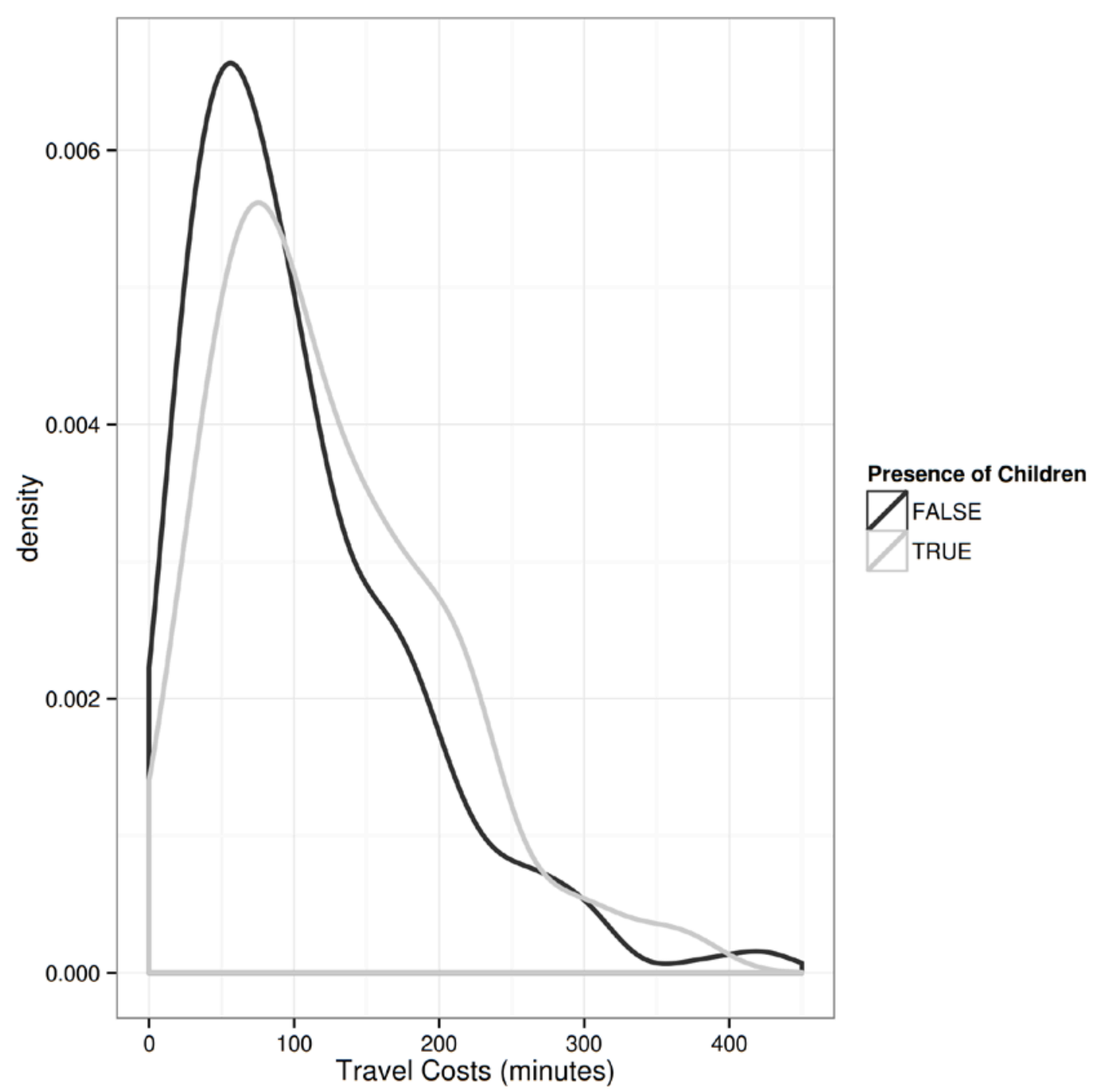

Figure 5.3: Density distributions of household-level travel costs by presence of children for Corvallis with 2011 OHAS data 
Again similar to Portland's pattern, the difference in travel costs across income groups becomes much smaller for Corvallis once household size is factored in (figure 5.4).

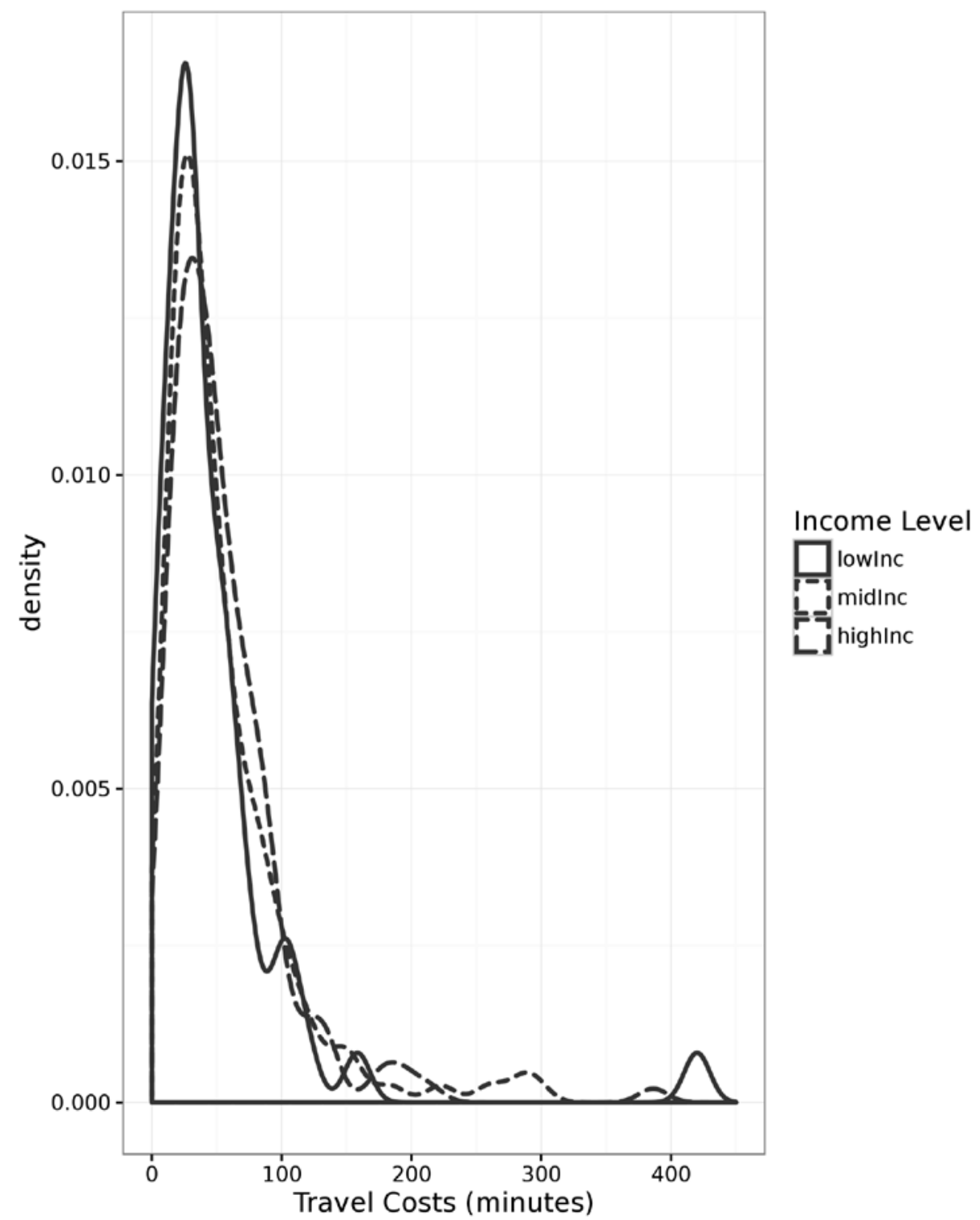

Figure 5.4: Density distributions of average travel costs per person by income for Corvallis with 2011 OHAS data 
Figure 5.5 shows trip-level travel costs by trip purpose and the traveler's household income for Corvallis.

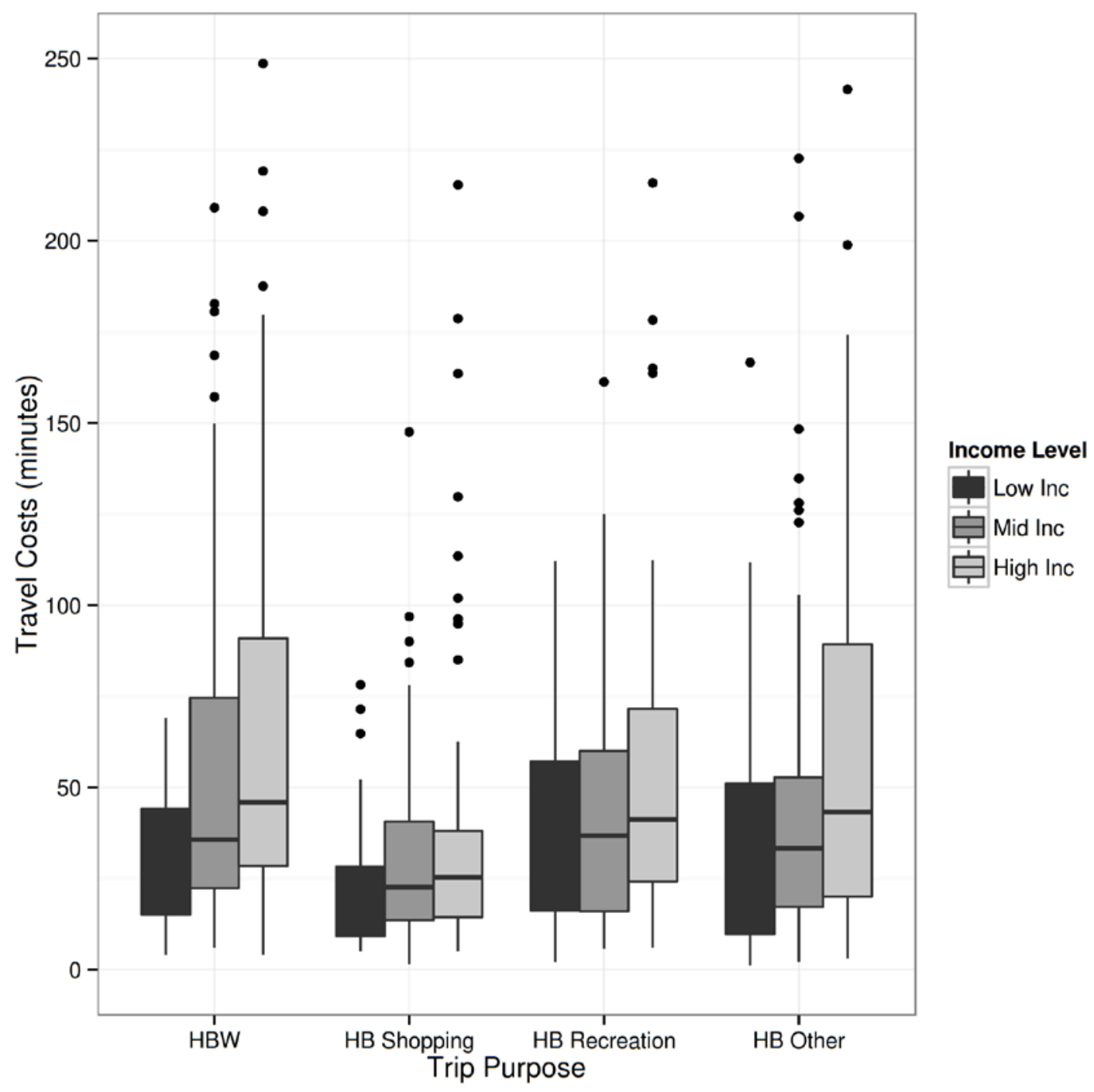

Figure 5.5: Box plots of trip-level travel costs by income level and trip purpose for Corvallis with 2011 OHAS data

\subsection{CLUSTER-BASED APPROACH}

The cluster-based approach has been described in early chapters of this report. This method defines a travel market for each of the four trip purposes: Home-Based Work (HBW), HomeBased Shopping (HBS), Home-Based Recreation (HBR) and Home-Based Other (HBO). For each trip purpose, the travel market basket is a set of geographic clusters that represent activity centers identified with the algorithm proposed by Giuliano and Small (1991). 
The cluster-based approach uses the travel demand model (TDM) data, including household and employment by TAZ, size terms in the destination choice model utility function, and travel time skims. This task uses data from the Corvallis JEMnR (Jointly Estimated Model in R) TDM, which is structured like the Portland TDM, although the size term formulas are different.

The steps to define travel markets are as follows.

\section{Step 1. Calculate TAZ-level employment density for HBW and size term density for HBR, HBS, and HBO;}

Employment density is employment divided by the area of the TAZ, and size term density is size term divided by the TAZ area. For each TAZ in Corvallis, the size terms are calculated as follows.

$$
\begin{array}{ll}
\text { HBS: } & \text { RetEmp + 0.025*NonRet + 0.019*Hhold } \\
\text { HBR: } & \text { NonRet + } 1.175 * \text { Hhold + 7.614*ParkAcres } \\
\text { HBO: } & 0.404 * \text { GvtEmp + RetEmp + 0.537*SvcEmp + 0.114*NonRetSvcGvt } \\
& +0.260 * \text { Hhold }
\end{array}
$$

where RetEmp = Retail trade employment (defined as in Section 4.2)

NonRet $=$ All employment other than retail

Hhold $=$ Number of households

ParkAcres $=$ Park Acres

GvtEmp = government administration employment

SvcEmp = service employment

NonRetSvcGvt = all employment other than retail, service and government

\section{Step 2. Identify TAZs with densities greater than cutoff D;}

\section{Step 3. Group TAZs identified in step 2 into contiguous clusters;}

\section{Step 4. Calculate total employment or size terms for each cluster identified in step 3; \\ Step 5. Eliminate clusters with total employment or size terms below cutoff $\mathbf{E}$ from centers identified in step 3 . The remaining are activity centers.}

There are two cutoffs in the algorithm above. The density cutoff (D) selects TAZs to form centers and the total cutoff (E) selects activity centers to form a travel market basket. In order to define a reasonable travel market basket, the cutoff values are crucial. Unfortunately, there is no theoretical ground for determining these cutoffs, as Giuliano and Small (1991) relied on expert opinion when determining them. Sensitivity analysis has been done to determine reasonable cutoff values. Figure 5.6 below shows travel market baskets for trip purpose HBW with various cutoff values. The noncenter area is red. In the top-left map, the area in dark blue is as the HBW travel market basket with density cutoff set at the 50th percentile and total cutoff at the 75th 
percentile; the areas in dark and light blue are the HBW travel market for a density cutoff at the 50th percentile and total cutoff at the 50th percentile.

The travel market basket becomes smaller as the density cutoff increases. The bottom-right map shows an HBW travel market with the density cutoff at the $95^{\text {th }}$ percentile (employment densities less than the $95^{\text {th }}$ percentile are eliminated). It is much smaller than the model area.

The process is repeated for other trip purposes (HBS, HBR and HBO) but the graphs are not included here to save space.
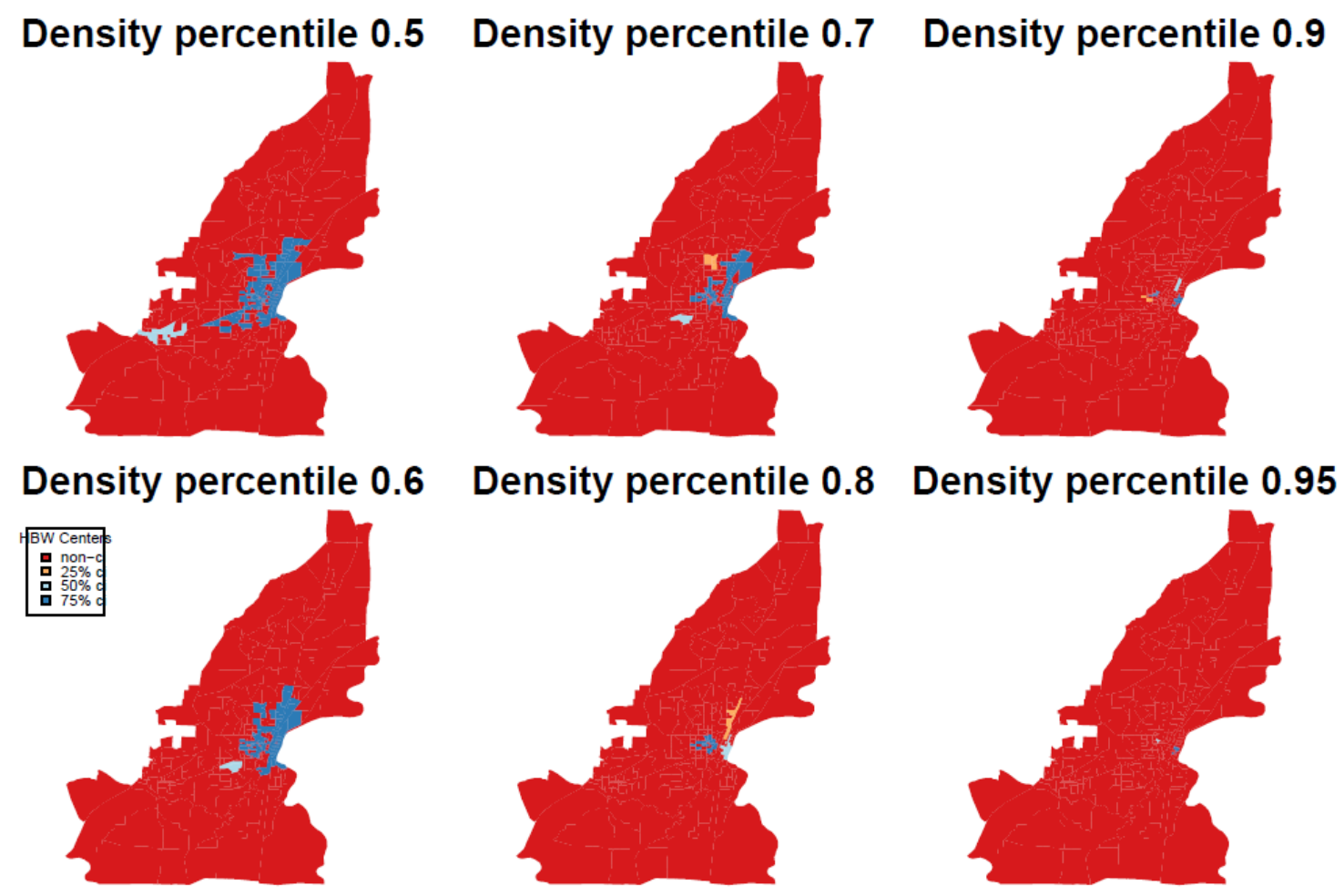

Figure 5.6: Sensitivity analyses of cutoff values for HBW trips

In addition to the travel market baskets, the travel cost of accessing the baskets identified with various cutoff values have been calculated, and are listed in Table 5.1. This also provides information to verify reasonable cutoff values. Each TAZ's travel costs have been aggregated by trip purpose and income group. The calculation process is the same as in the Portland study (see appendix C), so the results are comparable.

In Table 5.1, when the density cutoff increases, the mean, median, and $3^{\text {rd }}$ quartile travel costs are stable while the minimum and the $1^{\text {st }}$ quartile significantly decrease; the maximum slightly increases. From the analysis, a density cutoff larger than the 60th percentile is not suitable for Corvallis. 
Travel cost is not sensitive to the total cutoff; it changes little as the total cutoff increases. This is also observed from the Portland results. Further, Portland's travel cost has little change — unlike Corvallis' - when the density cutoff increases from the 50th to the 70th percentile. The 50th percentile is used in Corvallis for both density and total cutoffs.

The sensitivity analysis helps planners to determine reasonable cutoff values.

Table 5.1: Travel costs with various cutoff values

\begin{tabular}{|c|c|c|c|c|c|c|c|}
\hline \multicolumn{2}{|c|}{ Cutoff (percentile) } & \multicolumn{6}{|c|}{ Descriptive statistics } \\
\hline Density & Total & Min. & 1st Qu. & Median & Mean & 3rd Qu. & Max. \\
\hline \multirow[t]{3}{*}{50} & 25 & 0.59 & 0.77 & 1.00 & 1.24 & 1.63 & 3.84 \\
\hline & 50 & 0.59 & 0.77 & 1.01 & 1.24 & 1.63 & 3.84 \\
\hline & 75 & 0.57 & 0.76 & 0.99 & 1.24 & 1.62 & 3.83 \\
\hline \multirow[t]{3}{*}{60} & 25 & 0.49 & 0.72 & 0.97 & 1.20 & 1.64 & 3.86 \\
\hline & 50 & 0.49 & 0.72 & 0.97 & 1.20 & 1.64 & 3.86 \\
\hline & 75 & 0.48 & 0.71 & 0.97 & 1.20 & 1.63 & 3.87 \\
\hline \multirow[t]{3}{*}{70} & 25 & 0.44 & 0.69 & 0.99 & 1.18 & 1.62 & 3.90 \\
\hline & 50 & 0.44 & 0.69 & 0.99 & 1.19 & 1.62 & 3.90 \\
\hline & 75 & 0.42 & 0.68 & 0.98 & 1.18 & 1.62 & 3.90 \\
\hline \multirow[t]{3}{*}{80} & 25 & 0.37 & 0.65 & 0.96 & 1.16 & 1.61 & 3.93 \\
\hline & 50 & 0.36 & 0.63 & 0.96 & 1.16 & 1.62 & 3.96 \\
\hline & 75 & 0.39 & 0.61 & 0.97 & 1.15 & 1.63 & 3.98 \\
\hline \multirow[t]{3}{*}{90} & 25 & 0.27 & 0.55 & 0.95 & 1.10 & 1.52 & 4.04 \\
\hline & 50 & 0.25 & 0.54 & 0.91 & 1.07 & 1.46 & 4.03 \\
\hline & 75 & 0.22 & 0.50 & 0.93 & 1.06 & 1.45 & 4.08 \\
\hline \multirow[t]{3}{*}{95} & 25 & 0.19 & 0.49 & 0.97 & 1.08 & 1.54 & 4.11 \\
\hline & 50 & 0.19 & 0.49 & 0.97 & 1.08 & 1.54 & 4.11 \\
\hline & 75 & 0.21 & 0.48 & 0.95 & 1.07 & 1.52 & 4.10 \\
\hline
\end{tabular}


Figure 5.7 shows maps of activity centers for each of the trip purposes with the density cutoff of $50 \%$ and total cutoff of $50 \%$.
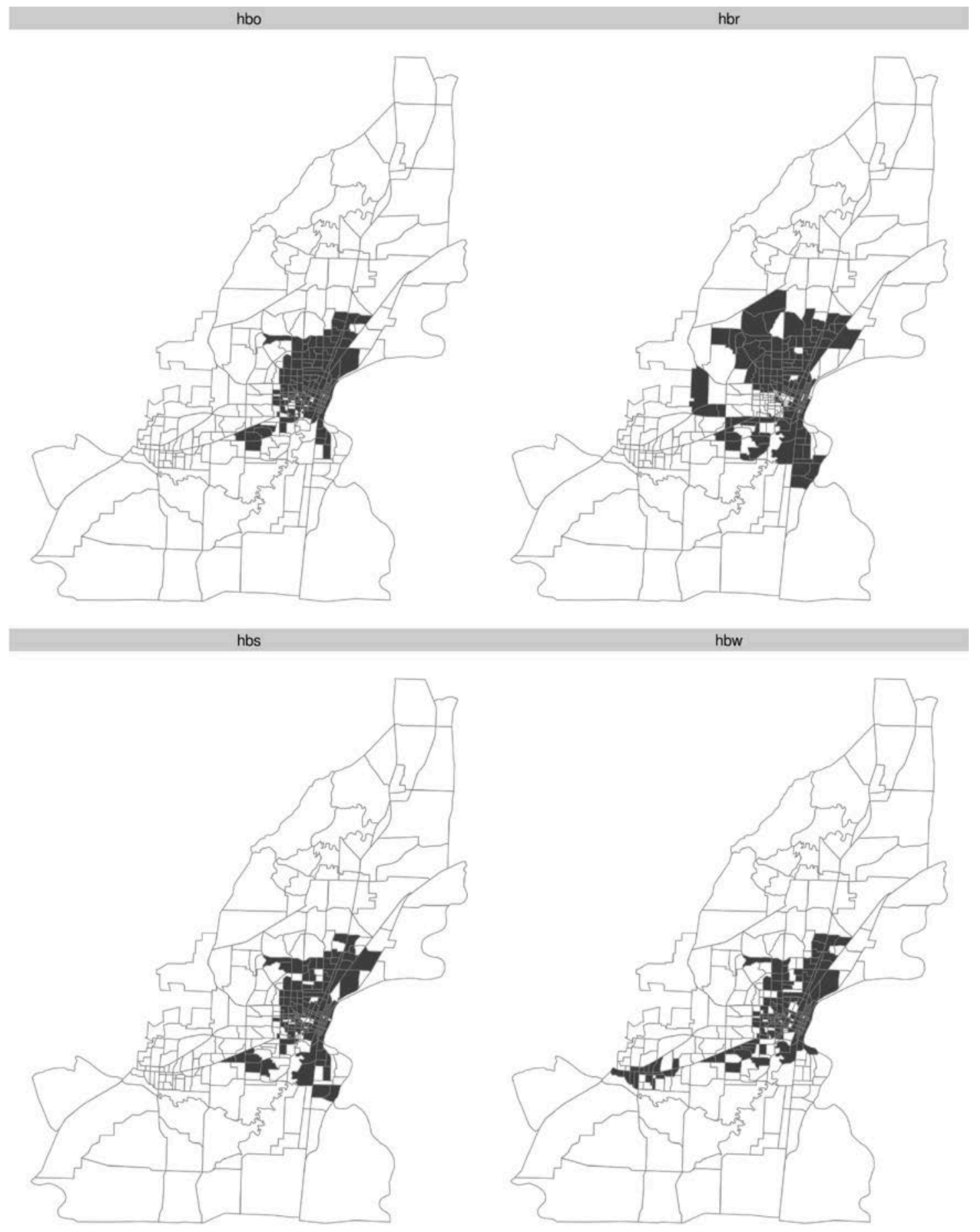

Figure 5.7: Activity centers by trip purpose for Corvallis identified with the cluster-based approach 
Figures 5.8 to 5.11 show results from the cluster-based approach for Corvallis. In figure 5.8, the pattern observed in Portland emerges again in Corvallis: With the cluster-based approach, lowincome households have higher travel costs, reversing the pattern in the results from the surveybased approach.

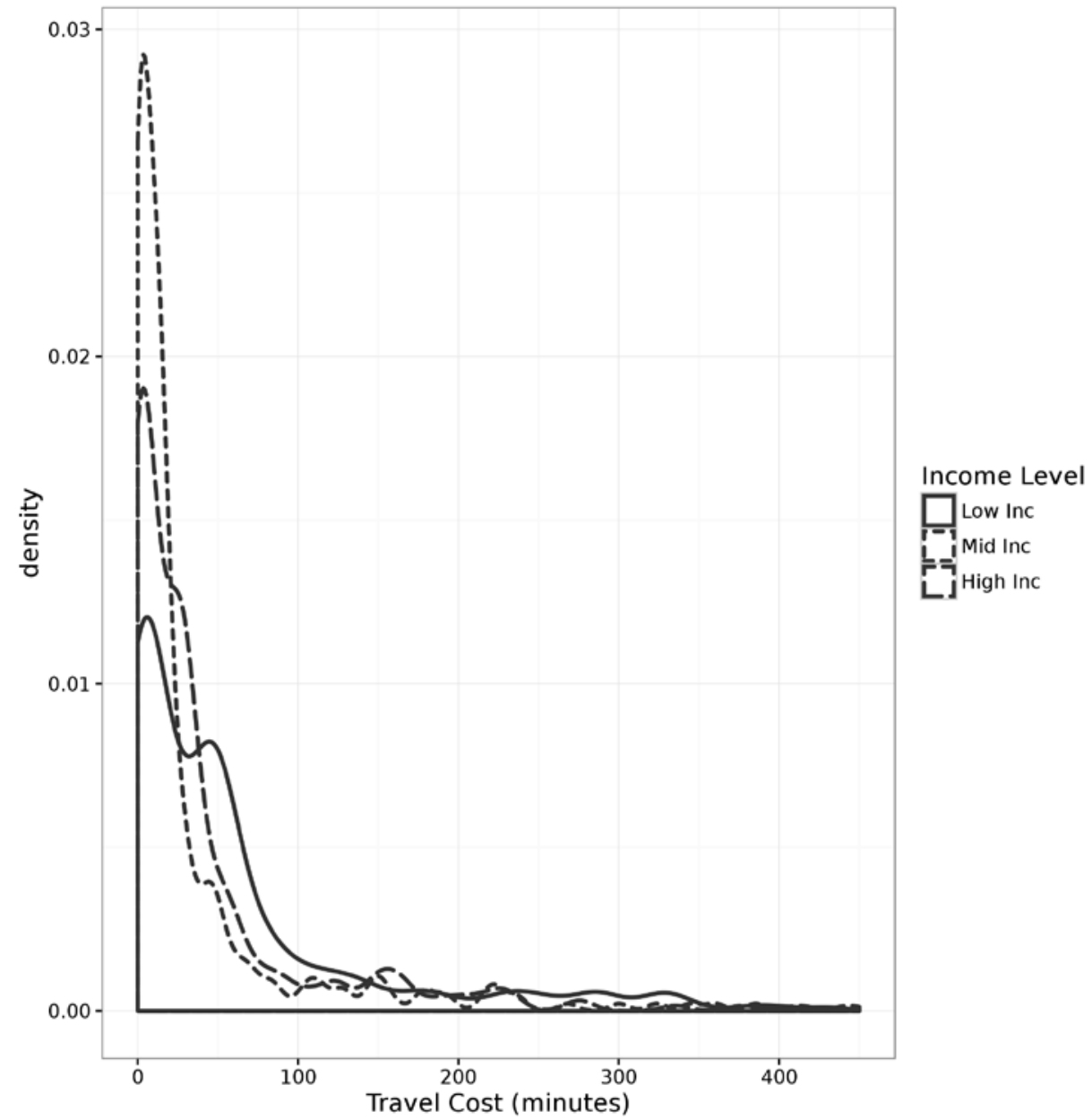

Figure 5.8: Density distributions of travel costs by income level for Corvallis with the 2010 CAMPO JEMnR model data 
The differences in travel costs by trip purpose are much smaller in Corvallis (figure 5.9) than in Portland, likely due to the fact that the centers identified for different purposes largely overlap with each other (figure 5.7). Figures 5.10 and 5.11 corroborate this observation.

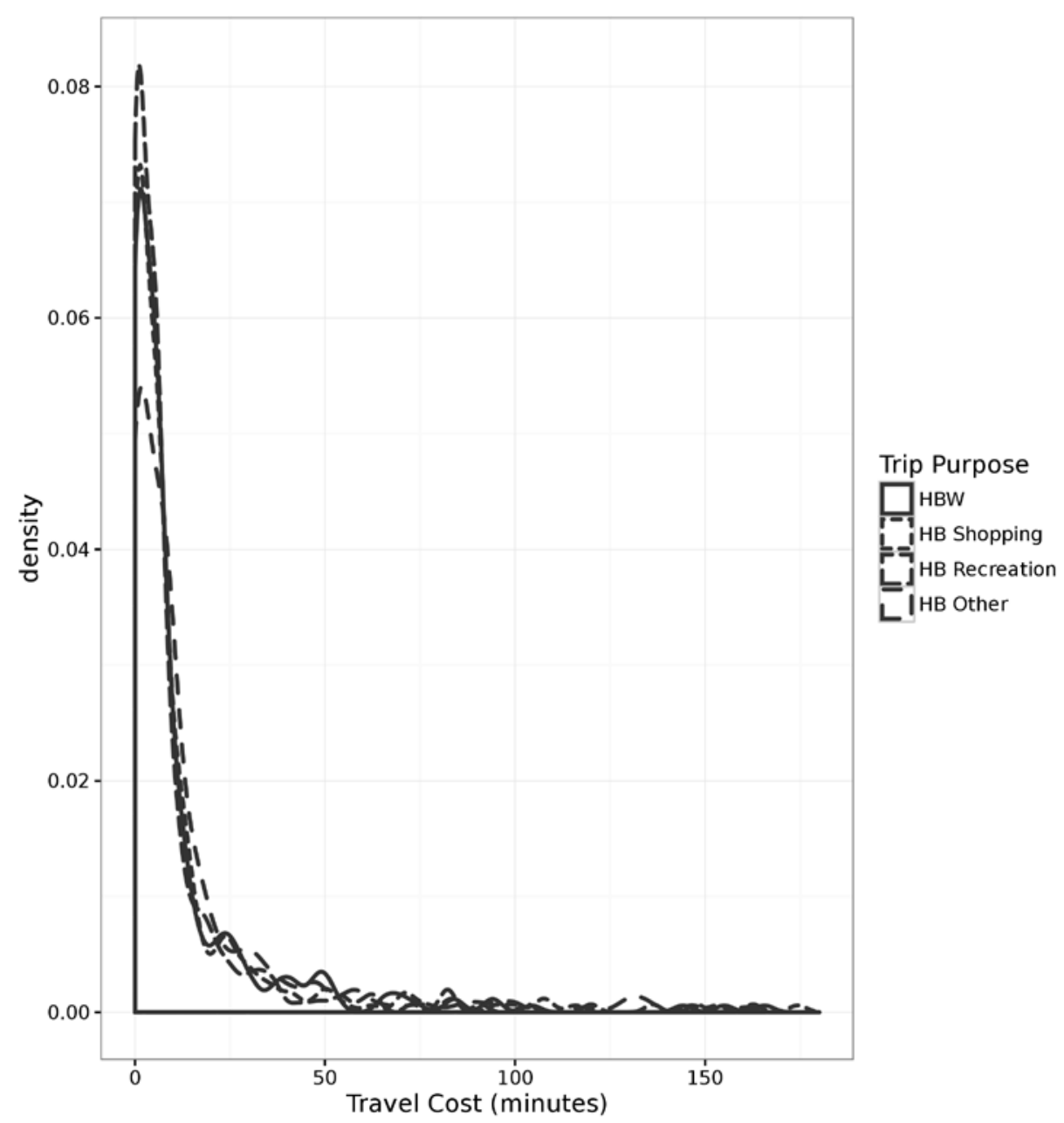

Figure 5.9: Density distributions of travel costs by trip purpose for Corvallis with the 2010 CAMPO JEMnR model data 


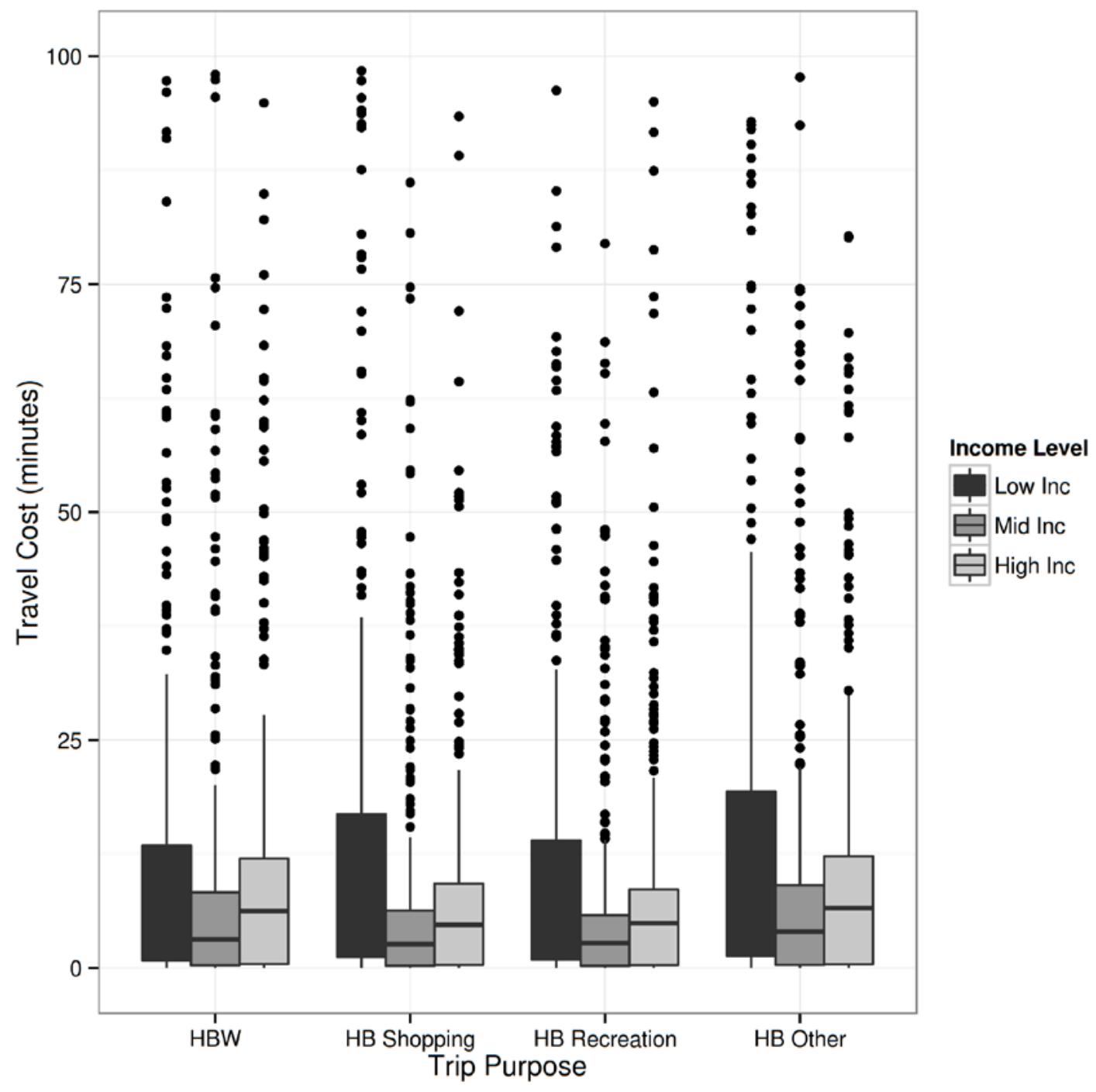

Figure 5.10: Box plot of travel costs by income level and trip purpose for Corvallis with the 2010 CAMPO JEMnR model data 

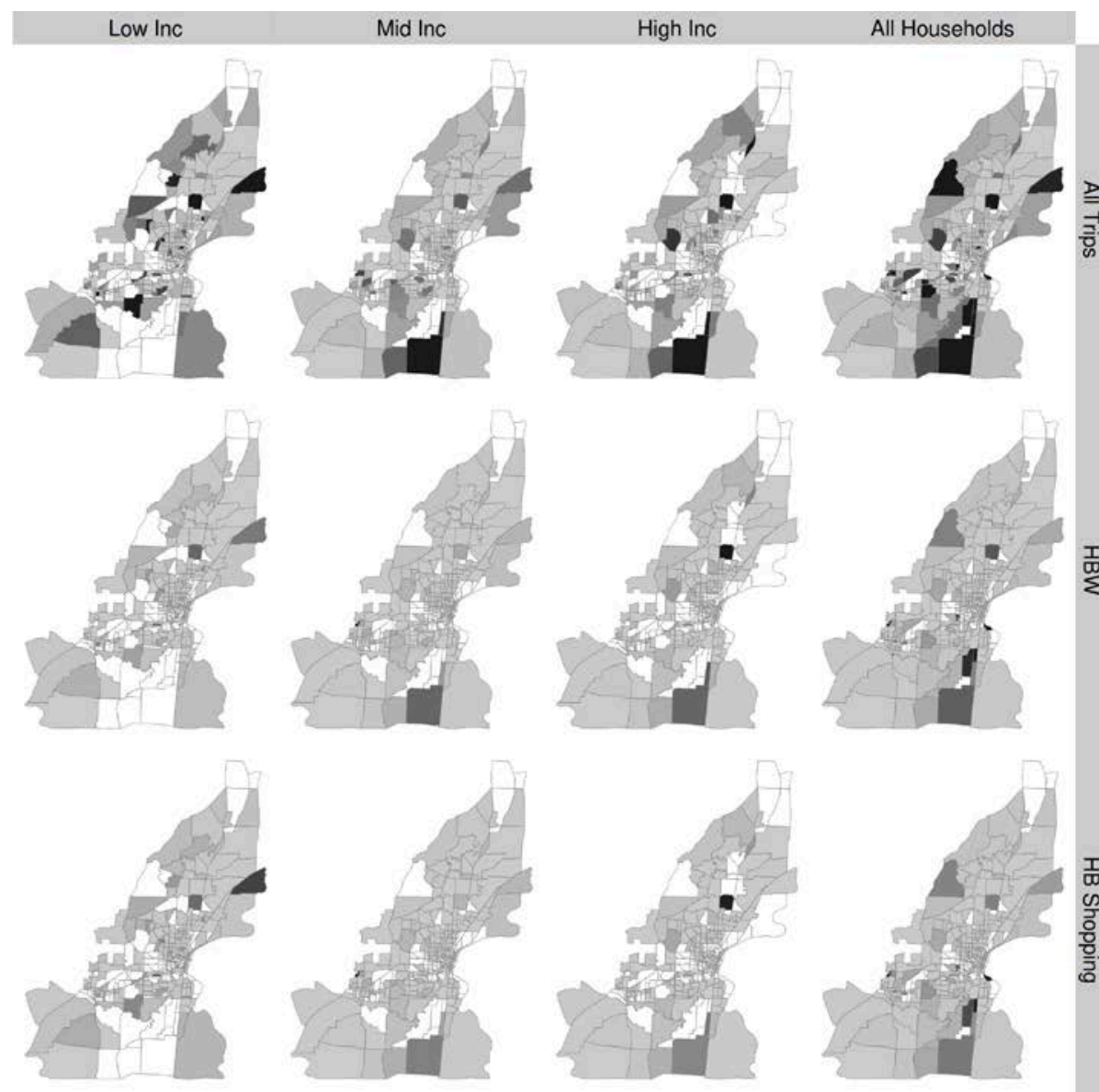

\section{Travel Cost (minutes)}
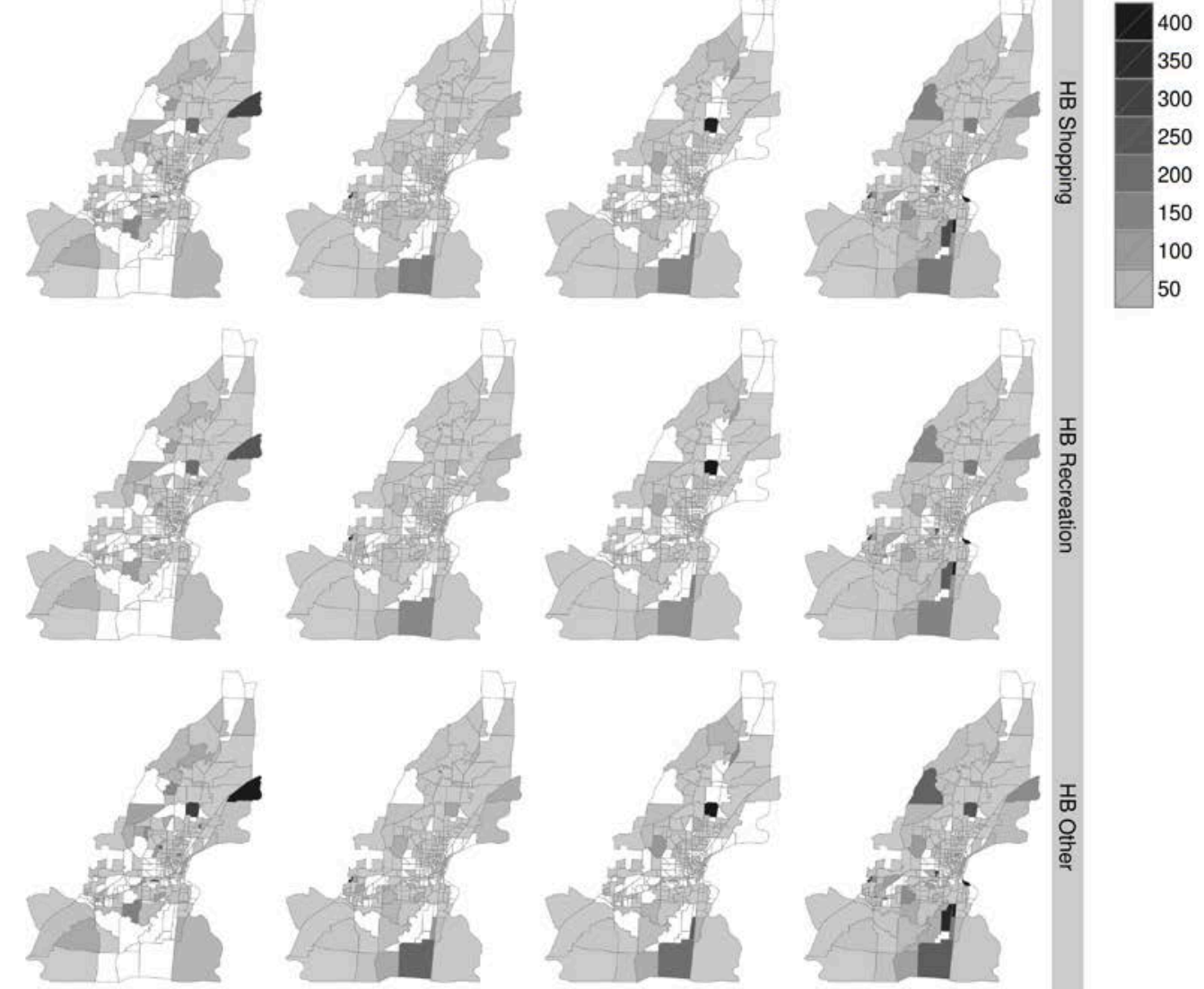

Figure 5.11: TAZ-level travel costs by income level and trip purpose for Corvallis with the 2010 CAMPO JEMnR model data 


\subsection{APPLICABILITY TESTING}

We set out to develop a Transportation Cost Index (TCI) that would apply in contexts including trend monitoring, policy screening, and scenario assessments. The survey-based approach can be used in trend monitoring, while the cluster-based approach is more useful for the latter two applications. To demonstrate the applicability of TCI in different situations, we apply the two approaches to two questions, first to monitor the trend of travel costs between 1994 and 2011 for Portland, and then to evaluate outcomes of transportation scenarios for Corvallis.

\subsection{TREND MONITORING}

Since the survey-based approach primarily relies on travel survey data as input, it can be easily applied to different historical periods or regions for which travel survey data are available. To showcase a trend monitoring application, we apply it to Portland with 1994 travel survey data.

To do this, we use the steps described in section 4.1. When classifying households as low-, middle-, or high-income, we use the ranges $<\$ 25 \mathrm{~K}, \$ 25-50 \mathrm{~K}$, and $\$ 50 \mathrm{~K}+$ (roughly equivalent, adjusted for inflation, to the thresholds used in the 2011 application). We re-use the per-distance monetary costs by mode and wage rate we established for 2011 (tables 3.1 and 3.2), because such information for 1994 is hard to find. As long as we use minutes as the units for travel costs, those parameters do not need to be adjusted for inflation.

The 1994 travel survey includes trip diaries for two days (the 2011 OHAS includes only one-day diary). We use the trips in one of these two days (the weekday if the other day is a weekend or day one if both days are weekdays).

One difference between the 2011 and 1994 survey data is that the household-level weights are available for the 2011 survey data, but not for 1994. Because of this difference, it is hard to assess how much of the trends we observe is real, and how much is due to weighting.

Figures 6.1 to 6.5 show the results for Portland in 1994.

Figure 6.1 shows the distributions of 1994 household-level travel costs by income level. Compared with 2011, the difference of travel costs between income groups is smaller in 1994 when the peaks of these distributions largely overlap. 


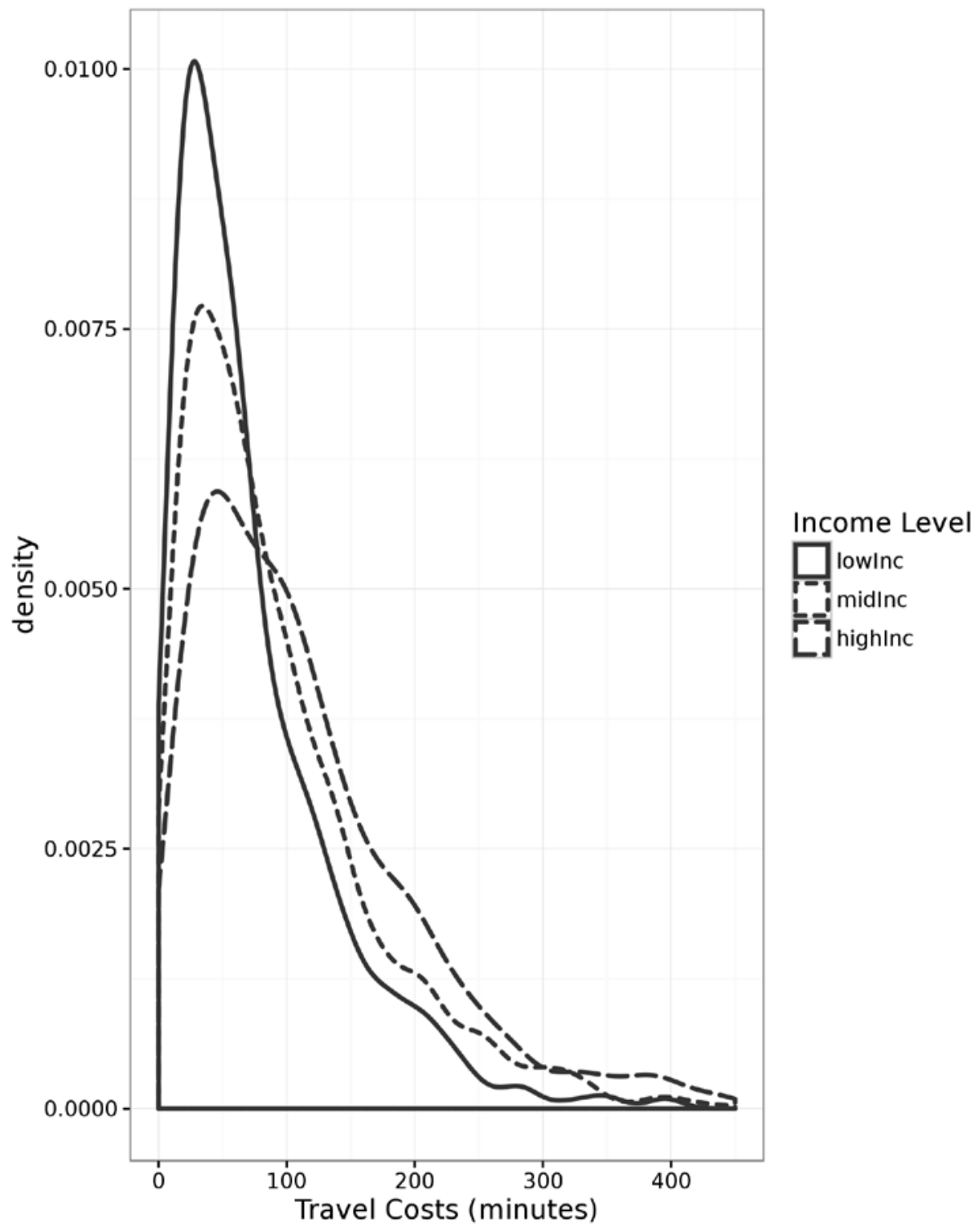

Figure 6.1: Density distributions of household-level travel costs by income level for Portland with 1994 travel survey data 
As in 2011, the household-level travel costs are highly correlated with household size (figure 6.2) and influenced by the presence of children (figure 6.3).

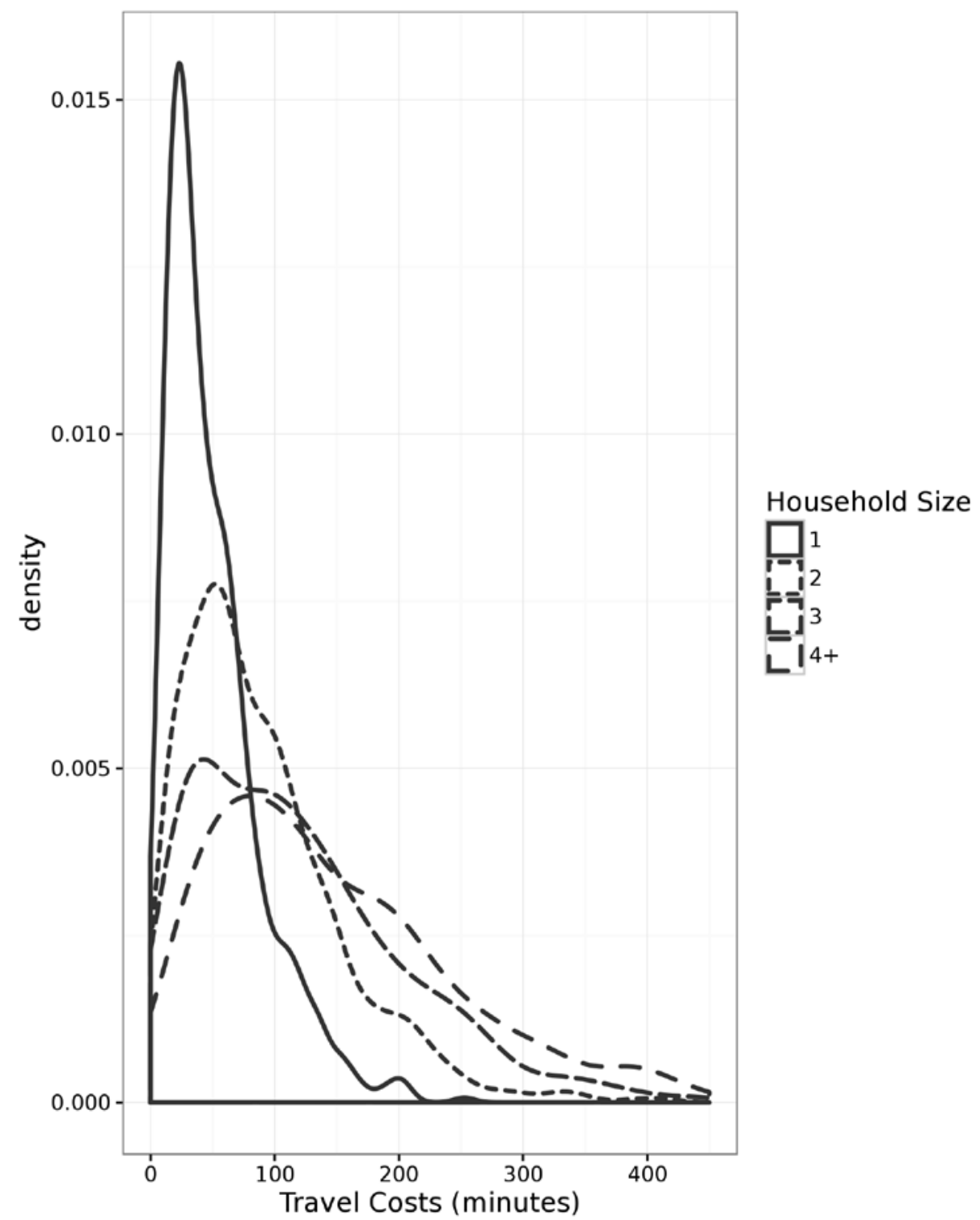

Figure 6.2: Density distributions of household-level travel costs by household size for Portland with 1994 travel survey data 


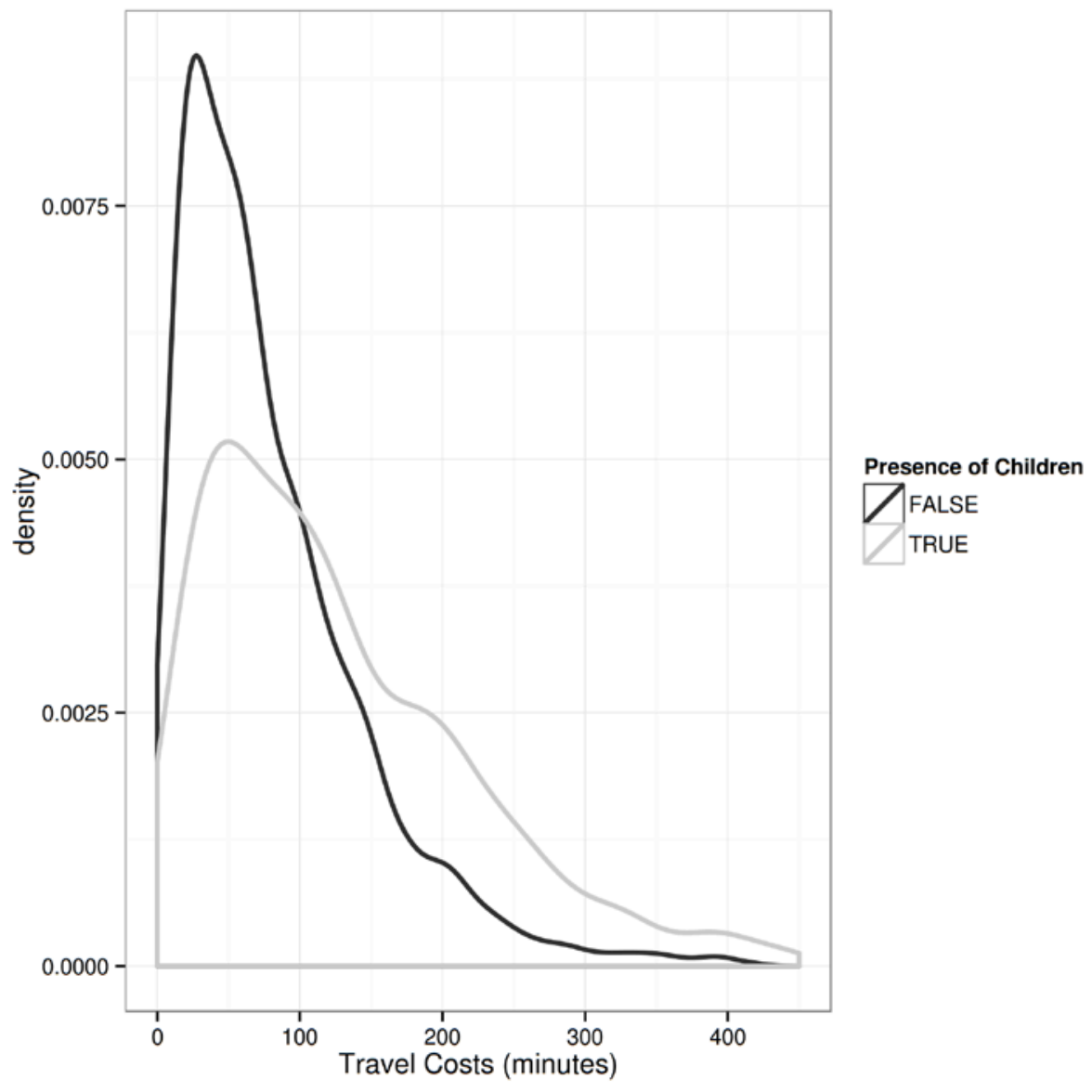

Figure 6.3: Density distributions of household-level travel costs by presence of children for Portland with 1994 travel survey data 
Similarly, the difference in household-level travel costs across income groups almost disappears when household size is factored in (figure 6.4). The distributions of average travel costs per person for the three income groups are almost identical in 1994; their difference grew bigger in 2011 (figure 4.4 in chapter 4).

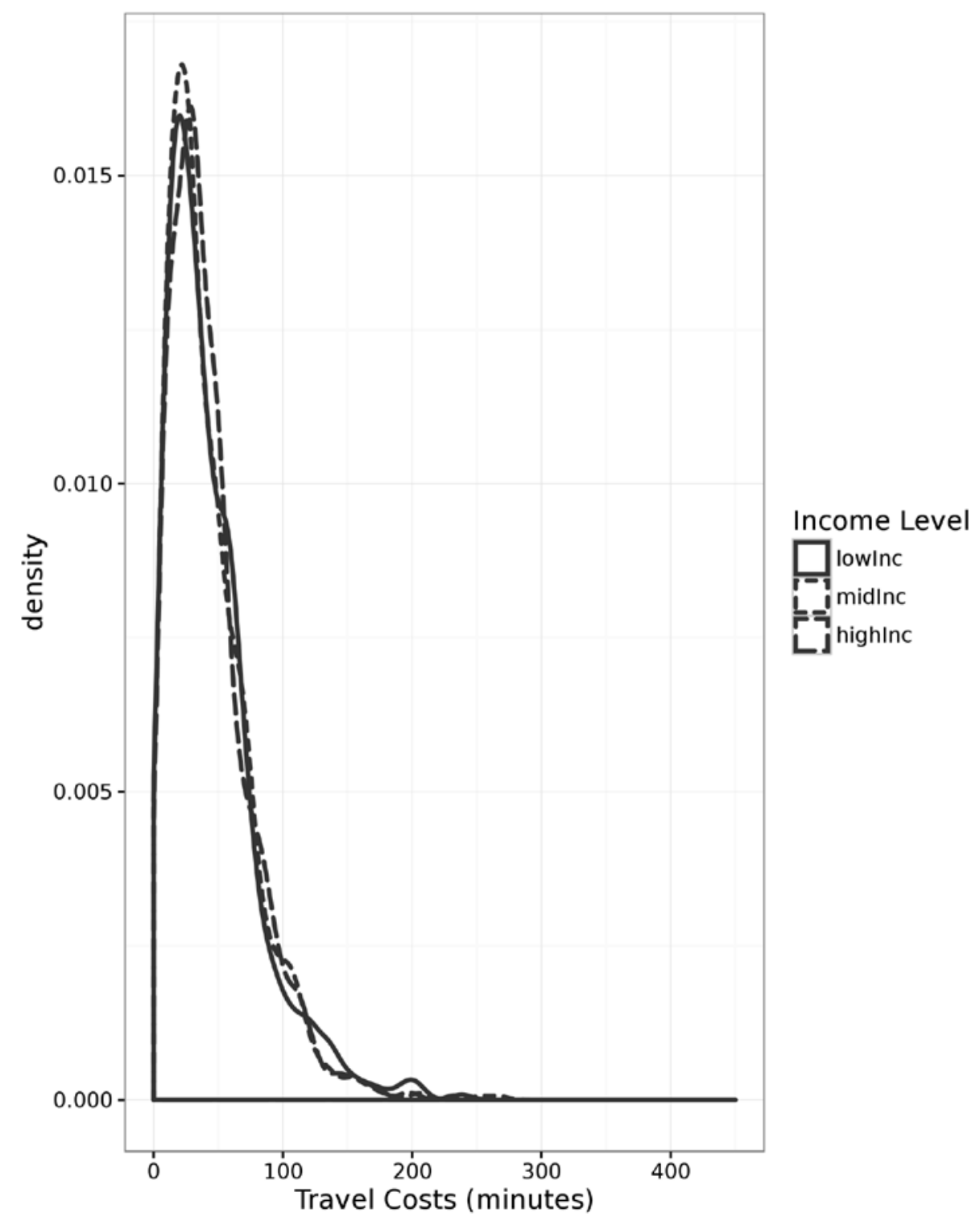

Figure 6.4: Density distributions of average travel costs per person by income for Portland with 1994 travel survey data 
Figure 6.5 shows trip-level travel costs by trip purpose and the traveler's household income in 1994. Comparing 1994 to 2011, the variations in the trip-level travel costs (measured by the height by the shaded boxes in figures 6.5 and 4.5 (chapter 4), respectively) vary between the two years, but the relationship across income groups is stable.

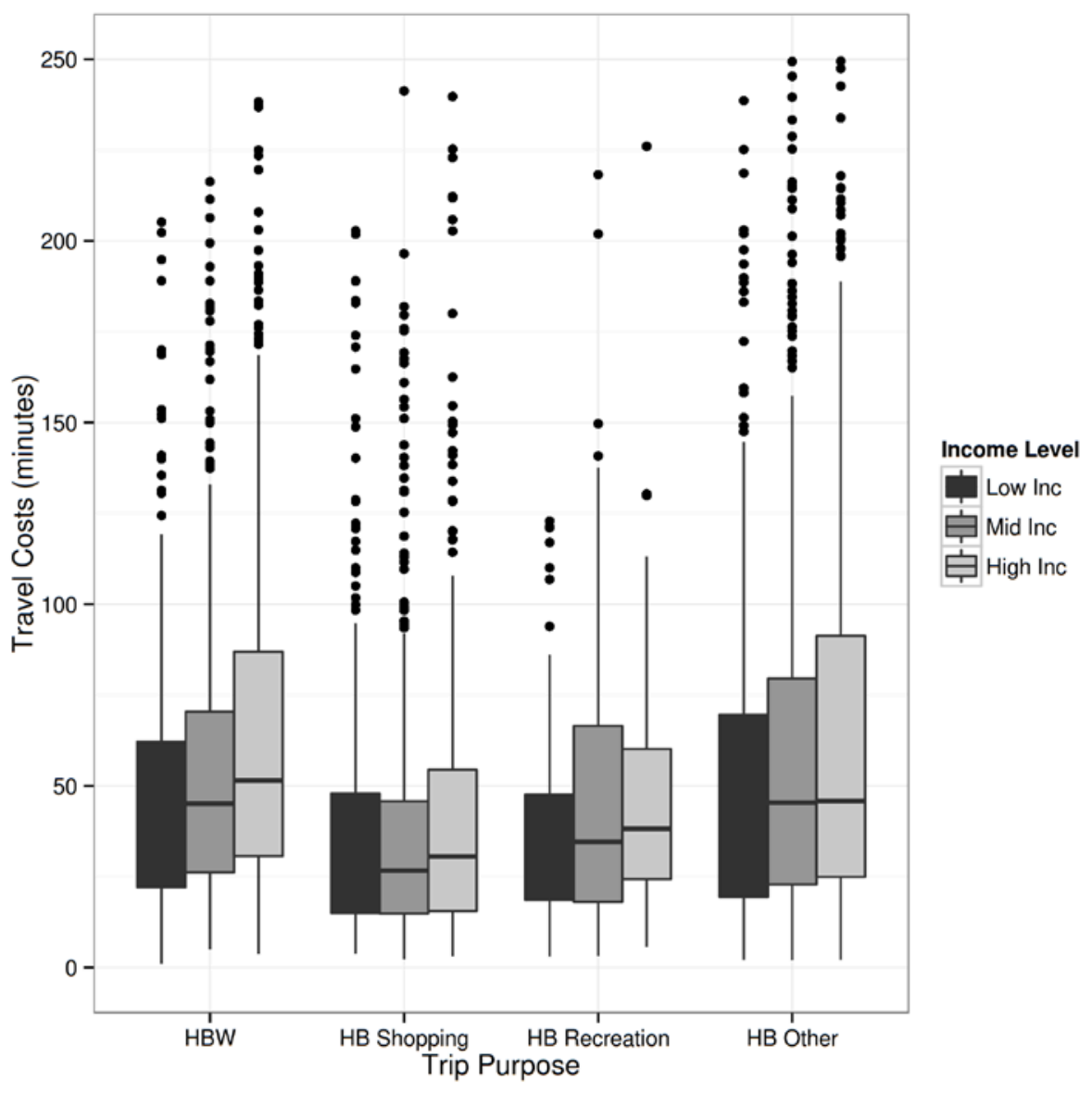

Figure 6.5: Box plots of trip-level travel costs by income level and trip purpose for Portland with 1994 travel survey data

\subsection{SCENARIO EVALUATION}

We expect that two types of application contexts involve scenario evaluation: 1.) Evaluating the effects of potential transportation network and/or land use changes in a screening or rapid response approach that does not entail running a travel demand model (TDM); and 2.) Estimating the effects of potential transportation network and/or land use changes in a more comprehensive analysis approach involving the use of a TDM (potentially with a land use model). In this subsection, we demonstrate the application of TCI in both contexts. Since the applications of TCI in these two contexts are almost limitless, the demonstrations are examples, instead of an exhaustive study. For the rapid response approach, we demonstrate the application of the cluster-based approach in two hypothetical scenarios for Corvallis that are set up in a way 
that is common in rapid response evaluations; for comprehensive analysis, we apply TCI to evaluate two 2030 transportation scenarios for Corvallis.

\subsubsection{Rapid Response Application}

In a rapid response situation, it is common to hypothesize a change to a certain input (or set of inputs) and to apply performance measures or evaluation models to assess the impact of such changes. Two hypothetical scenarios are created based on the 2010 Corvallis data: in scenario A, the auto travel time is reduced by half while everything else remains the same; in scenario $\mathrm{B}$, the transit travel time is reduced by half while everything else remains the same. Since auto is the predominant mode of travel in Corvallis, we expect to see larger impacts of scenario A on TCI, and since there is difference in mode shares spatially and across socio-demographical groups, we expect the effects of scenario B to vary - we have not assumed households would shift mode in response to the travel time deduction.

Figures 6.6 and 6.7 show the travel costs by income groups for scenario A and scenario B, respectively. Compared with the baseline (2010, in figure 5.8), halving auto travel time (scenario A) drastically reduces the travel costs, while halving bus travel time (scenario B) has little effect on travel costs, which makes sense given the low bus mode share. Similar effects are observed in travel costs plotted by trip purpose and income group (figures 6.8 and 6.9) 


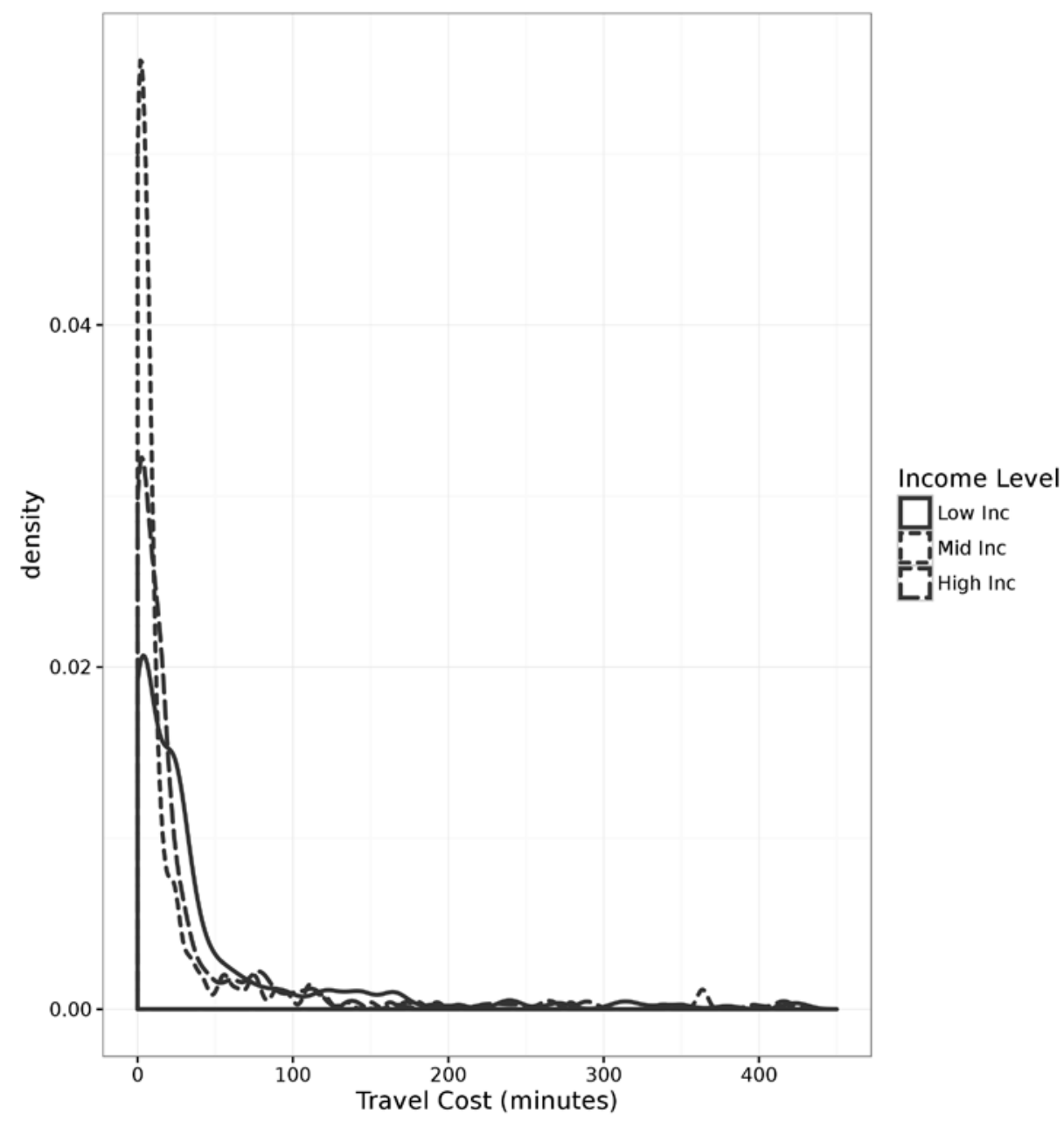

Figure 6.6: Density distributions of travel costs by income level for Corvallis Scenario A (halving auto travel time and leaving all other data unchanged from the 2010 CAMPO JEMnR model) 


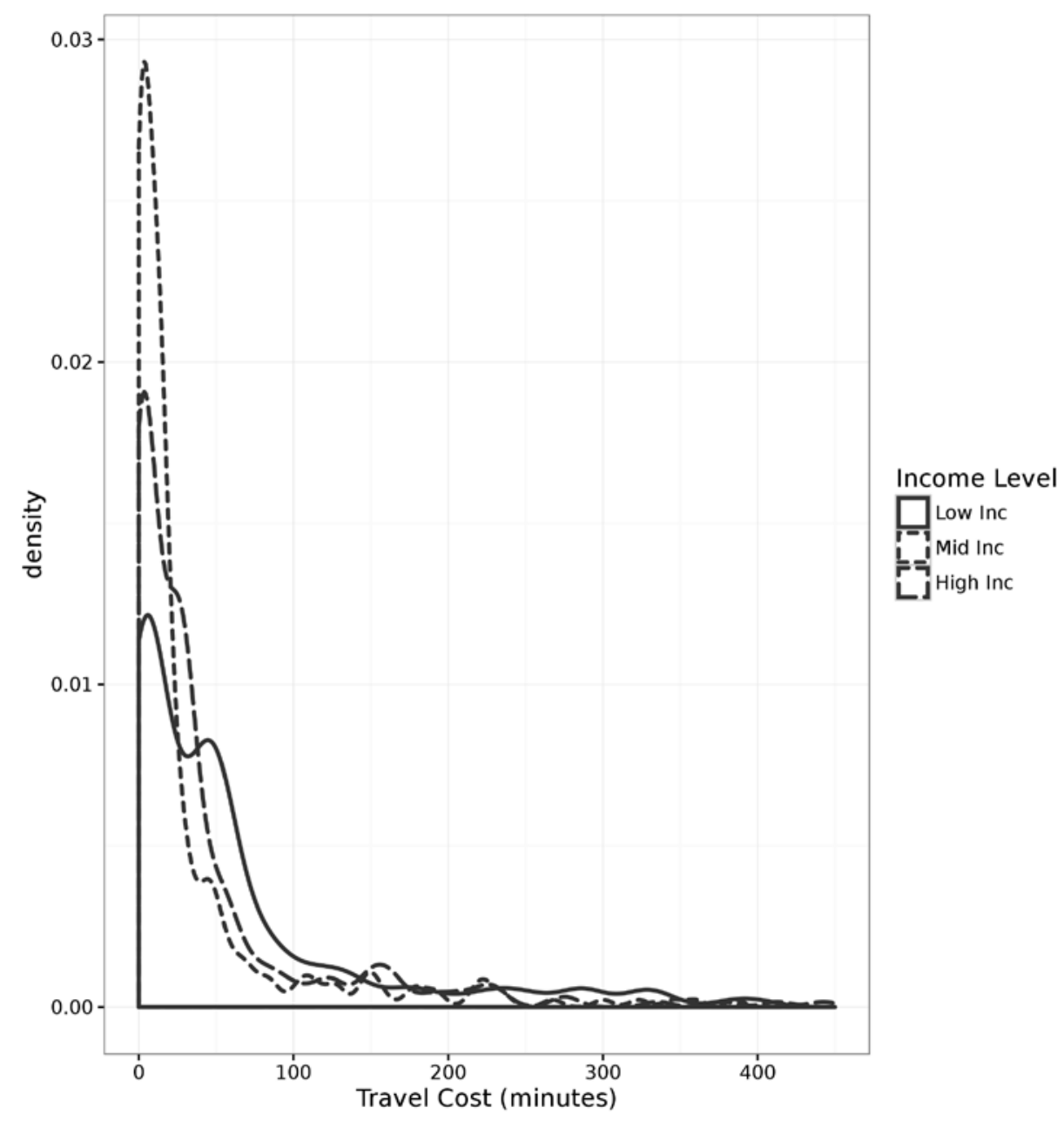

Figure 6.7: Density distributions of travel costs by income level for Corvallis Scenario B (halving bus travel time and leaving all other data unchanged from the 2010 CAMPO JEMnR model) 


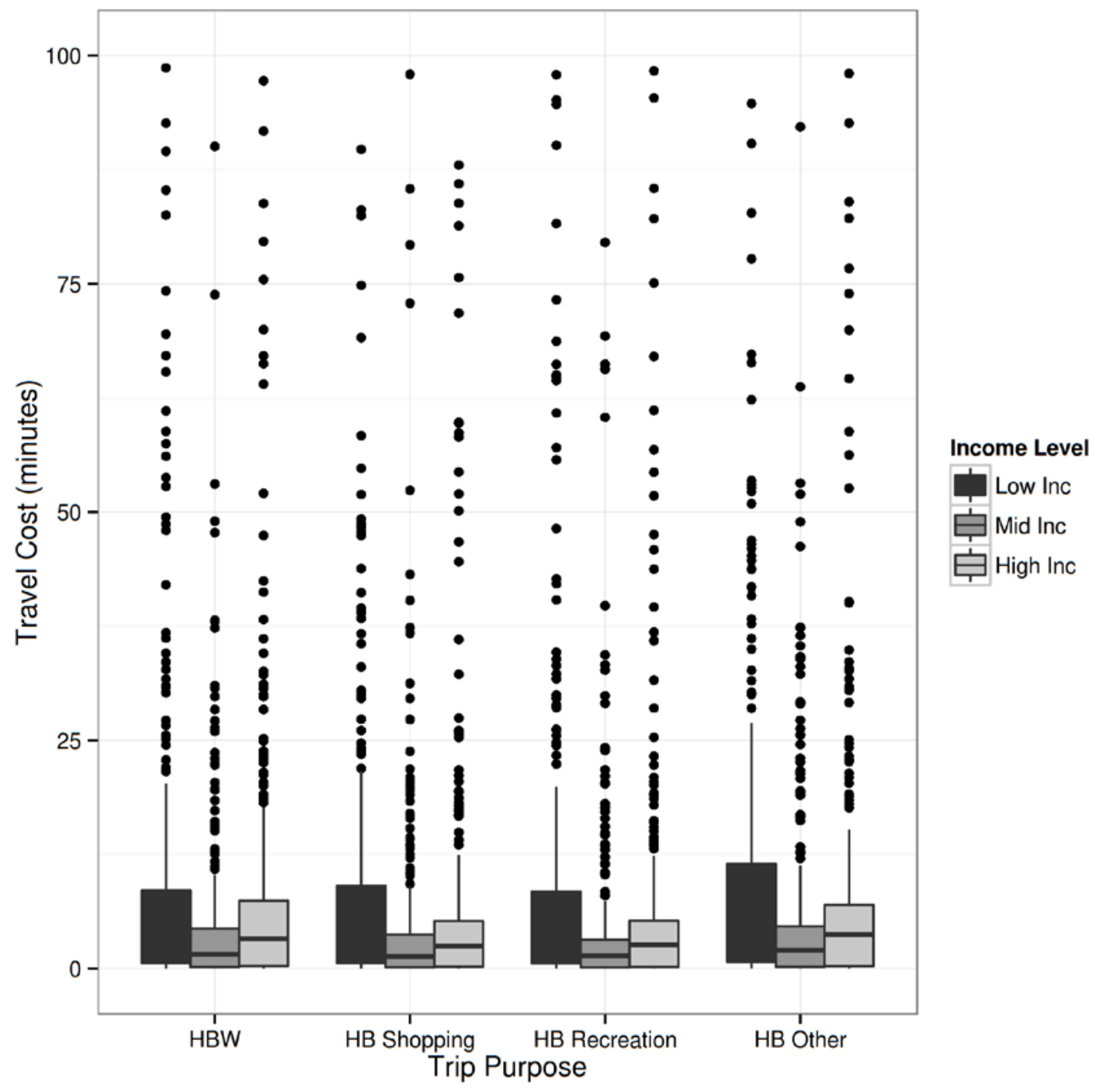

Figure 6.8: Box plot of travel costs by trip purpose and income level for Corvallis Scenario A (halving auto travel time and leaving all other data unchanged from the 2010 CAMPO JEMnR model) 


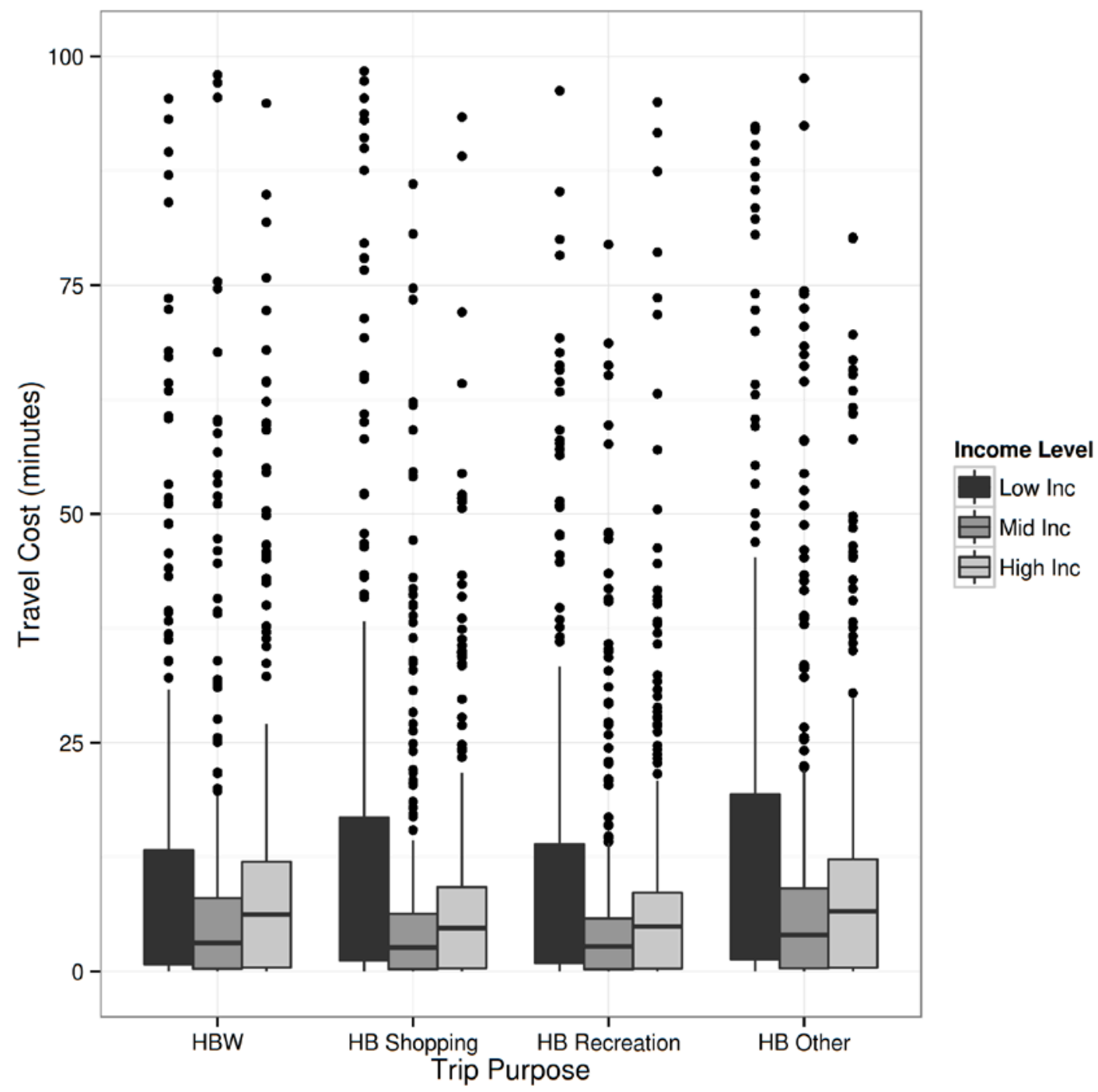

Figure 6.9: Box plot of travel costs by trip purpose and income level for Corvallis Scenario B (halving bus travel time and leaving all other data unchanged from the 2010 CAMPO JEMnR model)

In terms of spatial patterns, scenario A almost halves the travel costs universally (figure 6.10, compared with figure 5.11), while there is little discernable reduction of travel costs in scenario $\mathrm{B}$ (figure 6.11). 

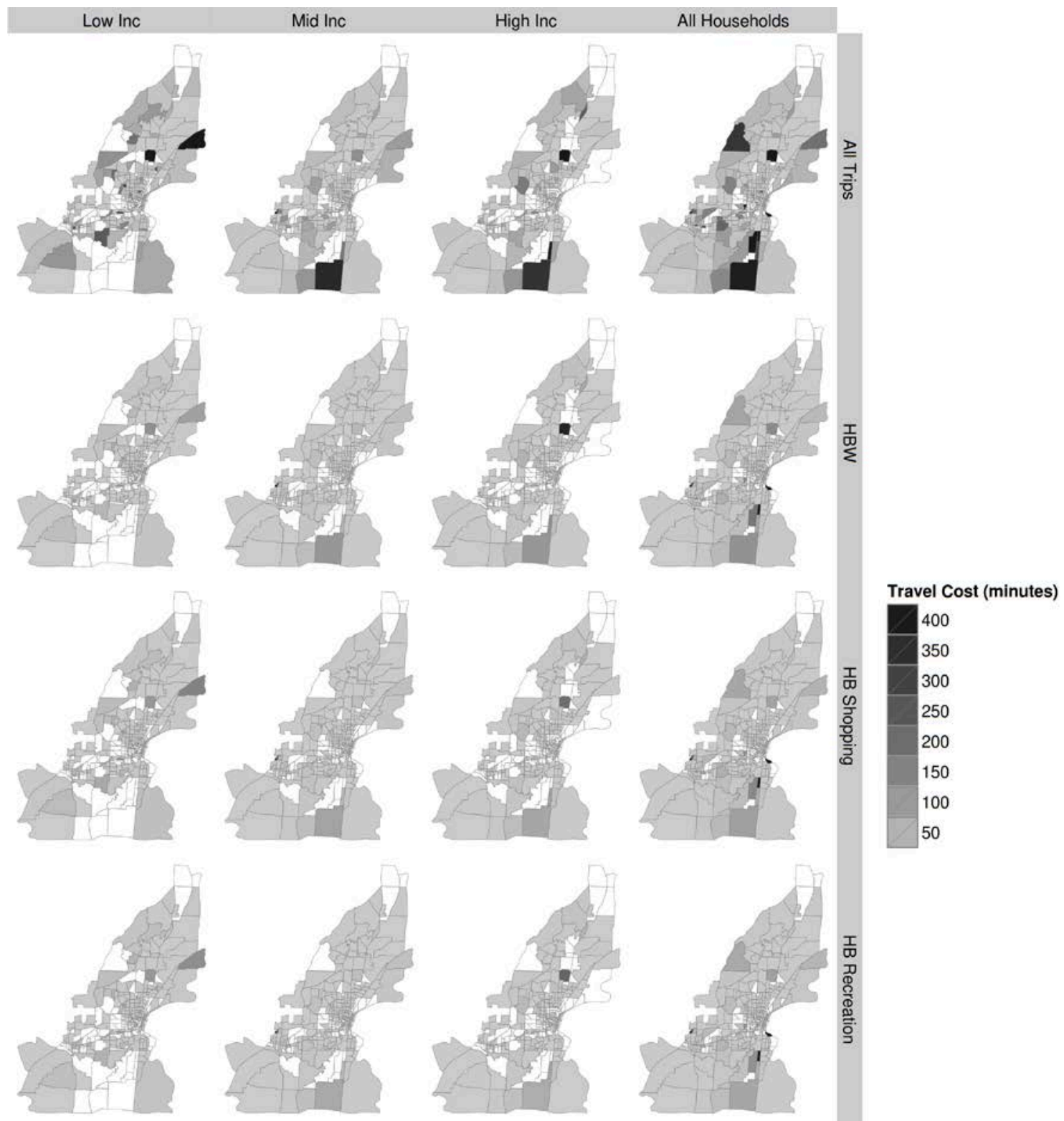

畐
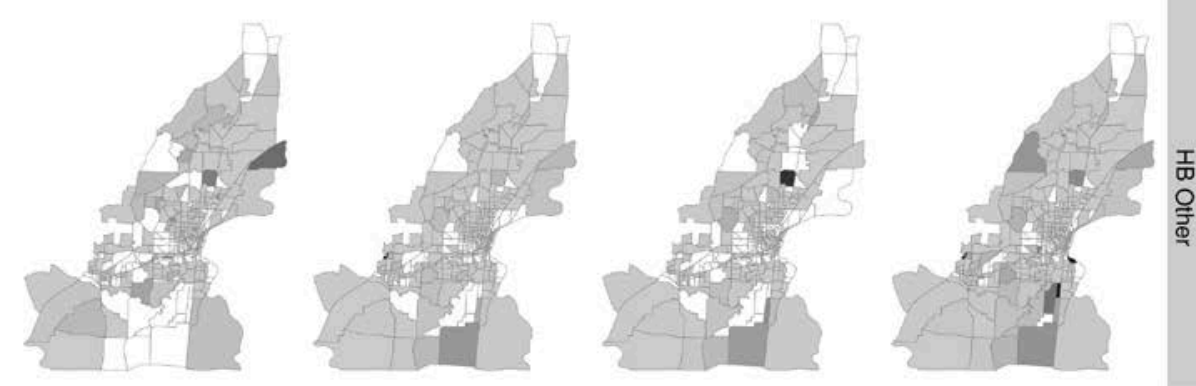

Figure 6.10: TAZ-level travel costs by income level and trip purpose for Corvallis Scenario A (halving auto travel time; leaving all other data unchanged from the 2010 CAMPO JEMnR model) 

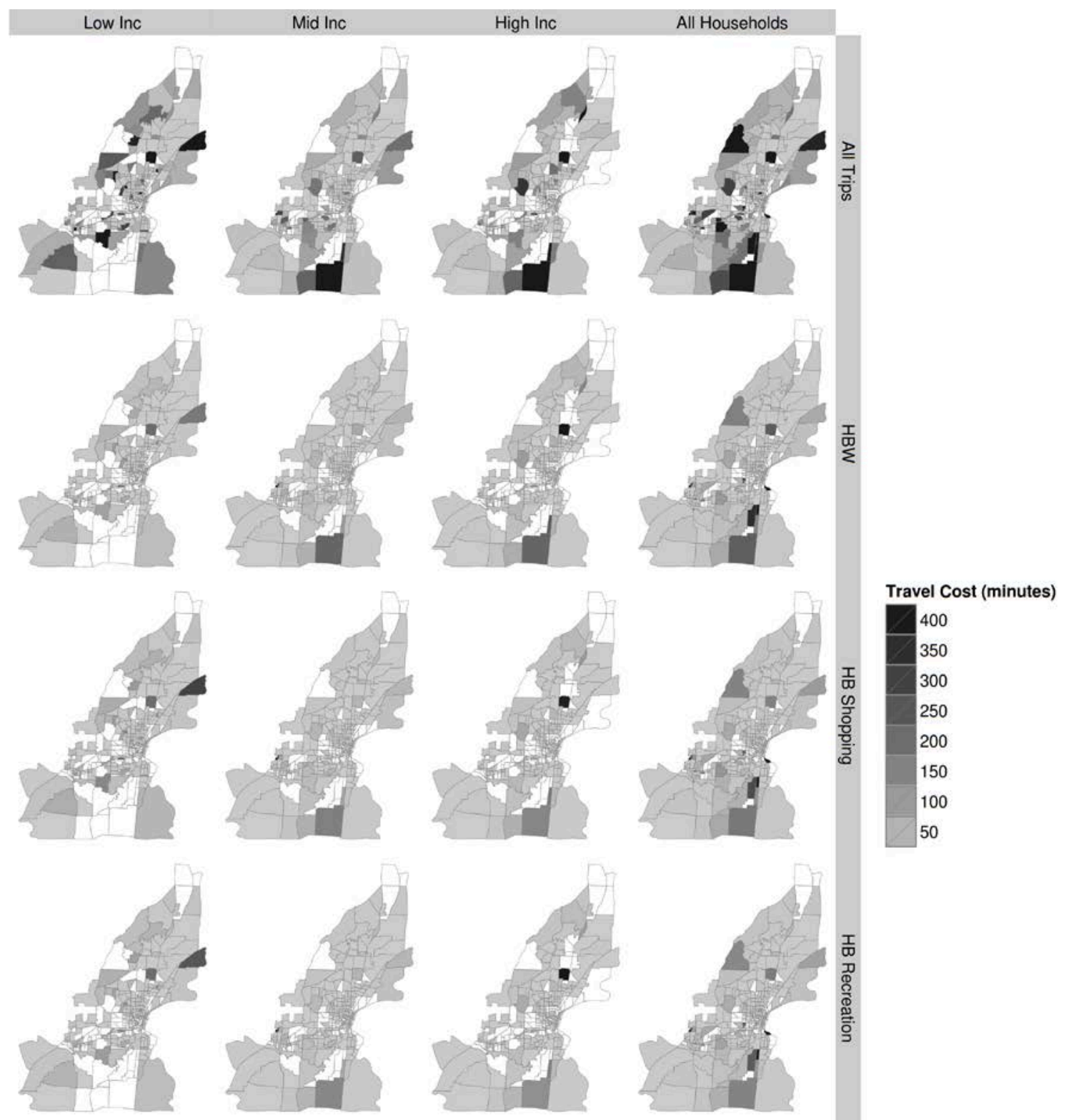

面
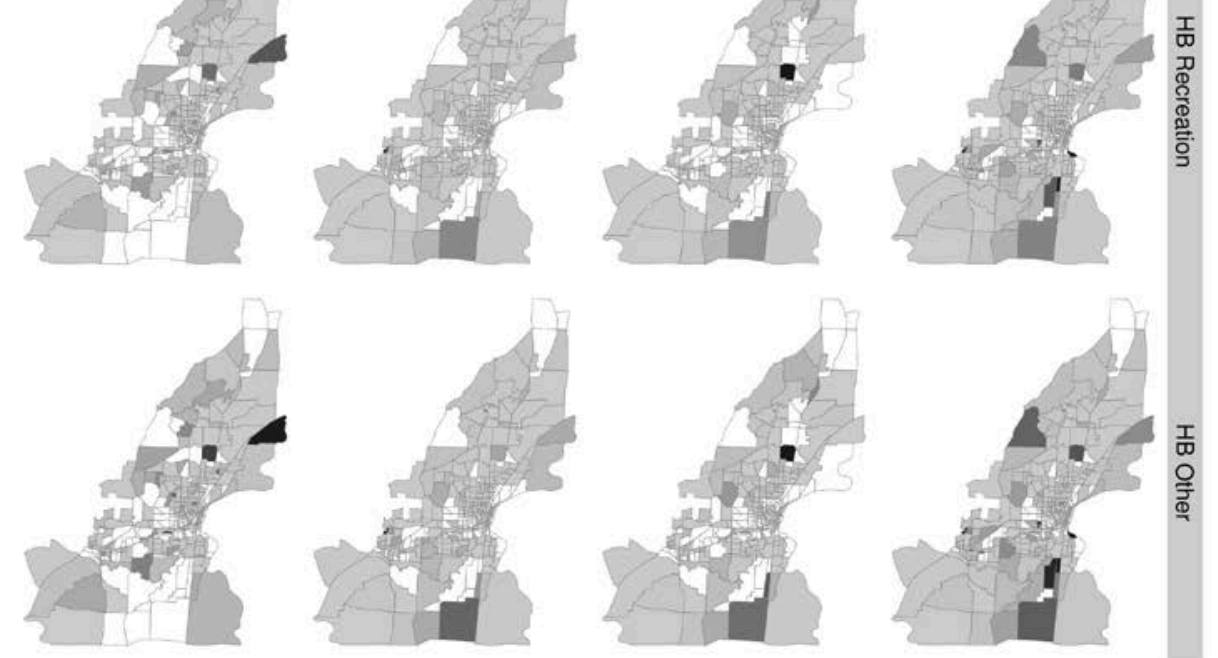

Figure 6.11: TAZ-level travel costs by income level and trip purpose for Corvallis Scenario B (halving bus travel time; leaving all other data unchanged from the 2010 CAMPO JEMnR model) 


\subsubsection{Comprehensive Analysis}

In a comprehensive analysis application, users evaluate the effects of various scenarios on travel costs via working with simulation models. TCI reads in results from TDM simulations and generates analysis for TDM outputs for each scenario. TDMs, usually integrated with land use models, enable evaluations of a large set of possible scenarios that may affect travel costs.

As an example, we use TCI to evaluate the impacts of two future scenarios considered in Corvallis' last RTP process: 2030 Preferred scenario (2030Preferred) and an altered 2030 Preferred scenario (2030Preferred_Scen1). In these scenarios, both the transportation and land use systems change from the base year (2010). The difference is subtle, as 2030Preferred_Scen1 was derived from 2030Preferred. We assess their impacts by a procedure similar to that we used for rapid response applications.

In both scenarios, the travel costs for low-income households decrease, while those for highincome households increase somewhat (figures 6.12 and 6.13, comparing with Figure 5.8), as the density curve for low-income households moves closer to 0 , while that for high-income households moves away from 0 . If these effects can be verified, it is a laudable if small improvement in transportation equity.

Looking into travel costs by trip purpose and income group (figures 6.14 and 6.15), the two scenarios are effective at reducing travel costs of HB Shopping, HB Recreation, and HB Other trips for low-income households, while they experience a small increase in travel costs of HB Work trips. High-income households see a small increase in travel costs for all trip purposes, while middle-income households have largely stable travel costs. Again, the impacts are very similar between the two scenarios.

Geographically, the impacts of the scenarios vary greatly due to changes in both transportation and land use systems. Traffic Analysis Zones (TAZs) with fewer than three households and thus fewer home-based trips are excluded to avoid abnormal values. There are fewer low-income households in 2030, and thus many more TAZs without travel cost values (left blank) for lowincome households (top left sub-figure in figure 6.16). Some TAZs experience a reduction in travel costs while some others see an increase. The effects vary spatially, by income and trip purpose. The difference between the two scenarios is again subtle: For example, the 2030Preferred_Scen1 (figure 6.17) produces some different impacts for central Corvallis TAZs. 


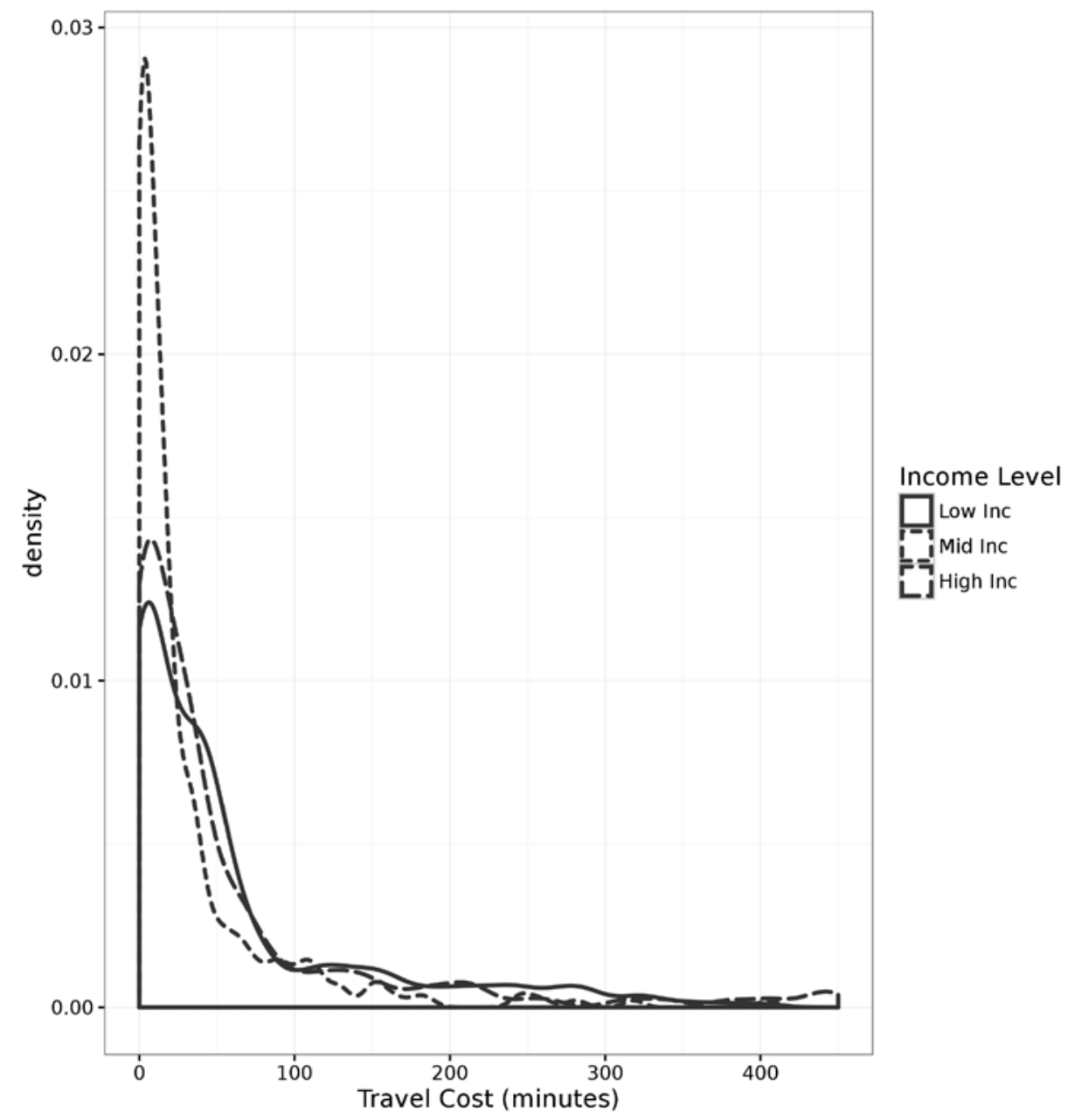

Figure 6.12: Density distributions of travel costs by income group for 2030Preferred Scenario 


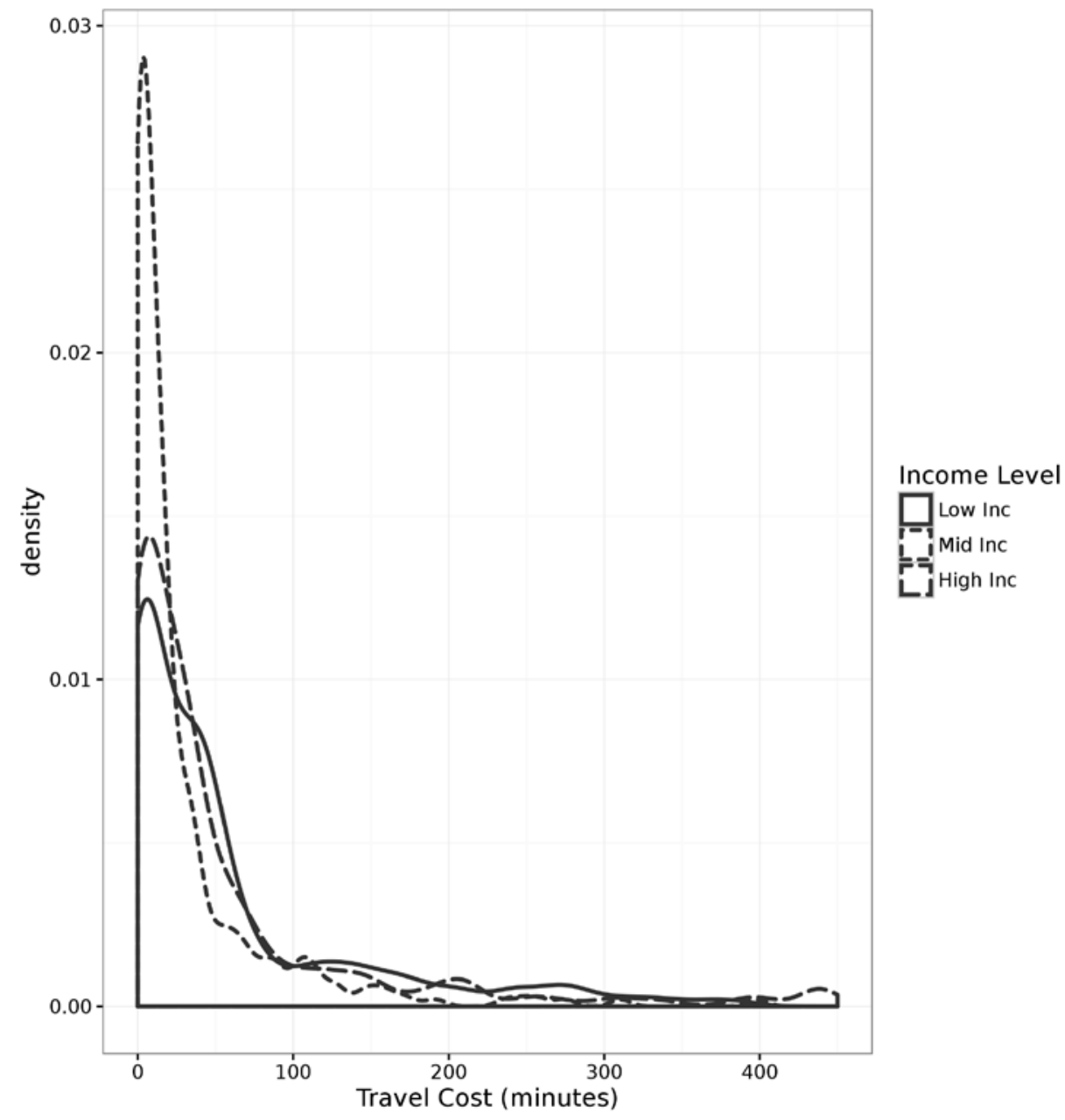

Figure 6.13: Density distributions of travel costs by income group for Corvallis 2030 Preferred Scenario 1 (2030Preferred_Scen1) 


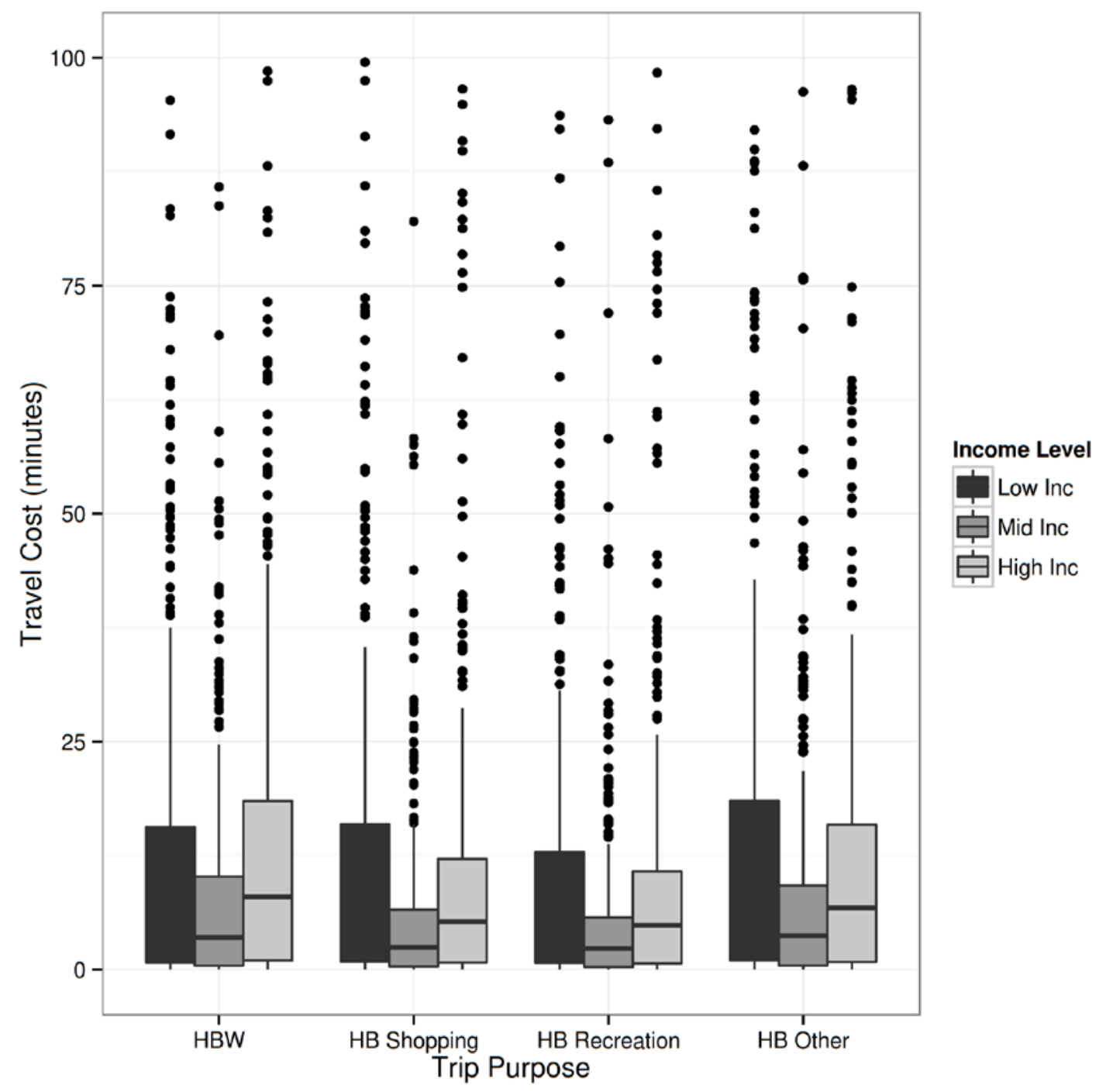

Figure 6.14: Box plot of travel costs by income level and trip purpose for Corvallis 2030Preferred Scenario 


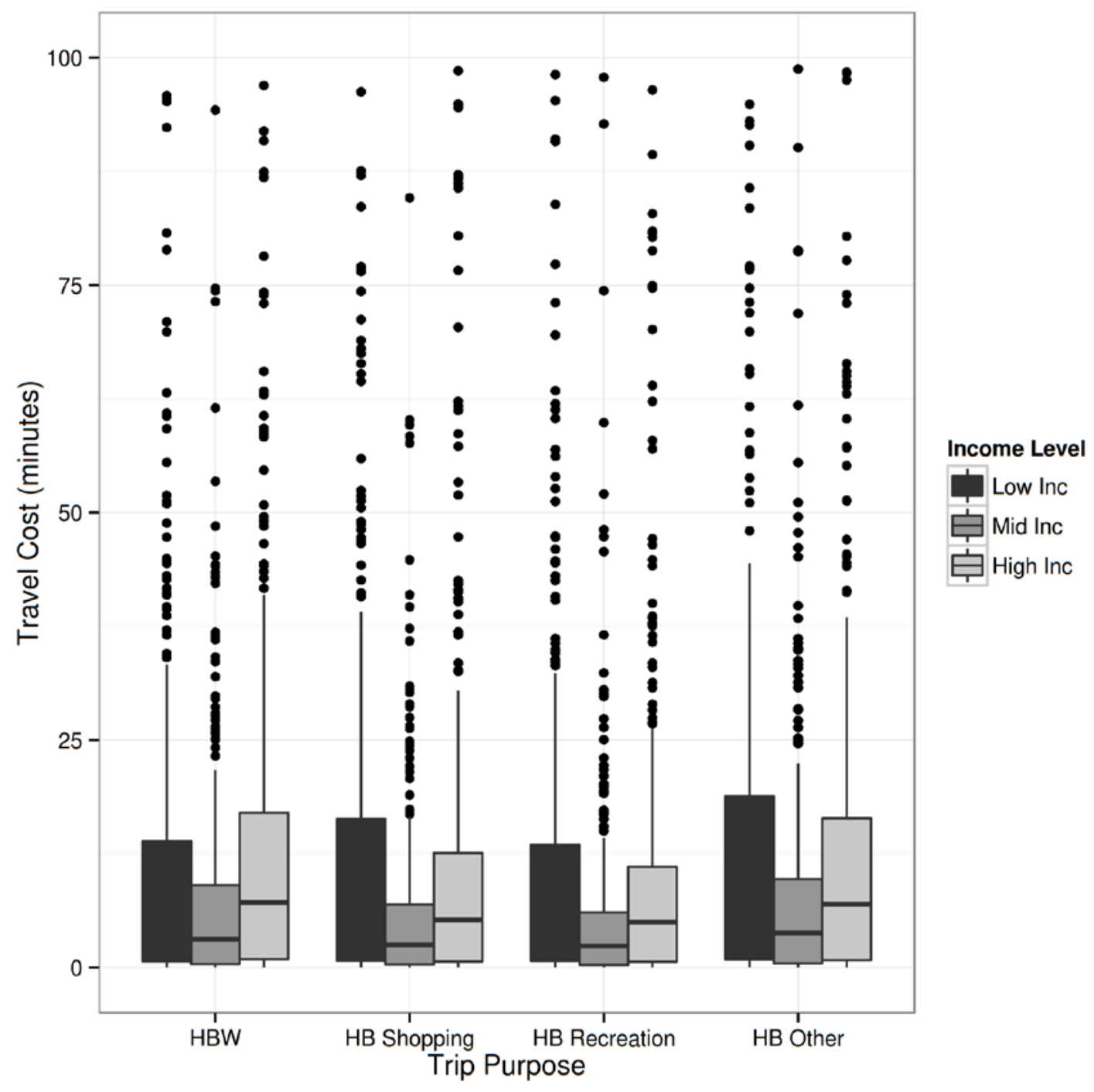

Figure 6.15: Box plot of travel costs by income level and trip purpose for Corvallis 2030 Preferred Scenario 1 (2030Preferred_Scen1) 

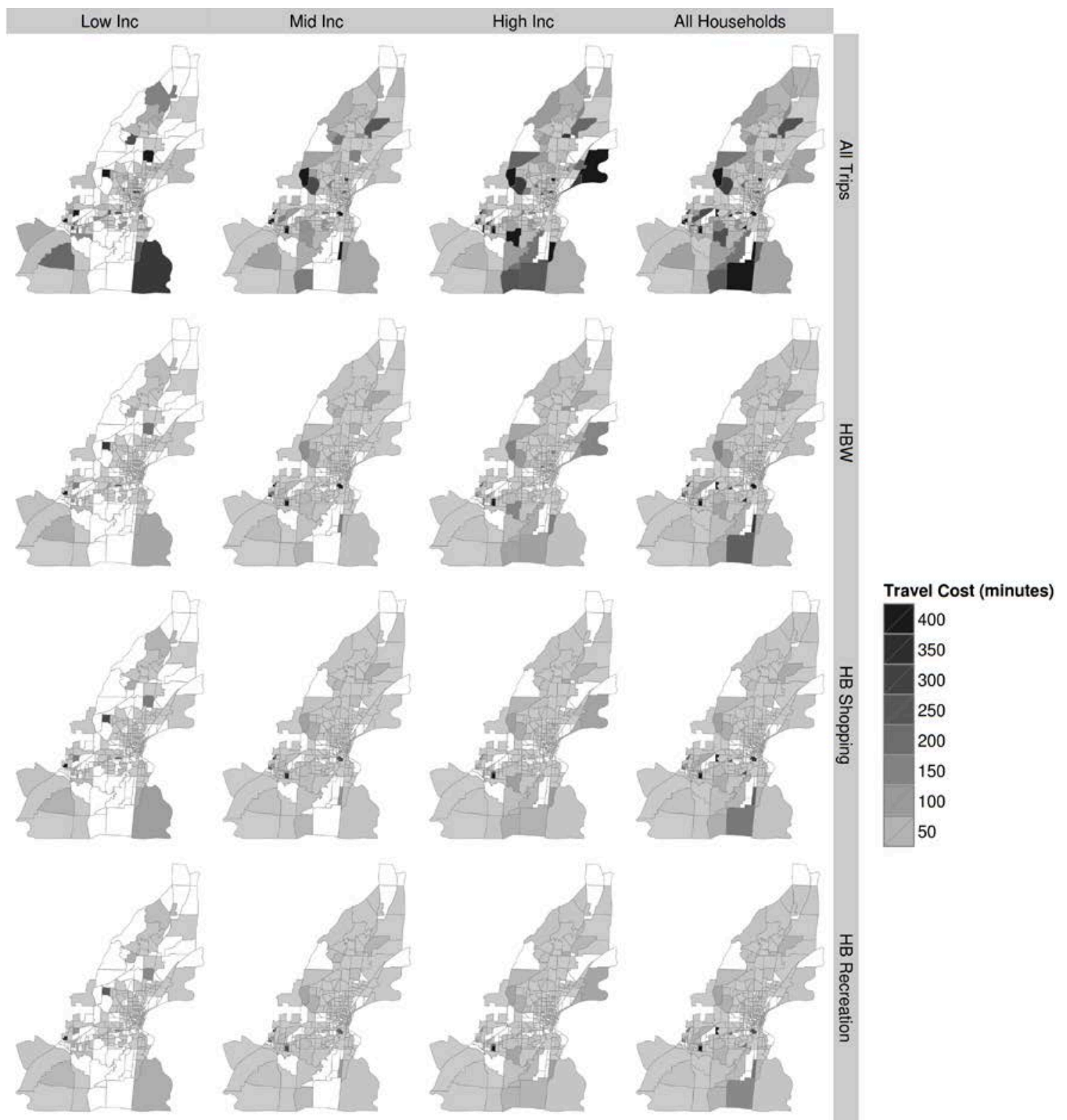

萝
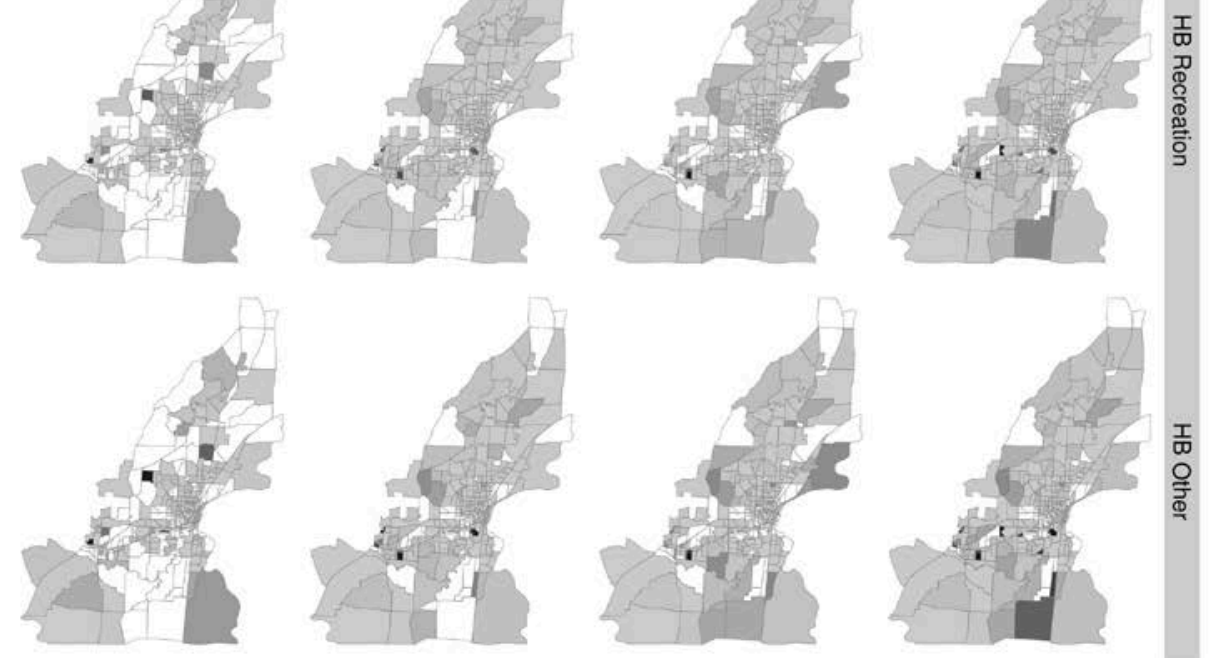

Figure 6.16: TAZ-level travel costs by income level and trip purpose for Corvallis 2030 Preferred Scenario 

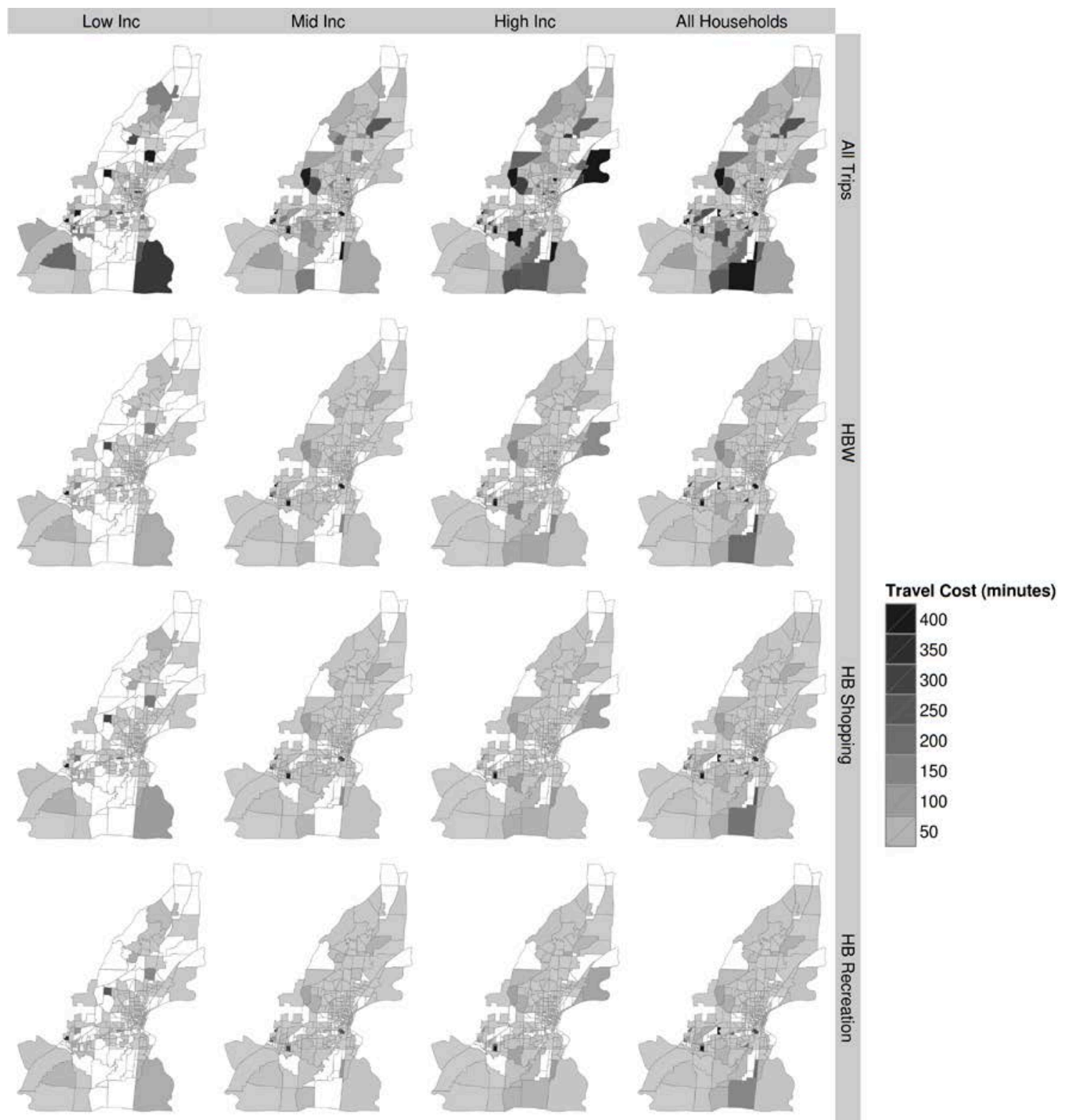

萝
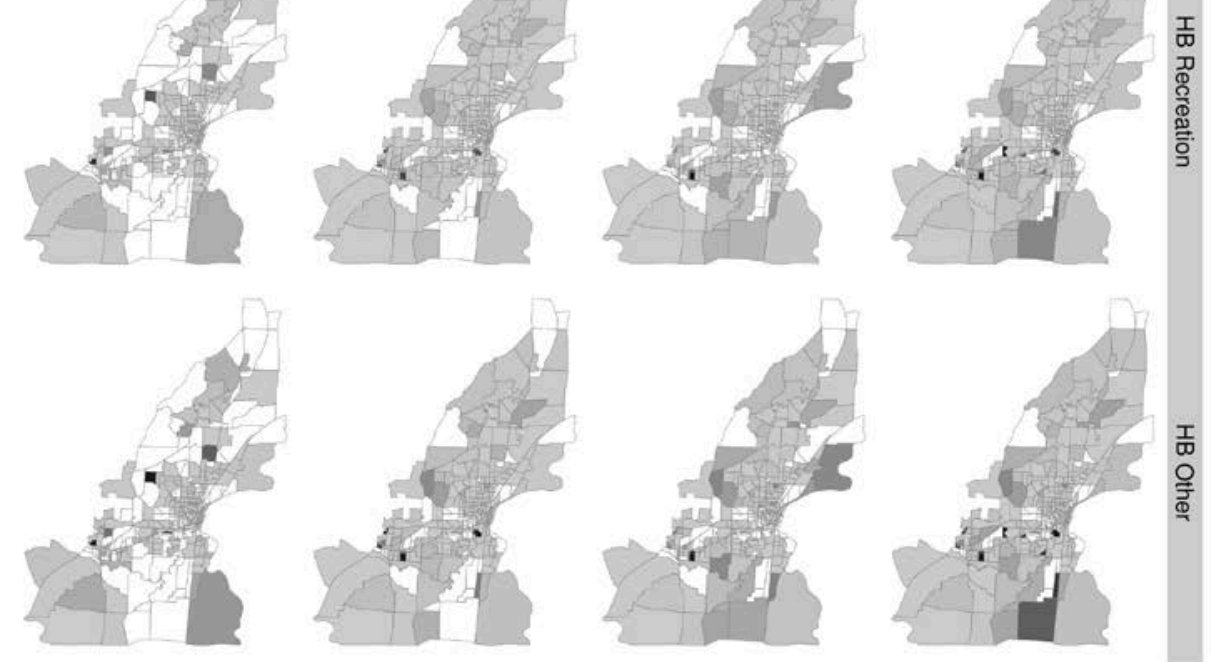

Figure 6.17: TAZ level travel costs by income level and trip purpose for Corvallis 2030 Preferred Scenario 1 (2030Preferred_Scen1) 


\subsection{APPLICATIONS TO UTAH, FLORIDA AND NATIONWIDE}

In this chapter, we apply the transportation cost index (TCI) measure to Salt Lake City, Utah, and Tampa, Florida, and then compare the result with that of Portland. We also compute and compare the TCI measure nationwide. Due to the limitation in accessing the travel demand model data and other required data sources for these places, we apply the survey-based approach in these applications. The data sources for the survey-based application include 2009 National Household Travel Survey (NHTS) (FHWA, 2011), 2012 Utah Household Travel Survey (UHTS) (Utah DOT, 2012) and 2011 Oregon Household Travel and Activity Survey (OHAS) (OMSC, 2011). We were not able to access regional travel survey data for Tampa.

Figure 7.1 shows the household travel costs for three regions using NHTS and regional travel survey data with boxplots. Even though there is small difference in median travel costs, the distribution of travel costs largely overlap.
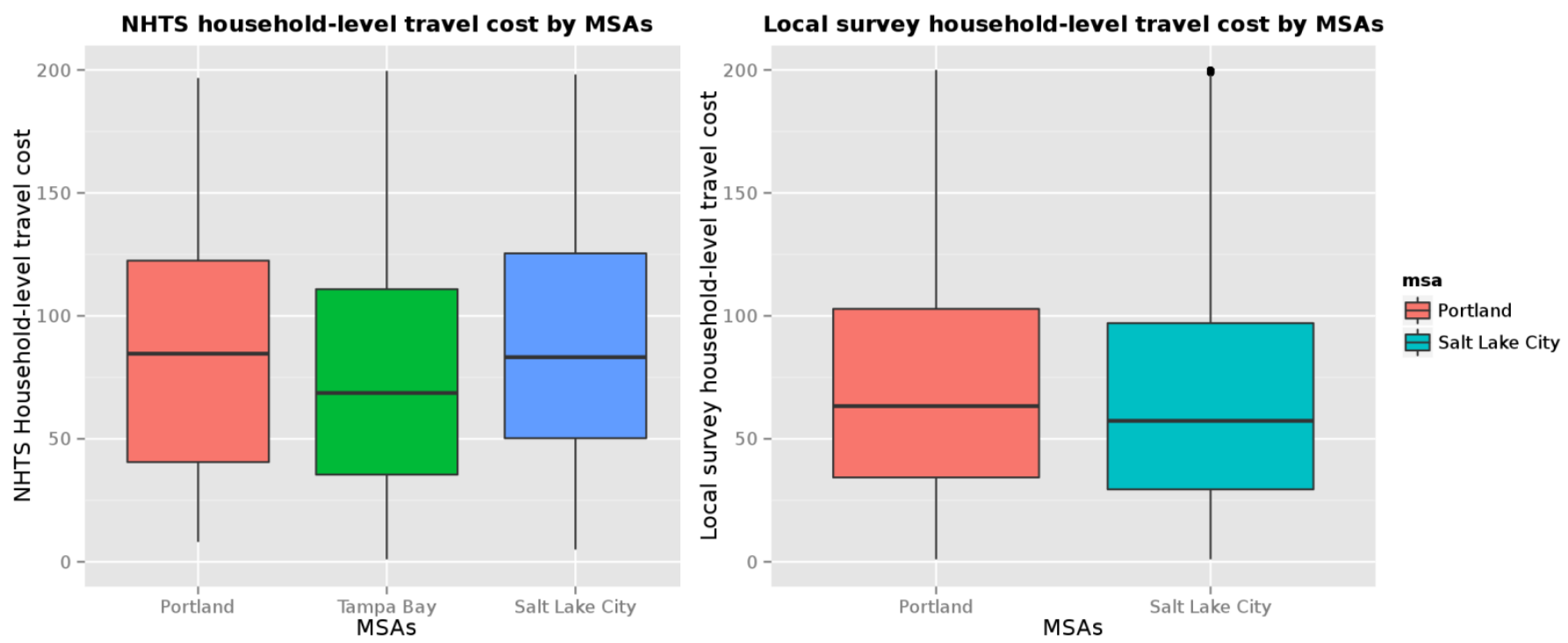

Figure 7.1 MSA-level household travel cost (minutes) for Portland, Tampa, and Salt Lake City using 2009 NTHS (left) and 2011 OHAS and 2012 UTHS (right)

To test the statistical significance of the difference in travel costs, we conduct analysis of variance (ANOVA) and t-tests on the travel costs for three regions. Table 7.1 shows the results of ANOVA of travel costs by Metropolitan Statistical Area (MSA) using 2009 NHTS, which indicates that the travel costs are significantly different between these three regions $(\mathrm{p}<0.01)$. Looking specifically between pairs of MSAs, Table 7.2 shows the results of t-tests. The t-tests indicate that the travel costs of households in Tampa are significantly lower than of those in Portland $(p=0.05)$ with a mean difference of 21.63 minutes, or those in Salt Lake City $(p<0.01)$ with a mean difference of 34.23 minutes, while there is no statistically significant difference in travel costs between households living in Salt Lake City and Portland ( $p=0.62)$. 
Table 7.1 ANOVA of travel costs by MSA using 2009 NHTS

\begin{tabular}{l|r|r|r|r|c} 
& \multicolumn{1}{c}{ df } & \multicolumn{1}{c}{ Sum Sq } & Mean Sq & F value & p value \\
\hline MSA & 2 & 129454 & 64727 & 7.566 & 0.000539 \\
Residuals & 1435 & 12275919 & 8555 & & \\
\hline
\end{tabular}

Table 7.2 t-tests of travel costs between pairs of MSAs using 2009 NHTS

\begin{tabular}{l|r|r|r} 
& Difference in Means & 95\% CI & p value \\
\hline Tampa - Portland & -21.63 & {$[-43.30,0.04]$} & 0.05 \\
Salt Lake City - Portland & 12.59 & {$[-19.02,44.21]$} & 0.62 \\
Salt Lake City-Tampa & 34.23 & {$[9.63,58.83]$} & 0.003 \\
\hline
\end{tabular}

However, if we switch to use the regional travel surveys for Portland and Salt Lake City, the conclusion is different. Table 7.3 presents the result of t-test of travel costs between Portland and Salt Lake City using regional travel survey data. The travel costs of Salt Lake City households are significantly lower than those in Portland $(\mathrm{p}<0.05)$ with a mean difference of 5.37 minutes. This demonstrates the benefit of using regional travel surveys, which generally have more samples for a region than those in 2009 NHTS and allow small differences to be captured.

Table 7.3 t-test of travel costs between Portland and Salt Lake City using regional travel surveys

\begin{tabular}{l|r|r|r} 
& Difference in Means & 95\% CI & p value \\
\hline Salt Lake City - Portland & -5.37 & {$[0.42,10.32]$} & 0.033 \\
\hline
\end{tabular}

From these comparisons and tests, we can see that households in Tampa have the lowest travel costs, followed by those in Salt Lake City and Portland.

We can further compare household travel costs by their income level, household size, and purpose using the regional travel survey data for Portland and Salt Lake City. Just like the overall different in travel costs between the two regions, travel costs by income, household size, and purpose have small differences, except for HB recreation and HB other trips, for which lowincome households in Portland have markedly high costs.

We also examine the differences in travel costs by income, household size and purpose using 2009 NHTS data, but the patterns are noisy due to small sample size for each sub-group. Thus the results are not included in this report. 

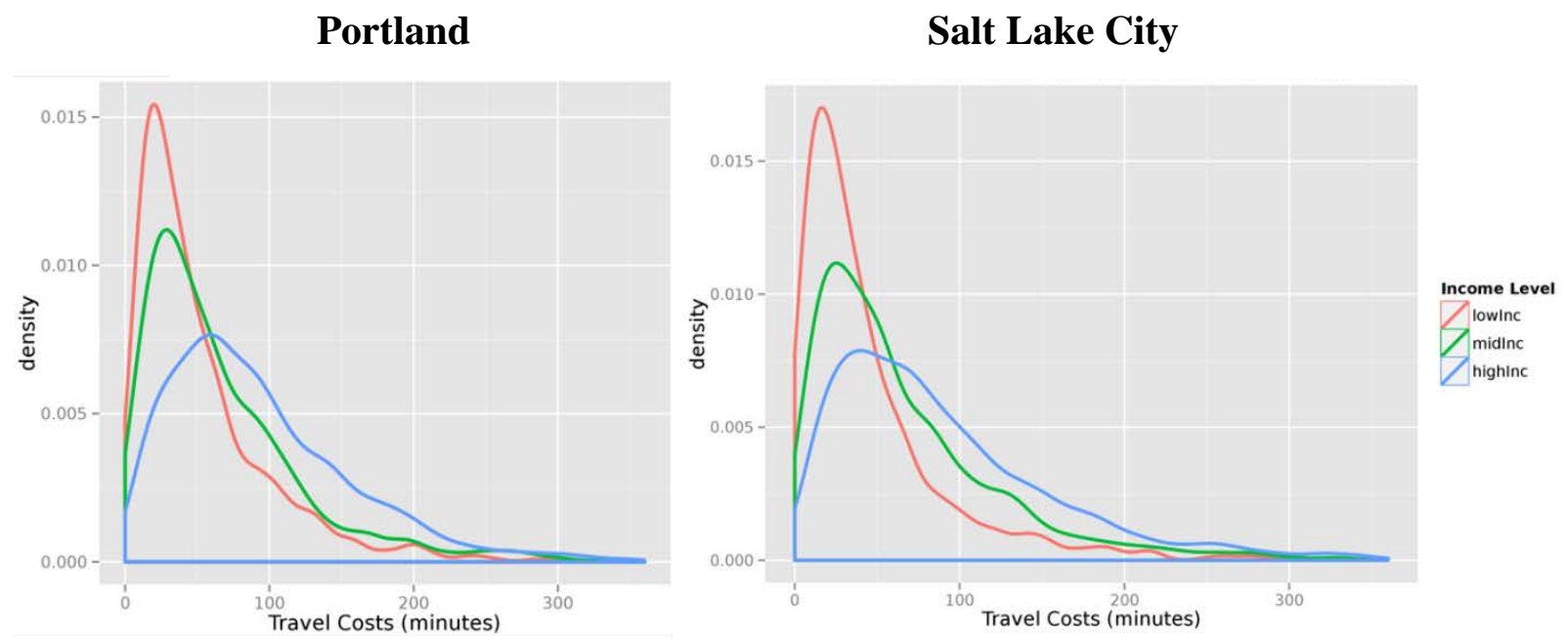

Figure 7.2 Household Travel Costs by Income Level for Portland and Salt Lake City

Portland

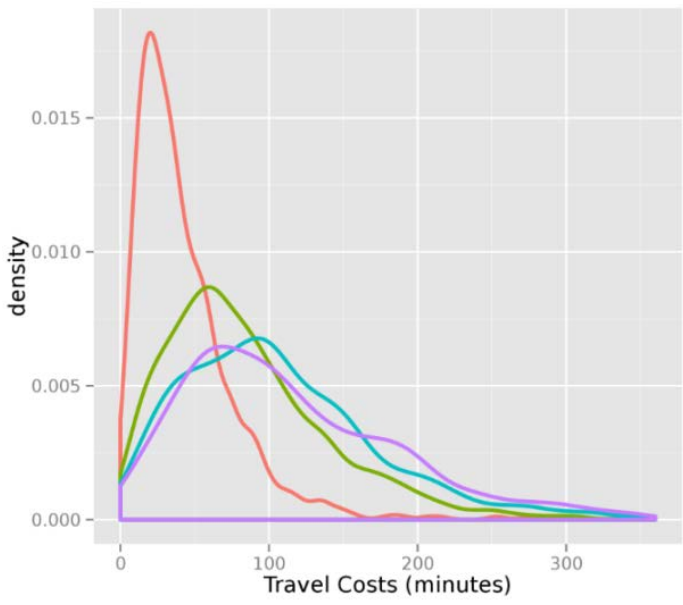

Salt Lake City

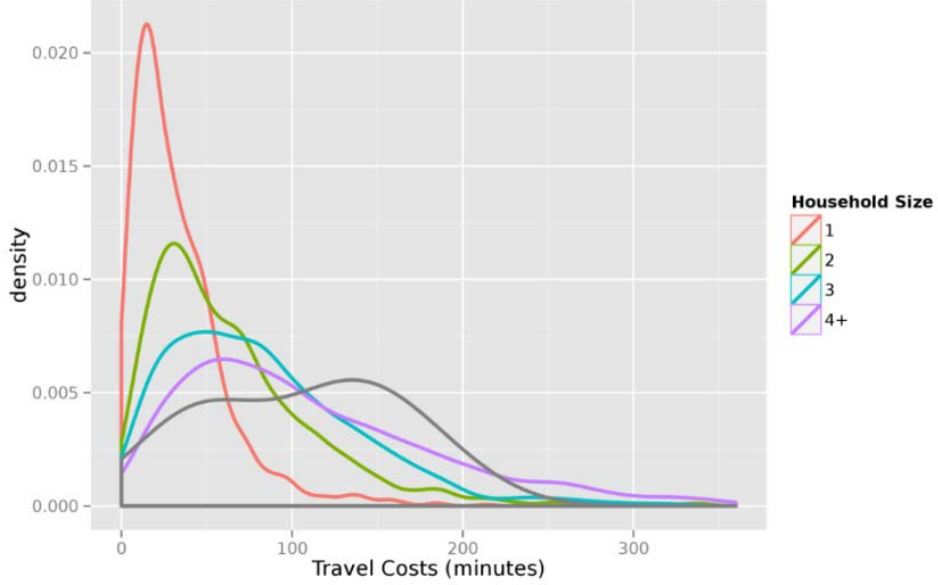

Figure 7.3 Household Travel Costs by Household Size for Portland and Salt Lake City

Portland

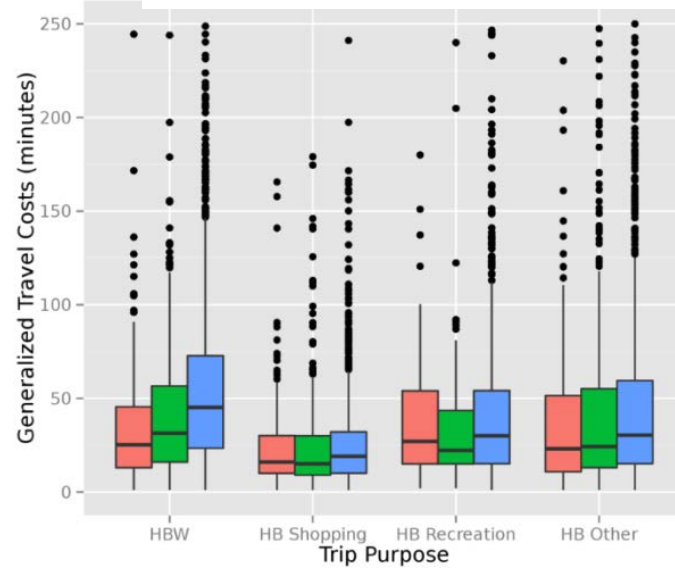

Salt Lake City

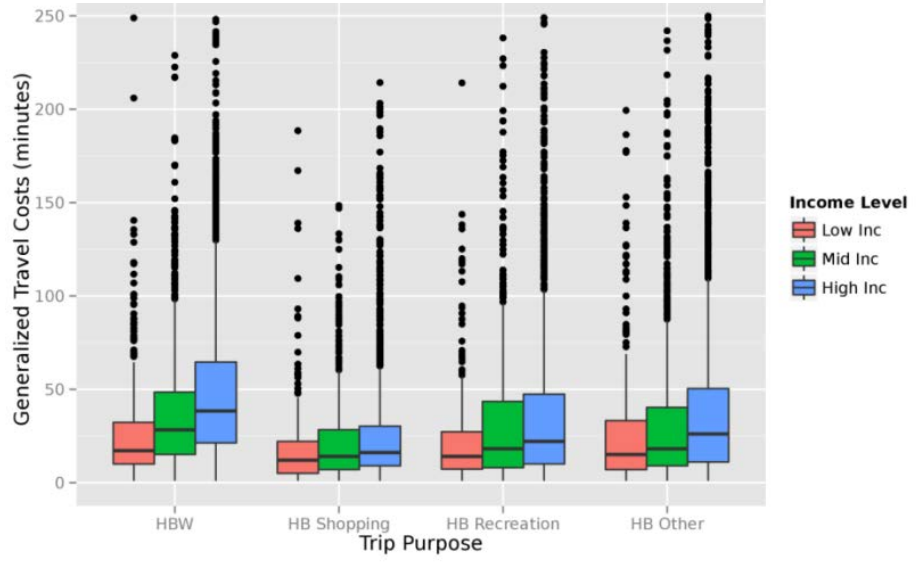

Figure 7.4 Household Travel Costs by Income Level and Trip Purpose 
Finally, we apply the survey-based method to all major MSAs using the 2009 NHTS data. Figure 7.5 shows the distribution of travel costs for all households in minutes, while figure 7.6 shows that for low-income households., Both figures are ranked by mean household travel costs. For example, Washington, D.C., ranks first on travel costs for all households, but ranks eighth for low-income households.

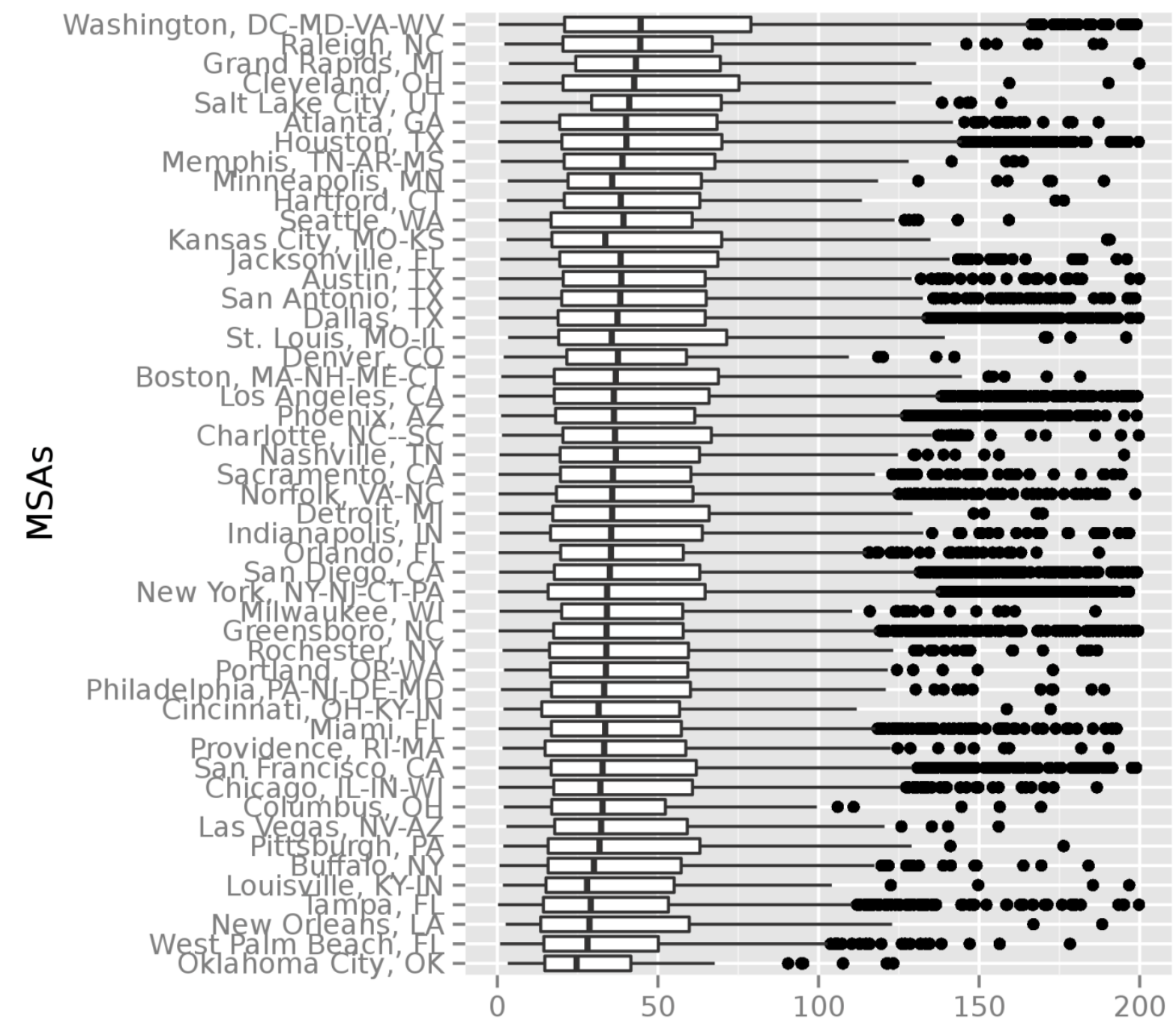

Figure 7.5 Travel costs (minutes) for all households by MSAs 


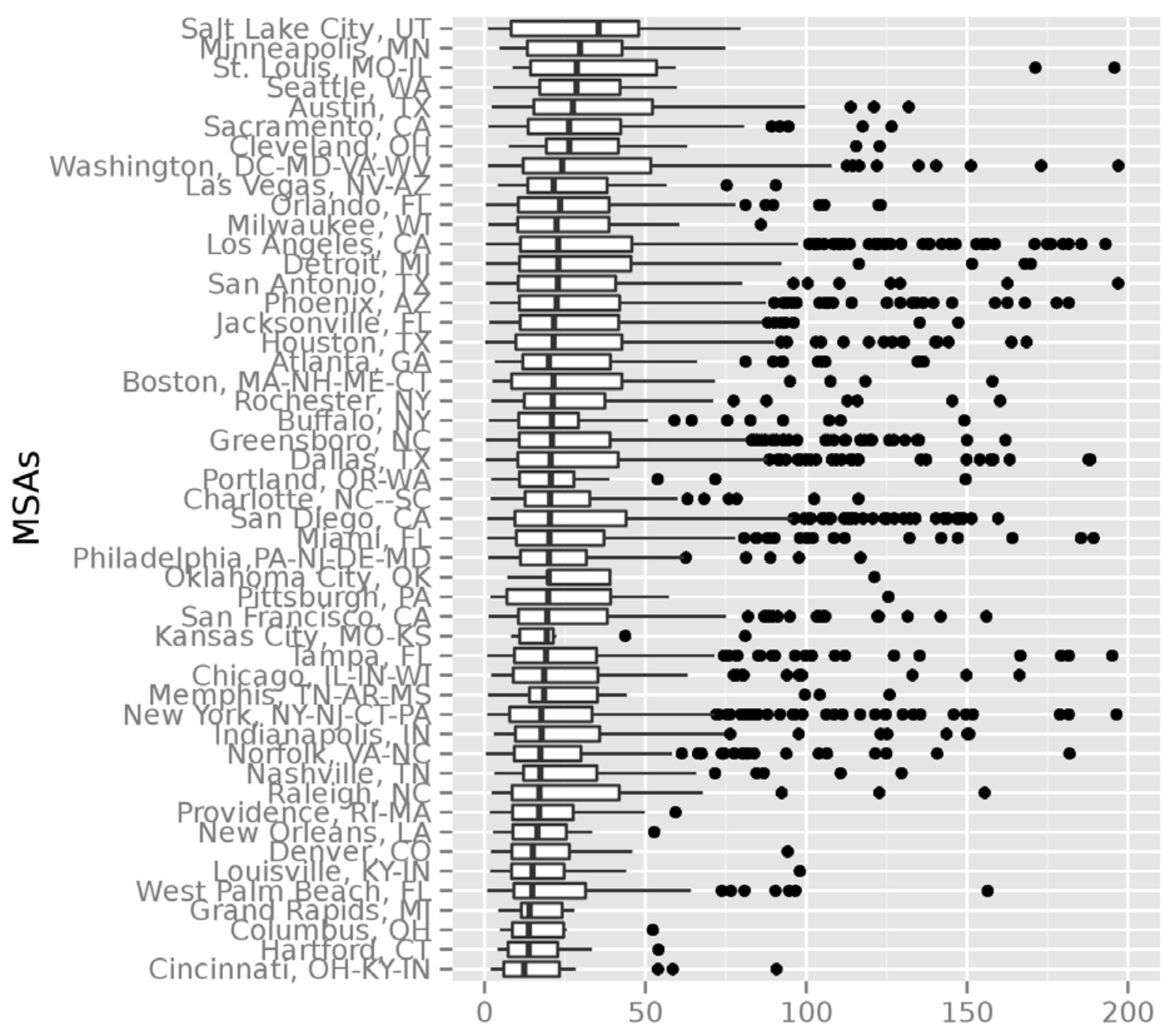

Figure 7.6 Travel costs (minutes) for low-income households by MSA 


\subsection{CONCLUSION AND FUTURE RESEARCH}

Transportation Cost Index (TCI) is a performance measure for transportation and land use systems originally proposed and piloted by Reiff and Gregor (2005). It fills important gaps in existing similar measures in terms of policy areas covered and applicability. The goal of this research project is to move TCI from prototype towards implementation and application by establishing robust definitions of travel market baskets and robust methods for calculating transportation costs. After reviewing relevant literature, we propose two methods of defining travel market baskets, namely the cluster-based approach and the survey-based approach, and one method of calculating travel costs, all of which are based on theoretic and empirical research and recommended practice. We develop these methods and implement them in $\mathrm{R}$ as an open source project. Furthermore, we demonstrate the application of TCI with various datasets, in particular with those from Portland and Corvallis in Oregon. With these applications, we show that both approaches work for regions of different size; that is, they have good scalability. We further test the usefulness of TCI for two types of questions: trend monitoring and scenario evaluation. The applicability testing demonstrates that the survey-based approach can be used for trend monitoring and the cluster-based approach for scenario evaluation. Overall, the project shows that the methods are robust in that they are well-justified by theory, scalable across communities large and small, and suitable for various applications.

There are a few limitations of the current TCI implementation. First, the data requirements for both approaches are rather intensive. The survey-based approach requires a travel survey dataset. To have confidence in the TCI results, especially when used to examine travel costs in detail, the survey needs a sufficient number of observations. And since travel surveys have not been done frequently for most regions in the U.S., relying on their input limits the ability of using TCI to do continuous trend monitoring and to investigate very long-term trends. While the cluster-based approach works well for areas with functioning travel demand models, it would be almost impossible to apply it to places without them. Second, the tests of TCI with the Portland and Corvallis applications may not be sufficient to demonstrate robustness, as they may not demonstrate how (or whether) TCI would work in extreme cases - for example, whether the cluster-based approach would still work when land use is more homogenous. Finally, the results of the survey-based and cluster-based approaches are not directly comparable. As discussed earlier in this report, the two approaches measure different things and their inputs have different levels of aggregation. Ideally, we would prefer comparable results from trend monitoring and scenario evaluation, but given the data available in different situations, it is a trade-off we have to make. The aggregation issue may be alleviated as regions move to activity-based travel models.

One issue that future research can address is to improve household income classification. The current scheme we use assigns households to income group regardless of the household size, but it is likely that household income is correlated with household size. As we show in this report, this could confound the analysis using TCI. A better practice would be to take household size into consideration when classifying households, especially for low-income households. For example, the federal poverty line varies by the number of people in a household. 


\subsection{REFERENCES}

American Auto Association (AAA). Driving cost per mile Archives. (undated) http://newsroom.aaa.com/tag/driving-cost-per-mile/. Accessed August 2, 2015.

Anas, A. A Unified Theory of Consumption, Travel and Trip Chaining. Journal of Urban Economics, Vol. 62, 2007, pp. 162-186.

Anas, A. The Estimation of Multinomial Logit Models of Joint Location and Travel Mode Choice from Aggregated Data. Journal of Regional Science, Vol. 21, 1981, pp. 223-242.

Anas, A., R. Arnott, and K.A.Small. 1998. Urban Spatial Structure. Journal of Economic Literature, Vol. 36, 1998, pp. 1426-1464.

Barnes, G., and P. Langworthy. Per Mile Costs of Operating Automobiles and Trucks. In Transportation Research Record: Journal of the Transportation Research Board, No. 1864, Transportation Research Board of the National Academies, Washington, D.C., 2004, pp. 71-77.

Becker, G.S. A Theory of the Allocation of Time. The Economic Journal, Vol. 75, 1965, pp. 493-517. doi:10.2307/2228949

Bhat, C.R. Incorporating Observed and Unobserved Heterogeneity in Urban Work Travel Mode Choice Modeling. Transportation Science, Vol. 34, 2000, pp. 228-238.

Bhat, C.R. Accommodating Flexible Substitution Patterns in Multi-Dimensional Choice Modeling: Formulation and Application to Travel Mode and Departure Time Choice. Transportation Research Part B: Methodological, Vol. 32, 1998a, pp. 455-466.

Bhat, C.R. Analysis of Travel Mode and Departure Time Choice for Urban Shopping Trips. Transportation Research Part B: Methodological, Vol. 32, 1998b, pp. 361-371.

Bhat, C.R. A Heteroscedastic Extreme Value Model of Intercity Travel Mode Choice. Transportation Research Part B: Methodological, Vol. 29, 1995, pp. 471-483.

Bureau of Labor Statistics. The Consumer Price Index. 2007. In Handbook of Methods (Chapter 17). U.S. Department of Labor. Retrieved from http://www.bls.gov/opub/hom/pdf/homch17.pdf Accessed on February 7th, 2014.

Cambridge Systematics. NCHRP Report 446: A Guidebook for Performance-based Transportation Planning. National Academy Press, Washington, D.C., 2000.

Carr, T., S. Hajiamiri, and S. Gros. Specific Indicator Data Sources and Estimation Methods. Oregon Least Cost Planning Accessibility IDT Team, Jul. 2012. 
Cascetta, E., A. Cartenì, and M. Montanino. A New Measure of Accessibility based on Perceived Opportunities. Procedia - Social and Behavioral Sciences, Vol. 87, Oct. 2013, pp. 117-132.

Chen, H.-P. The Simulation of a Proposed Nonlinear Dynamic Urban Growth Model. The Annals of Regional Science, Vol. 30, 1996, pp. 305-319. doi:10.1007/BF01580524

Chen, Y., S. Ravulaparthy, K. Deutsch, P. Dalal, S. Yoon, T. Lei, K. Goulias, R. Pendyala, C. Bhat, and H.-H. Hu. Development of Indicators of Opportunity-Based Accessibility. Transportation Research Record: Journal of the Transportation Research Board, Vol. 2255, No. -1, Dec. 2011, pp. 58-68.

COWI, Economic Evaluation Of Cycle Projects - Methodology And Unit Prices, Samfundsøkonomiske Analyser Af Cykeltiltag - Metode Og Cases and the accompanying note Enhedsværdier for Cykeltrafik, prepared by COWI for the City of Copenhagen (www.kk.dk/cyklernesby), 2009.

Diana, M., and P.L. Mokhtarian. Desire to Change One’s Multimodality and Its Relationship to the Use of Different Transport Means. Transportation Research Part F: Traffic Psychology and Behaviour, Vol. 12, No. 2, 2009, pp. 107-119.

Fosgerau, M., K. Hjorth, and S.V. Lyk-Jensen. Between-Mode-Differences in the Value of Travel Time: Self-Selection or Strategic Behaviour? Transportation Research Part D: Transport and Environment, Vol. 15, 2010, pp. 370-381.

Ellwanger, G., External Environmental Costs of Transport - Comparison of Recent Studies, Social Costs and Sustainable Mobility, ZEW, Physica-Verlag, 2000, pp. 15-20.

Gandavarapu, S. Using Google Transit Feed Specification in Travel Modeling. Presented at the 4th Transportation Research Board Conference on Innovations in Travel Modeling, Tampa, Fla. 2012.

Geurs, K., B. Zondag, G. de Jong, and M. de Bok. Accessibility appraisal of land-use/transport policy strategies: More than just adding up travel-time savings. Transportation Research Part D: Transport and Environment, Vol. 15, No. 7, Oct. 2010, pp. 382-393.

Geurs, K. T., and B. van Wee. Accessibility evaluation of land-use and transport strategies: review and research directions. Journal of Transport Geography, Vol. 12, No. 2, Jun. 2004, pp. 127-140.

Gillen, D.W. Estimation and Specification of the Effects of Parking Costs on Urban Transport Mode Choice. Journal of Urban Economics, Vol. 4, 1977, pp. 186-199.

Giuliano, G., C. Redfearn, A. Agarwal, C. Li, and D. Zhuang. Employment Concentrations in Los Angeles, 1980-2000. Environment and Planning A, Vol. 39, 2007, pp. 2935-2957.

Giuliano, G., and K.A. Small. Is the Journey to Work Explained by Urban Structure? Urban Studies, Vol. 30, 1993, pp. 1485-1500. 
Giuliano, G., and K.A. Small. Subcenters in the Los Angeles Region. Regional Science and Urban Economics, Vol. 21, 1991, pp. 163-182.

Greene, R.P. Urban Peripheries as Organizers of what Remains of the Center: Examining the Evidence from Los Angeles and Chicago. Urban Geography, Vol. 29, 2008, pp.138-153. doi:10.2747/0272-3638.29.2.138

Handy, S. L., and D. A. Niemeier. Measuring accessibility: an exploration of issues and alternatives. Environment and Planning A, Vol. 29, No. 7, 1997, pp. 1175 - 1194.

Helsley, R.W., and A.M. Sullivan. Urban Subcenter Formation. Regional Science and Urban Economics, Vol. 21, 1991, pp. 255-275.

Hensher, D.A. Stated Preference Analysis of Travel Choices: The State of Practice. Transportation, Vol. 21, 1994, pp. 107-133.

IntelliChoice, I. Complete Car Cost Guide. Intellichoice, 2002.

Jiang, M., and T. Morikawa. Theoretical Analysis on the Variation of Value of Travel Time Savings. Transportation Research Part A: Policy and Practice, Vol. 38, 2004, pp. 551-571.

Kahn, D., J.-L Deneubourg, and A. De Palma. 1981. Transportation Mode Choice. Environment and Planning A, Vol. 13, 1981, pp. 1163-1174.

Koopmans, C., W. Groot, P. Warffemius, J. A. Annema, and S. Hoogendoorn-Lanser. Measuring generalised transport costs as an indicator of accessibility changes over time. Transport Policy, Vol. 29, Sep. 2013, pp. 154-159.

Krizek, K., A.M. El-Geneidy, M. Iacono, and J. Horning. Access to Destinations: Refining Methods for Calculating Non-Auto Travel Times, No. MnDOT 2007-24. University of Minnesota, Center for Transportation Studies, Minneapolis, Minn. 2007.

Lee, D.B. Full Cost Pricing of Highways. John A. Volpe National Transportation Systems Center. 1995.

Litman, T. and E. Doherty. Transportation Cost and Benefit Analysis: Techniques, Estimates and Implications, second edition. Victoria Transport Policy Institute, Victoria, B.C., Canada, 2009.

Litman, T. Build for Comfort, Not Just Speed: Valuing Service Quality Impacts in Transportation Planning. Victoria Transport Institute, Victoria, B.C., Canada. 2007.

Louviere, J.J. Conjoint Analysis Modelling of Stated Preferences: a Review of Theory, Methods, Recent Developments and External Validity. Journal of Transport Economics and Policy, 1988, pp. 93-119. 
Louviere, J.J., and D.A. Hensher. 1982. Design and Analysis of Simulated Choice or Allocation Experiments in Travel Choice Modeling. In Transportation Research Record: Journal of the Transportation Research Board, No. 890, Transportation Research Board of the National Academies, Washington, D.C. 1982, pp. 11-17.

Martin, W.A., and N.A. McGuckin. Barton-Aschman Associates, lnc. 1998. Travel Estimation Techniques for Urban Planning. In National Cooperative Highway Research Program, No. 365, Transportation Research Board of the national Academies, Washington, D.C., 1998.

Mason, C., and C. Butler. 1987. New Basket of Goods and Services Being Priced in Revised CPI. Monthly Labor Review, 1987, pp. 3-22.

McDonald, J.F. Econometric Studies of Urban Population Density: A survey. Journal of Urban Economics, Vol. 26, 1989, pp. 361-385. doi:10.1016/0094-1190(89)90009-0

McDonald, J.F., and D.P. McMillen. Employment Subcenters and Subsequent Real Estate Development in Suburban Chicago. Journal of Urban Economics, Vol. 48, 2000, pp. 135-157.

McMillen, D.P. Nonparametric Employment Subcenter Identification. Journal of Urban Economics, Vol. 50, 2001, pp. 448-473. doi:10.1006/juec.2001.2228

Metro Research Center and Transportation Research and Modeling Services. 2013 Trip-Based Travel Demand Model Methodology Report. The Portland Metro, Portland, OR. 2013.

Moving Ahead for Progress in the 21st Century (MAP-21). National Goals and Performance Management Measures. Public Law 112-141. 23 USC Chapter 1 - FEDERAL-AID HIGHWAYS §150. 2012.

ODOT. The Value of Travel-Time: Estimates of the Hourly Value of Time for Vehicles in Oregon 2011. Oregon Department of Transportation Programs and Economic Analysis Unit. 2012.

Oja, P., S. Titze, A. Bauman, B. De Geus, P. Krenn, B. Reger-Nash, and T. Kohlberger. Health Benefits of Cycling: a Systematic Review. Scandinavian Journal of Medicine \& Science in Sports, Vol. 21, No. 4, 2011, pp. 496-509.

Oregon Modeling Steering Committee (OMSC), Oregon Household Travel and Activity Survey (OHAS). Oregon Modeling Steering Committee, Salem, Oregon, 2011.

Oregon Secretary of State. Transportation Planning Rule. Goal 12: Transportation. Oregon Administrative Rules, Vol. OAR 660-015-0000, No. 12, 2002.

Owen, A., and D. Levinson. Access Across America: Auto 2013. University of Minnesota. 2013.

Owen, A., and D. Levinson. Access Across America: Transit 2014. University of Minnesota. 2014. 
Owen, A., and D. Levinson. Access to Destinations: Annual Accessibility for the Twin Cities Metropolitan Area. Technical Report 2012-34, Minnesota Department of Transportation. 2012.

Ozbay, K., B. Bartin, and J. Berechman. Estimation and Evaluation of Full Marginal Costs of Highway Transportation in New Jersey. Journal of Transportation and Statistics, Vol. 4, 2001, pp. 81-103.

Pinjari, A.R., R.M. Pendyala, C.R. Bhat, and P.A. Waddell. Modeling the Choice Continuum: An Integrated Model of Residential Location, Auto Ownership, Bicycle Ownership, and Commute Tour Mode Choice Decisions. Transportation, Vol. 38, 2011, pp. 933-958.

Polzin, S.E., X. Chu, and V.S. Raman. Exploration of a Shift in Household Transportation Spending from Vehicles to Public Transportation. University of South Florida, Center for Urban Transportation Research. 2008.

Portland Facts. Cost of Transit and Cars. (undated) URL http://www.portlandfacts.com/cost_of_transit_\&_cars.html Accessed August 2, 2015.

Portland Taxi Cab Company. Rates and Fares. (undated) URL http://portlandtaxi.net/rates.php. Accessed August 2, 2015.

Quinet, E., “Meta-Analysis Of Western European External Cost Estimates,” Transportation Research D, Vol. 9, Nov. 2004, pp. 465-476.

Redfearn, C.L. The Topography of Metropolitan Employment: Identifying Centers of Employment in a Polycentric Urban Area. Journal of Urban Economics, Vol. 61, 2007, pp. 519541. doi:10.1016/j.jue.2006.08.009

Reiff, B., and B. Gregor. Transportation Planning Performance Measures. SPR 357. Oregon Department of Transportation, Salem, OR. 2005.

Schmidt, M.L. Comparing Market Basket Changes and the CPI. Bureau of Labor Statistics, 1995.

Smith, N. C., D. W. Veryard and R. P. Kilvington, Relative Costs And Benefits Of Modal Transport Solutions, Research Report 393, NZ Transport Agency, 2009

Train, K. A Structured Logit Model of Auto Ownership and Mode Choice. The Review of Economic Studies, 1980, pp. 357-370.

Train, K., and D. McFadden. The Goods/Leisure Tradeoff and Disaggregate Work Trip Mode Choice Models. Transportation Research, Vol. 12, 1978, pp. 349-353.

U.S. Department of Transportation. Revised Departmental Guidance on Valuation of Travel Time in Economic Analysis. U.S. Department of Transportation, Washington, D.C. 2011. 
Federal Highway Administration, 2009 National Household Travel Survey. U.S. Department of Transportation, Washington, D.C. 2011.

Waddell, P. Integrated Land Use and Transportation Planning and Modelling: Addressing Challenges in Research and Practice. Transport Reviews, Vol. 31, No. 2, 2011, pp. 209-229.

Wanner, M., T. Götschi, E. Martin-Diener, S. Kahlmeier, and B.W. Martin. Active Transport, Physical Activity, and Body Weight in Adults: A Systematic Review. American Journal of Preventive Medicine, Vol. 42, No. 5, 2012, pp. 493-502.

Wang, L., P. Waddell, and M.L. Outwater. Incremental Integration of Land Use and ActivityBased Travel Modeling. In Transportation Research Record: Journal of the Transportation Research Board, No. 2255, Transportation Research Board of the National Academies, Washington, D.C., 2011, pp. 1-10.

Wang, Liming, Bud Reiff, Brian Gregor, Huajie Yang, and Jenny Liu, Transportation Cost Index: A Comprehensive Multimodal Performance Measure of Transportation and Land Use Systems, presented at the 94th Annual Meeting of Transportation Research Board, Washington, D.C., January 11-15, 2015.

Wang, Liming, Huajie Yang, and Jenny Liu, Transportation Cost Index as a Performance Measure for Transportation and Land Use Systems: New Approaches and Application in Portland, Oregon, presented at the 94th Annual Meeting of Transportation Research Board, Washington, D.C., January 10-14, 2016.

Wang, Liming and Jenny Liu, Multi-Modal Performance Measures In Oregon: Developing A Transportation Cost Index, Oregon DOT, available at http://www.oregon.gov/ODOT/TD/TP_RES/ docs/Reports/2016/SPR760_TCIFinalReport.pdf.

Utah DOT, Utah Household Travel Survey (UHTS). Utah DOT, Salt Lake City, UT, 2012. Zhao, H., X. Yan, and Z. Gao. Transportation Serviceability Analysis for Metropolitan Commuting Corridors Based on Modal Choice Modeling. Transportation Research Part A: Policy and Practice, 2013, Vol. 49, pp. 270-284. 



\section{APPENDIX A}

INPUT DATA FOR THE SURVEY-BASED APPROACH 



\section{APPENDIX A: INPUT DATA FOR THE SURVEY-BASED APPROACH}

\section{Travel Survey Data}

- Household Characteristics:

o Residence location (X, Y coordinate or Traffic

Analysis Zone (TAZ))

o Income level

o Household size

o Presence of children (optional)

o Place type (optional)

- Trip Attributes:

o Mode

o Trip Duration

o Trip Distance

GIS shape files

- Traffic Districts (optional) 

APPENDIX B

INPUT DATA FOR THE CLUSTER-BASED APPROACH 



\section{APPENDIX B: INPUT DATA FOR THE CLUSTER-BASED APPROACH}

\section{Land Use Data}

o Employment counts by Traffic Analysis Zone (TAZ) by employment type:

o Household counts by TAZ by income level

o Park acres by TAZ

o Other variables that are used in size term

\section{Trips and Skims from Travel Demand Model}

o Trips by trip purpose, mode, time-of-day and income level

o Travel time skims by mode and time-of-day

o Travel distance by mode and time-of-day

o Mode utilities matrix by trip purpose, mode and income level (optional)

GIS shape files

o TAZ

o Traffic Districts (optional) 

APPENDIX C: SENSITIVITY ANALYSIS OF CUTOFFS FOR THE CLUSTER-BASED APPROACH FOR PORTLAND 



\section{APPENDIX C: SENSITIVITY ANALYSIS OF CUTOFFS FOR THE CLUSTER-BASED APPROACH FOR PORTLAND}

The 50th, 60th, 70th, 80th, 90th and 95th percentiles for density cutoff are tested in the sensitivity analysis. For each density cutoff, the 25th, 50th and 75th percentiles for total cutoff are tested. Figures C.1 to C. 4 show maps of the identified centers with different cutoffs. With density cutoffs ranging from the 50th to the 70th percentile, the spatial pattern of centers is persistent across all trip purposes. Only when the cutoffs are above the 80th percentile, especially when they are as high as the 90th or 95th percentile, is the identified center restricted to a few groups of Traffic Analysis Zones (TAZs). From this observation, it seems that cutoffs at the $50^{\text {th }}$ to 70th percentiles are appropriate.
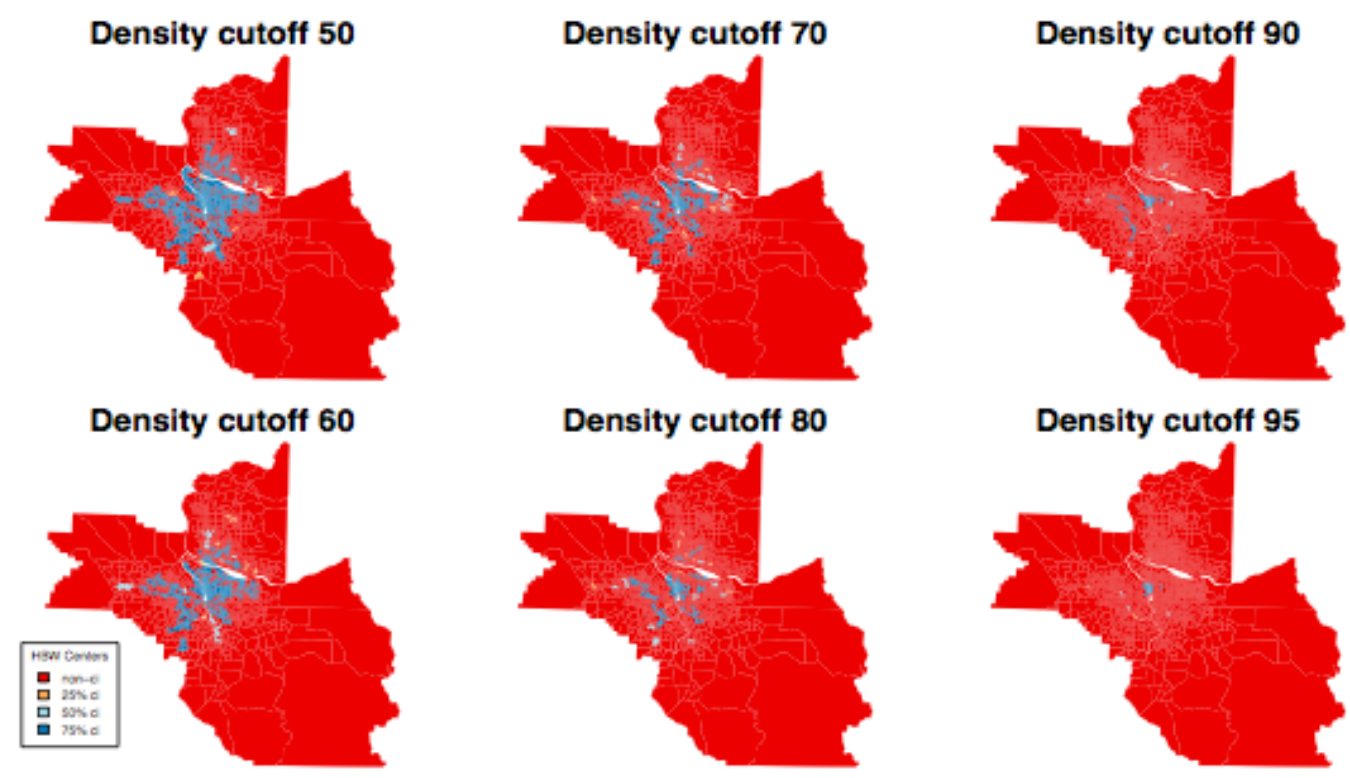

Figure C.1: Maps of identified centers for HB Work with different percentile cutoff 

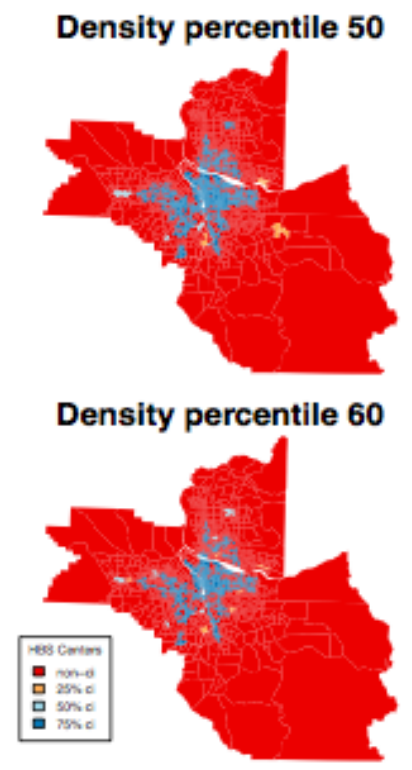
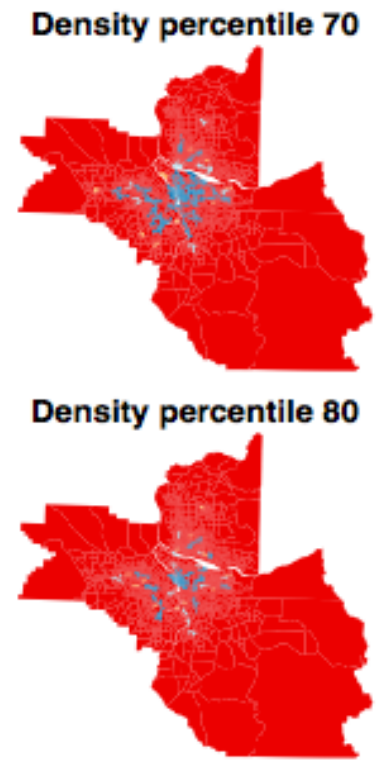

Density percentile 90

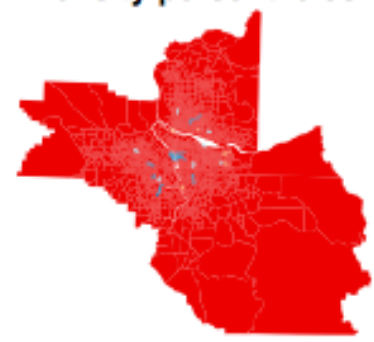

Density percentile 95

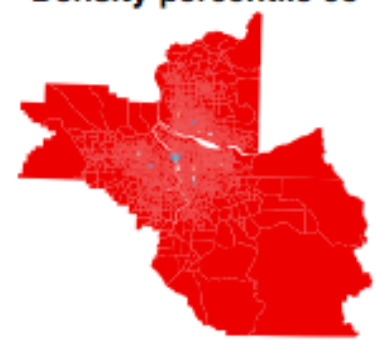

Figure C.2: Maps of identified centers for HB Shopping with different percentile cutoffs

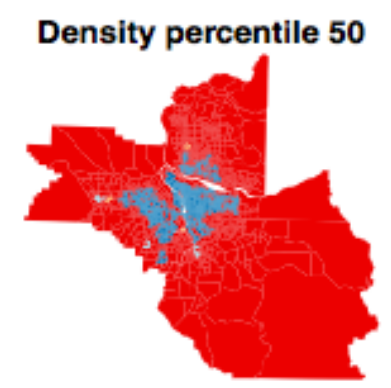

Density percentile 60

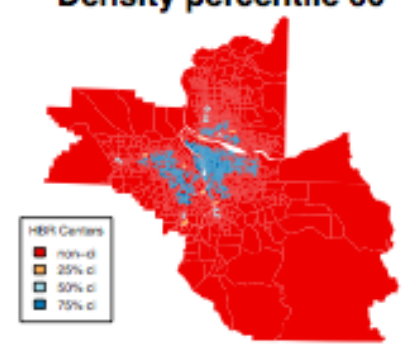

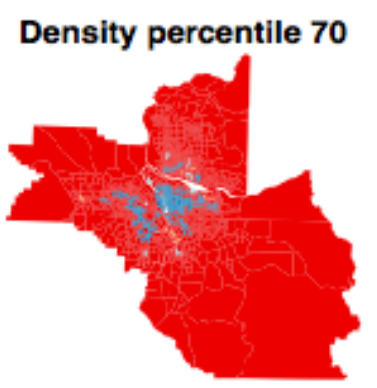

Density percentile 80

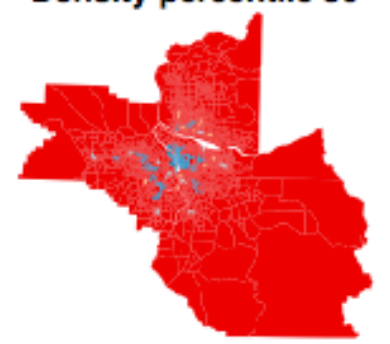

Density percentile 90

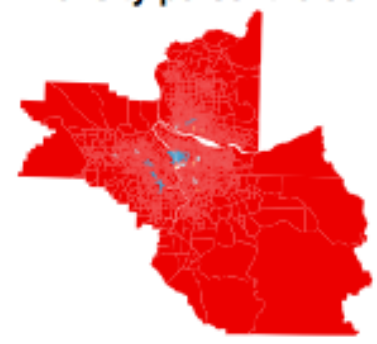

Density percentile 95

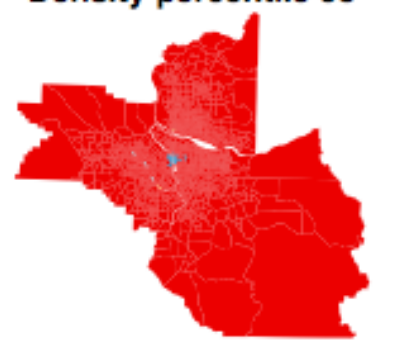

Figure C.3: Maps of identified centers for HB Recreation with different percentile cutoffs 

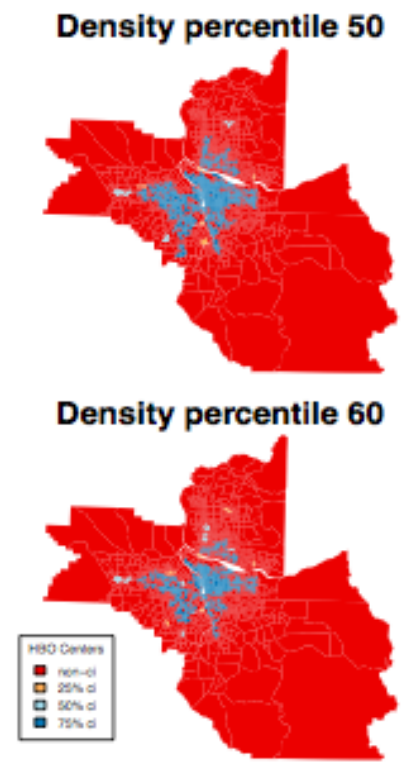

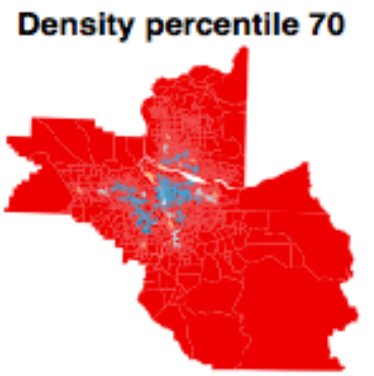

Density percentile 80

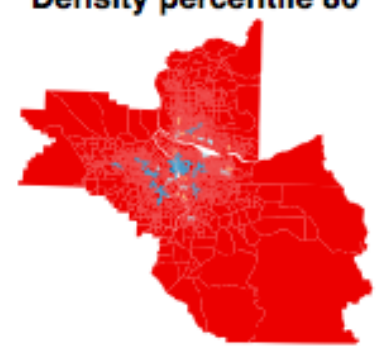

Density percentile 90

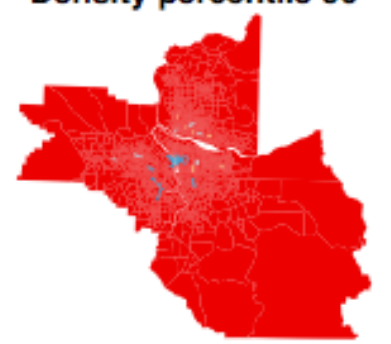

Density percentile 95

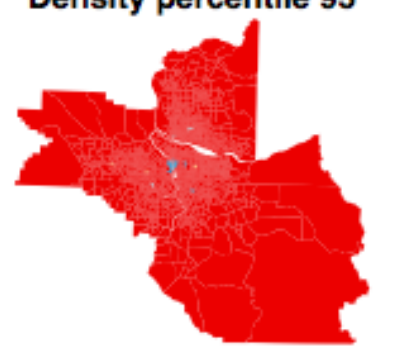

Figure C.4: Maps of identified centers for HB Other with different percentile cutoffs

Next, we calculate the travel costs based on different cutoffs. Tables C.1-C.3 show the minimum, $1^{\text {st }}$ quartile, median, mean, $3^{\text {rd }}$ quartile, and maximum travel costs with different cutoffs. The aggregated travel costs are stable as the cutoffs range between the 50th and 80th percentiles. 
Table C.1: Weighted TAZ-level aggregated travel costs for peak period with different cutoffs

\begin{tabular}{|l|l|l|l|l|l|l|l|}
\hline \multicolumn{2}{|c|}{ Cutoff (percentile) } & \multicolumn{6}{c|}{ Descriptive statistics } \\
\hline Density & Total & Min & $1^{\text {st }}$ Qu. & Median & Mean & $3^{\text {rd }}$ Qu. & Max \\
\hline 70 & $1000^{\text {a }}$ & 2.113 & 3.332 & 3.910 & 4.163 & 4.815 & 10.820 \\
\hline 50 & 25 & 2.217 & 3.194 & 3.580 & 3.903 & 4.434 & 10.400 \\
\hline 50 & 50 & 2.214 & 3.190 & 3.582 & 3.921 & 4.463 & 10.440 \\
\hline 50 & 75 & 2.211 & 3.185 & 3.592 & 3.972 & 4.597 & 10.570 \\
\hline 60 & 25 & 2.195 & 3.204 & 3.640 & 3.955 & 4.509 & 10.620 \\
\hline 60 & 50 & 2.191 & 3.199 & 3.637 & 3.992 & 4.593 & 10.620 \\
\hline 60 & 75 & 2.182 & 3.211 & 3.699 & 4.098 & 4.779 & 10.980 \\
\hline 70 & 25 & 2.160 & 3.238 & 3.752 & 4.064 & 4.706 & 10.600 \\
\hline 70 & 50 & 2.153 & 3.237 & 3.810 & 4.126 & 4.817 & 10.650 \\
\hline 70 & 75 & 2.140 & 3.371 & 4.076 & 4.340 & 5.082 & 11.570 \\
\hline 80 & 25 & 2.108 & 3.318 & 4.015 & 4.105 & 4.871 & 10.690 \\
\hline 80 & 50 & 2.101 & 3.424 & 4.140 & 4.333 & 5.059 & 10.720 \\
\hline 80 & 75 & 2.077 & 3.604 & 4.453 & 4.602 & 5.453 & 11.850 \\
\hline 90 & 25 & 2.026 & 3.585 & 4.430 & 4.532 & 5.286 & 11.800 \\
\hline 90 & 50 & 2.020 & 3.702 & 4.554 & 4.697 & 5.582 & 11.880 \\
\hline 90 & 75 & 2.003 & 4.440 & 5.450 & 5.529 & 6.566 & 12.200 \\
\hline 95 & 25 & 1.975 & 4.110 & 4.990 & 5.109 & 6.032 & 12.380 \\
\hline 95 & 50 & 1.967 & 4.402 & 5.433 & 5.492 & 6.516 & 12.440 \\
\hline 95 & 75 & 1.956 & 4.982 & 6.060 & 6.056 & 7.100 & 12.920 \\
\hline
\end{tabular}

a 1000 is the absolute amount of employment or size term 
Table C.2: Weighted TAZ-level aggregated travel costs for off-peak period with different cutoffs

\begin{tabular}{|c|c|c|c|c|c|c|c|}
\hline \multicolumn{2}{|c|}{ Cutoff } & \multicolumn{6}{|c|}{ Descriptive statistics } \\
\hline Density & Total & Min & $1^{\text {st }} \mathrm{Qu}$. & Median & Mean & $3^{\text {rd }} \mathrm{Qu}$. & Max \\
\hline $70 \%$ & $1000^{\mathrm{a}}$ & 2.027 & 2.997 & 3.474 & 3.689 & 4.165 & 9.886 \\
\hline $50 \%$ & $25 \%$ & 2.202 & 2.927 & 3.244 & 3.508 & 3.905 & 9.590 \\
\hline $50 \%$ & $50 \%$ & 2.199 & 2.921 & 3.240 & 3.522 & 3.930 & 9.675 \\
\hline $50 \%$ & $75 \%$ & 2.189 & 2.914 & 3.249 & 3.563 & 4.031 & 9.681 \\
\hline $60 \%$ & $25 \%$ & 2.172 & 2.930 & 3.277 & 3.543 & 3.969 & 9.736 \\
\hline $60 \%$ & $50 \%$ & 2.160 & 2.922 & 3.277 & 3.571 & 4.030 & 9.741 \\
\hline $60 \%$ & $75 \%$ & 2.137 & 2.927 & 3.315 & 3.653 & 4.163 & 9.774 \\
\hline $70 \%$ & $25 \%$ & 2.135 & 2.943 & 3.370 & 3.623 & 4.080 & 9.784 \\
\hline $70 \%$ & $50 \%$ & 2.122 & 2.943 & 3.411 & 3.670 & 4.187 & 9.814 \\
\hline $70 \%$ & $75 \%$ & 2.078 & 3.035 & 3.576 & 3.831 & 4.392 & 9.987 \\
\hline $80 \%$ & $25 \%$ & 2.059 & 3.005 & 3.556 & 3.721 & 4.217 & 9.813 \\
\hline $80 \%$ & $50 \%$ & 2.023 & 3.076 & 3.627 & 3.814 & 4.356 & 9.836 \\
\hline $80 \%$ & $75 \%$ & 1.959 & 3.203 & 3.855 & 4.016 & 4.657 & 10.030 \\
\hline $90 \%$ & $25 \%$ & 1.916 & 3.197 & 3.741 & 3.960 & 4.514 & 10.030 \\
\hline $90 \%$ & $50 \%$ & 1.885 & 3.273 & 3.924 & 4.081 & 4.746 & 10.270 \\
\hline $90 \%$ & $75 \%$ & 1.946 & 3.789 & 4.582 & 4.685 & 5.474 & 10.620 \\
\hline $95 \%$ & $25 \%$ & 1.967 & 3.585 & 4.271 & 4.379 & 5.076 & 10.610 \\
\hline $95 \%$ & $50 \%$ & 1.960 & 3.765 & 4.539 & 4.663 & 5.439 & 10.500 \\
\hline $95 \%$ & $75 \%$ & 1.949 & 4.161 & 5.028 & 5.074 & 5.823 & 10.940 \\
\hline
\end{tabular}

a 1000 is the absolute amount of employment or size term 
Table C.3: Weighted TAZ-level aggregated travel costs with different cutoffs

\begin{tabular}{|l|l|l|l|l|l|l|l|}
\hline \multicolumn{2}{|c|}{ Cutoff } & \multicolumn{7}{c|}{ Descriptive statistics } \\
\hline Density & Total & Min & $1^{\text {st }}$ Qu. & Median & Mean & $3^{\text {rd }}$ Qu. & Max \\
\hline $70 \%$ & $1000^{\text {a }}$ & 2.055 & 3.052 & 3.542 & 3.759 & 4.259 & 10.010 \\
\hline $50 \%$ & $25 \%$ & 2.204 & 2.967 & 3.295 & 3.564 & 3.977 & 9.686 \\
\hline $50 \%$ & $50 \%$ & 2.201 & 2.961 & 3.293 & 3.578 & 4.007 & 9.774 \\
\hline $50 \%$ & $75 \%$ & 2.198 & 2.956 & 3.298 & 3.621 & 4.106 & 9.780 \\
\hline $60 \%$ & $25 \%$ & 2.183 & 2.972 & 3.331 & 3.691 & 4.046 & 9.838 \\
\hline $60 \%$ & $50 \%$ & 2.178 & 2.966 & 3.328 & 3.630 & 4.112 & 9.843 \\
\hline $60 \%$ & $75 \%$ & 2.169 & 2.971 & 3.367 & 3.715 & 4.252 & 9.882 \\
\hline $70 \%$ & $25 \%$ & 2.148 & 2.985 & 3.420 & 3.684 & 4.160 & 9.889 \\
\hline $70 \%$ & $50 \%$ & 2.141 & 2.988 & 3.464 & 3.734 & 4.265 & 9.922 \\
\hline $70 \%$ & $75 \%$ & 2.112 & 3.085 & 3.649 & 3.901 & 4.477 & 10.110 \\
\hline $80 \%$ & $25 \%$ & 2.089 & 3.052 & 3.616 & 3.788 & 4.304 & 9.926 \\
\hline $80 \%$ & $50 \%$ & 2.056 & 3.129 & 3.696 & 3.886 & 4.456 & 9.951 \\
\hline $80 \%$ & $75 \%$ & 1.990 & 3.264 & 3.936 & 4.095 & 4.757 & 10.250 \\
\hline $90 \%$ & $25 \%$ & 1.943 & 3.254 & 3.924 & 4.038 & 4.626 & 10.230 \\
\hline $90 \%$ & $50 \%$ & 1.914 & 3.334 & 4.005 & 4.165 & 4.859 & 10.420 \\
\hline $90 \%$ & $75 \%$ & 1.968 & 3.870 & 4.705 & 4.795 & 5.641 & 10.780 \\
\hline $95 \%$ & $25 \%$ & 1.968 & 3.657 & 4.366 & 4.478 & 5.195 & 10.780 \\
\hline $95 \%$ & $50 \%$ & 1.961 & 3.855 & 4.668 & 4.774 & 5.576 & 10.740 \\
\hline $95 \%$ & $75 \%$ & 1.950 & 4.270 & 5.153 & 5.200 & 5.988 & 11.140 \\
\hline 1000 is & 5614 & & & & \\
\hline
\end{tabular}

a 1000 is the absolute amount of employment or size term 


\section{APPENDIX D}

\section{SOURCE CODE AND INSTRUCTIONS}





\section{APPENDIX D: SOURCE CODE AND INSTRUCTIONS}

\section{Source Code}

The source code that implements the survey-based approach and the cluster-based approach in $\mathrm{R}$ is available as an open source project under GPL License at https://github.com/cities-lab/tci. Since it has more than 10,000 lines of code and will keep evolving as the NITC project progresses, it has not been included in this report but we refer anyone who wants to access a copy of the code to download it from https://github.com/cities-lab/tci/releases. As of the writing of this report, the current version is 0.4 .

\section{Instructions}

\section{Prerequisites}

Before running the TCI R scripts, $\mathrm{R}$ and the prerequisite $\mathrm{R}$ packages have to be installed. $\mathrm{R}$ can be downloaded and installed for most operating systems from http://cran.us.rproject.org/. The prerequisite R packages are specified in code/installation . R, which can be installed by sourcing code/installation. R in R command line terminal or by running Rscript code/installation. R in a terminal of the operating system.

\section{Code Organization}

The code subdirectory contains R code organized by different approaches of computing TCI, including survey (for the survey-based approach), cluster (for the clusterbased approach) and individual (for the individual-based approach, unfinished due to extensive data requirements and poor computation performance). The scripts shared across different approaches are directly inside the code subdirectory, and include:

- settings . R defines common settings for all projects and approaches; some of the settings may be overridden for a specific approach or project;

- functions . R defines common functions that are used throughout the TCI project;

- installation. R specifies and installs prerequisite $\mathrm{R}$ packages.

Other subdirectories inside the code directory contain scripts that are auxiliary to TCI computation:

- code/tests subdirectory contains unit-test scripts;

- code/misc subdirectory contains miscellaneous scripts;

- code/thirdparty subdirectory contains open-source scripts that come from a third party. 
Input data will be read into $\mathrm{R}$ by default from the data subdirectory, where it is assumed that they are organized following [project.name]/[year] structure. These default settings can be overridden by changing the INPUT_DIR variable.

Output will be saved by default to the output subdirectory, organized following [project.name]/[year]/[method.name]/[unit.name] structure. Again, these default settings can be overridden by changing the OUTPUT_DIR variable.

\section{Survey-based Approach}

For each approach, start computing TCI by sourcing a start_[project] [year].R script in code/cluster or code/survey subdirectory.

Below is a description of what each of the scripts does in the process of computing TCI:

- start_[project] [year].R invokes the TCI computation for a specific project and year,

- code/settings. $\mathrm{R}$ is default common settings for all projects and approaches,

- settings_[project . name].R (optional) are approach- or project-specific settings that override those defined in code/settings.R,

- prepare_[project . name] [year].R (optional) prepares inputs for TCI computation,

- compute. R computes TCI and saves outputs, and

- $\quad$ plot . R plots and saves graphs and maps for computed TCI

Take the Portland 2011 project as an example.

code/survey/start_Portland2011. R calculates TCI for Portland with the survey-based approach using the 2011 Oregon Household and Activity Survey (OHAS) data. Sourcing this R script file in R will read required inputs from the data/Portland/2011 directory, compute and plot travel costs, and save results and plots in the output/survey/Portland/2011 directory (default input and output directory location can be changed by users).

start_Portland2011.R first defines project.name, method.name, year, unit.name and abbreviation, before it sources relevant $\mathrm{R}$ script files in sequence to compute and plot travel costs:

- $\quad$ project.name is the name of the project;

- method.name is the name of the approach used to calculate TCI; 
- year is the year for the input data, used for specifying the default input and output directory with scenario.name;

- unit.name determines the unit ("minutes” or “dollars") for transportation cost results;

- abbreviations defines abbreviations for income groups, trip purposes, travel modes and time periods;

- Directories (optional) customizes the input directory, output directory and directory for intermediate outputs. By default, the input directory (INPUT_DIR) would be in data/[project.name]/[year], while the output directory in output/[project.name]/ [year]/[method.name]/[unit.name]. These default settings can be overridden by users in the start_[project.name][year].R script.

settings_OHAS.R stores settings shared among projects using the OHAS dataset (note that OHAS, an alternative name for OHAS, is used). Since both the Portland and Corvallis projects use the same dataset, the settings common to the OHAS dataset such as the value of time parameters by mode, are kept in settings_OHAS. R so that they don't have to be specified in two separate files.

prepare_Portland2011. R transforms the OHAS data set from the original format to the format required by compute.R:

- It converts trip duration to hours and trip distance to miles;

- It reclassifies income into low, middle and high categories (low income: $\$ 0-\$ 24,999$ per year; middle income: $\$ 25,000-\$ 49,999$; high income: $\$ 50,000$ or more, all in 1994 dollars);

- It identifies the Traffic Analysis Zones (TAZs) and geographical districts of households.

compute. $\mathrm{R}$ then computes trip-level transportation costs and aggregates them by household, trip purpose, income group, and TAZs and/or districts. It also saves the numeric results into an $\mathrm{R}$ image file, tcost . RData, in the output directory.

Finally plot . R plots transportation cost results in plots of various form, including density line plots, boxplots, line chart plots and maps for appropriate outputs.

Other projects in the survey subdirectory, such as Corvallis, the National Household Travel Survey (NHTS) and Wasatch Front Regional Council (WFRC), provide more examples of how the survey-based approach is applied. Users can create their own start_[project] [year] . R script by modeling these examples, customizing settings, and preparing input. 


\section{Cluster-based Approach}

Similarly, code/cluster/start_Portland2010.R calculates TCI for Portland with the cluster-based approach using data from Metro's 2010 travel demand model. Although the approach and corresponding inputs are different, the code is organized in the same way as the survey-based approach. A user should be able to understand and customize the scripts following the process described above for the survey-based approach.

One feature specific to the cluster-based approach is the capability to compute TCI for different scenarios. In a start script for the cluster-based approach, a vector of scenario.names will be iterated to calculate transportation costs for each scenario specified. Scenarios are handled in a way similar to how year is handled in the surveybased approach, in term of default input and output directory location. 
Transportation Research and Education Center

Portland State University

1900 S.W. Fourth Ave., Suite 175

Portland, OR 97201 